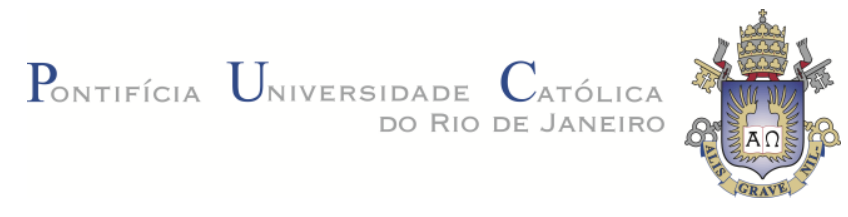

Fernando Alves Rodrigues

Transmissor Óptico baseado no Chaveamento

de Polarização da Luz

Dissertação de Mestrado

Dissertação de Mestrado apresentada como requisito parcial para obtenção do grau de Mestre pelo Programa de Pós-Graduação em Engenharia Elétrica do Departamento de Engenharia Elétrica do Centro Técnico Científico da PUC-Rio.

Orientador: Prof. Jean Pierre von der Weid

Rio de Janeiro

Março de 2012 


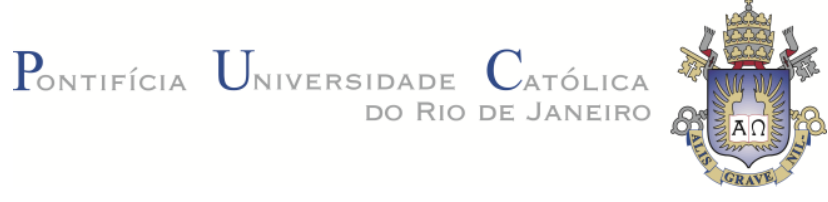

Fernando Alves Rodrigues

\section{Transmissor Óptico baseado no Chaveamento \\ de Polarização da Luz}

Dissertação de Mestrado apresentada como requisito parcial para obtenção do grau de Mestre pelo Programa de Pós-Graduação em Engenharia Elétrica do Departamento de Engenharia Elétrica do Centro Técnico Científico da PUC-Rio. Aprovada pela Comissão Examinadora abaixo assinada

Prof. Jean Pierre von der Weid Orientador

Departamento de Engenharia Elétrica - PUC-Rio

Prof. Giancarlo Vilela de Faria Departamento de Engenharia Elétrica - PUC-Rio

Prof. Guilherme Penello Temporão Departamento de Engenharia Elétrica - PUC-Rio

Prof. Rogério Passy

MLS Wireless

Prof. Jose Eugenio Leal Coordenador Setorial do Centro Técnico Científico - PUC-Rio 
Todos os direitos reservados. É proibida a reprodução total ou parcial do trabalho sem autorização da universidade, do autor e do orientador.

\section{Fernando Alves Rodrigues}

Fernando Alves Rodrigues graduou-se em Engenharia Elétrica com ênfase em Telecomunicações pela Universidade do Estado do Rio de Janeiro (UERJ) no ano de 2004, no ano de 2010 especializou-se em automação e instrumentação pelo Instituto SENAI de Ensino Superior (ISES), atuou como Técnico em Regulação de Serviços Públicos da Agência Nacional de Telecomunicações (ANATEL). Desde 2008 atua como Pesquisador Tecnologista em Sistemas de Comunicações no Instituto Nacional de Metrologia, Qualidade e Tecnologia (Inmetro).

Ficha Catalográfica

Rodrigues, Fernando Alves

Transmissor óptico baseado no chaveamento de polarização da luz / Fernando Alves Rodrigues; orientador: Jean Pierre von der Weid. - 2012.

100 f. : il. (color.) ; $30 \mathrm{~cm}$

Dissertação(mestrado)-Pontifícia Universidade Católica do Rio de Janeiro, Departamento de Engenharia Elétrica, 2012.

Inclui bibliografia

1. Engenharia elétrica - Teses. 2. Engenharia elétrica. 3. Telecomunicações. 4. Comunicações ópticas. 5. Polarização. 6. Parâmetros de Stokes. 7. Dispositivos eletro-ópticos. I. Weid, Jean Pierre von der. II. Pontifícia Universidade Católica do Rio de Janeiro. Departamento de Engenharia Elétrica. III. Título.

CDD: 621.3 
Aos meus pais pela luta incansável.

A minha esposa Claudia e meus filhos pela compreensão e apoio.

Em especial dedico à memória de meu pai, Jeronilio Batista Rodrigues 


\section{Agradecimentos}

Agradecimentos a todo o pessoal da Ditel - Divisão de Metrologia de Telecomunicações do Instituto Nacional de Metrologia, Qualidade e Tecnologia (Inmetro), em especial a Rodolfo Saboia, chefe da Ditel, pelo apoio essencial para realização deste curso de mestrado.

Ao professor Silva Mello pela oportunidade concedida e pelo vital apoio que me foi dado desde o início.

Ao professor Jean Pierre por acreditar na ideia deste trabalho desde o começo, pelas dicas valiosas, pela orientação e dedicação.

A todo pessoal do CETUC e CPTI, pela cordialidade, pela amizade, pelo apoio logístico e pela imensa paciência com as minhas infindáveis medições de polarização.

Agradecimentos especiais a Tarcísio e Gustavo pela ajuda com o desenvolvimento da aplicação FPGA.

Ao Giancarlo pelo suporte e pelas informações sobre o controlador de polarização.

A todo o pessoal da secretaria do Departamento de Engenharia Elétrica, em especial à Maria Alcina, pela atenção, pelo indispensável e constante apoio que recebi desde o primeiro dia em que cheguei a PUC.

Por fim, mas não por último. Agradeço a Deus, que se manifestou na figura de todas as pessoas que de alguma forma contribuíram para o sucesso deste trabalho. 


\section{Resumo}

Rodrigues, Fernando Alves; Weid, Jean Pierre von der. Transmissor Óptico Baseado no Chaveamento de Polarização da Luz. Rio de Janeiro, 2012. 100p. Dissertação de Mestrado - Departamento de Engenharia Elétrica, Pontifícia Universidade Católica do Rio de Janeiro.

O presente trabalho tem como objetivo a realização de um transmissor experimental para comunicações ópticas baseado na modulação por chaveamento de polarização da luz, conhecida como Polarization Shift Keying (PolSK). Realizamos análise teórica das vantagens e desvantagens da modulação PolSK frente aos requisitos de desempenho das comunicações ópticas atuais, entre os quais a eficiência espectral, o consumo de energia e roteamento totalmente óptico em redes transparentes. A principal abordagem da dissertação está relacionada ao ganho em eficiência espectral que pode ser alcançado com o uso de constelações de símbolos num espaço dimensional denominado "espaço de Stokes". Dados obtidos de um transmissor experimental de baixa velocidade demonstram a geração de constelações de símbolos tridimensionais contendo oito símbolos numa geometria de hexaedro (cubo). Com base nos conceitos teóricos, o arranjo experimental que construímos pode ser reproduzido para funcionar em velocidades compatíveis com as taxas de transmissão das comunicações ópticas atuais.

\section{Palavras-chave}

Polarização; comunicações ópticas; parâmetros de Stokes; dispositivos eletro-ópticos. 


\section{Abstract}

Rodrigues, Fernando Alves; Weid, Jean Pierre von der (Advisor). Optical Transmitter based on Polarization Shift Keying. Rio de Janeiro, 2012. 100p. MSc. Dissertation - Departamento de Engenharia Elétrica, Pontifícia Universidade Católica do Rio de Janeiro.

The present work aims the experimental realization of an optical transmitter based on the Polarization Shift Keying modulation - known as (PolSK). We analyze theoretically both, advantages and disadvantages of PolSK modulation, emergent performance requirements for current optical communications systems, including spectral efficiency, power consumption and routing in the context of transparent all-optical networks. The main approach of the dissertation is related to the spectral efficiency gain that can be achieved when we use constellations of symbols in a dimensional space called 'Stokes space'. Data from a low speed experimental transmitter demonstrate the generation of three-dimensional constellations of symbols containing eight symbols on hexahedron (cube) geometry. Based on the theoretical concepts we built the experiment, the setup can be replicated to operate at speeds compatible with transmission rates of current optical communications systems.

\section{Keywords}

Polarization; optical communications; Stokes parameters; electro-optical devices. 


\section{Sumário}

1 Introdução 14

1.1. Fluxo do trabalho e análise 16

$\begin{array}{ll}\text { 1.2. Revisão Bibliográfica } & 17\end{array}$

2 Sistemas de comunicações ópticas no contexto atual 21

2.1. Requisitos para sistemas de comunicações ópticas de última geração 21

2.1.1. Eficiência espectral e capacidade do canal óptico 22

2.1.2. Redução do consumo de potência 24

2.1.3. Granularidade da taxa de bits 25

2.1.4. Múltiplas topologias de redes 26

2.1.5. Relação custo benefício 26

$\begin{array}{ll}\text { 2.1.6. Interoperabilidade } & 27\end{array}$

$\begin{array}{ll}\text { 2.2. Considerações de projeto } & 27\end{array}$

3 Análise teórica dos fenômenos de polarização da luz 29

3.1. Teoria e modelo matemático para a propagação da luz 29

3.1.1. Representações das interações da luz com o meio 36

3.1.2. Efeito eletro-óptico linear 38

4 O transmissor PolSK 42

4.1.1. Eficiência espectral teórica do transmissor PolSK 42

4.1.2. Conversão eletro-óptica no transmissor PolSK 43

4.1.3. O cálculo matricial de Jones 45

4.1.4. Matrizes de Mueller 46

5 Teoria do receptor PolSK $\quad 48$ 
5.1. Requisitos de desempenho do receptor PolSK com detecção coerente

6 Caracterização dos componentes eletro-ópticos 55

6.1. O controlador de polarização 55

6.2. Aquisição, armazenamento e processamento dos dados 58

6.2.1. Dados sobre a geometria das constelações PolSK 68

6.2.2. Mapeamento e codificação no espaço de Stokes 75

$\begin{array}{ll}7 \text { Especificação e projeto do transmissor } & 77\end{array}$

7.1. Especificação e projeto dos chaveadores eletrônicos 77

7.1.1. Chaveadores MOSFET rápidos 77

7.2. Montagem experimental do transmissor PolSK 79

7.2.1. O gerador de padrões (FPGA) 80

7.3. Análise de desempenho dos chaveadores MOSFET 82

8 Resultados obtidos $\quad 83$

8.1. Resultados para a constelação do tetraedro 83

8.2. Resultados para a constelação do hexaedro (cubo) 84

8.3. Resultados para a constelação do poliedro irregular 85

8.4. Dados relativos à caracterização do sinal modulado 86

9 Conclusões 90

10 Trabalhos futuros 93 


\section{Lista de Tabelas}

Tabela 1 - Recentes recordes de comunicações ópticas e respectivas eficiências espectrais.

Tabela 2 - Mapeamento de tensões com o uso do circuito chaveador de polaridade de tensão.

Tabela 3 - Vetores Stokes e seus respectivos ângulos geradores.

Tabela 4 - Exemplo de código binário e vetores de Stokes da codificação 8-PolSK.

Tabela 5 - Tabela verdade do codificador para o MD1711

Tabela 6 - Estados de polarização da constelação de 04 estados e os respectivos valores de voltagem fornecidos pelo chaveador.

Tabela 7 - Estados de polarização da constelação de 08 estados e os respectivos valores de voltagem fornecidos pelo chaveador.

Tabela 8 - Estados de polarização da constelação de 14 estados e os respectivos valores de voltagem fornecidos pelo chaveador.

\section{Lista de llustrações}

Ilustração 1 - Fluxo de processamento dos vetores de Stokes em comparação com a constelação de referência.

Ilustração 2 - Fluxo de validação dos valores de tensão e o respectivo estado de polarização de saída do controlador. 


\section{Lista de Figuras}

Figura 1 - Visualização de mapeamento simétrico dos estados de polarização.

Figura 2 - Representação gráfica da propagação e seus eixos de referência.

Figura 3 - Elipse de polarização (não padronizada).

Figura 4 - Esfera de Poincaré com a representação de suas coordenadas esféricas.

Figura 5 - Transformador de polarização experimental composto de 04 estágios.

Figura 6 - Constelações PolSK a) 2-PolSK b) 4-PolSK c) 8-PolSK. 49 Figura 7 - a) Constelação do Tetraedro regular b) Constelação do Poliedro composto por um hexaedro e um octaedro.

Figura 8 - Diagrama de blocos simplificado de um receptor coerente heteródino.

Figura 9 - Diagrama de blocos simplificado de um receptor coerente homódino.

Figura 10 - Controlador de polarização multiestágio.

Figura 11 - Representação do guia de onda equivalente para cada estágio do EOSPACE.

Figura 12 - Arranjo de retardadores compondo um transformador de polarização arbitrário para arbitrário.

Figura 13 - Foto do "setup" inicial de caracterização do controlador de polarização.

Figura 14 - Vista frontal do equipamento A2000.

Figura 15 - Diagrama em blocos do aparato de caracterização do EOSPACE.

Figura 16 - Circuito equivalente do chaveador de polaridade para tensões das fontes. 
Figura 17 - Placa de circuito para conexão do EOSPACE com as fontes de alimentação.

Figura 18 - Exemplo de placa de circuito impresso de conexão auxiliar.

Figura 19 - Visualização da interface gráfica utilizada na caracterização do EOPSACE.

Figura 20 - Plotagem de estados de polarização feita em tempo real. 65

Figura 21 - Detalhe da estrutura de dados utilizada para armazenar as medidas de polarização.

Figura 22 - Representação gráfica do plano que contém a diagonal do cubo inscrito na esfera.

Figura 23 - Representação gráfica do cone de decisão.

Figura 24 - Constelação para $\chi=150=\pi 12$ nos estados elípticos.

Figura 25 - Visualização de estados de polarização que aderiram às constelações de referência para um ângulo de aceitação de $11,4^{\circ}$ $(0,2$ radianos $)$.

Figura 26 - Visualização de uma sequência densa com 5000 pontos, onde "buracos" no espaço mapeado foram visualizados.

Figura 27 - Exemplo de codificação binária. a) 4-PolSK (tetraedro), b) 4-PolSK (quadrado) c) 8-PolSK (cubo).

Figura 28 - Exemplo de código binário para mapeamento de um hipercubo.

Figura 29 - Estágio de saída do chaveador MOSFET MD1711DB2. $\quad 78$

Figura 30 - Diagrama de blocos do transmissor PolSK.

Figura 31 - Forma de onda teórica que é gerada na saída de um canal do módulo MD1711DB2 em função dos sinais de entrada.

Figura 32 - Placas de circuito da montagem experimental do transmissor PolSK

Figura 33 - Detalhe do circuito do decodificador 2-4.

Figura 34 - Resultado de uma sequência pseudoaleatória de 4096 símbolos transmitidos para a constelação do tetraedro regular a) após 1024 símbolos recebidos b) após 4096 símbolos recebidos.

Figura 35 - Resultado de uma sequência pseudoaleatória de 8192 
símbolos transmitidos para a constelação do cubo. a) após 1024 símbolos recebidos b) após 8192 símbolos recebidos.

Figura 36 - Resultado de uma sequência pseudoaleatória de 14336 símbolos transmitidos para a constelação do poliedro irregular de 14 vértices. a) após 1024 símbolos recebidos b) após 14336 símbolos recebidos.

Figura 37 - Padrão obtido na reprodução do tetraedro, com tensões fixas, 04 pontos foram observados.

Figura 38 - Transição entre os estados de polarização do tetraedro. 87

Figura 39 - Visualização da variação dos parâmetros de Stokes. 88

Figura 40 - Variação de potência do sinal modulado em polarização em $d B m$.

Figura 41 - Variação de potência do sinal modulado em polarização em $m W$ 


\section{Introdução}

O objetivo deste trabalho é realizar um transmissor experimental para comunicação óptica baseado na modulação por chaveamento de polarização da luz, também conhecida como Polarization Shift Keying (PolSK), o transmissor deverá operar nas faixas de 20, 40 e $100 \mathrm{MHz}$, com eficiência espectral máxima de $3 \mathrm{bit} / \mathrm{s} / \mathrm{Hz}$. De acordo com [1], o termo comunicações ópticas compreende as comunicações por meio de ondas eletromagnéticas em frequências portadoras de ordem elevada (aproximadamente $100 \mathrm{THz}$ ), na faixa da luz visível ou próximo da região de infravermelho do espectro eletromagnético. Subdividindo-se ainda entre as comunicações ópticas no espaço livre, e a comunicação óptica por meio guiado, esta última é tipicamente realizada através de fibras ópticas. Para efeito deste trabalho, o termo comunicações ópticas irá se referir unicamente às comunicações através de fibras ópticas, outros tipos serão descritos de forma explicita e diferenciada.

Em termos históricos, a expansão das comunicações ópticas observada na década de 1980 foi alavancada pela demanda por comunicação global de serviços de dados, voz e principalmente pela internet $[1,2,3]$. No início da expansão, o elevado custo dos enlaces ópticos restringia o uso desta tecnologia aos núcleos das redes de telefonia e/ou para interligações backbones de longa distância via cabos submarinos intercontinentais. A demanda por banda de transmissão aumentou continuamente e os investimentos em pesquisa e desenvolvimento levaram a avanços tecnológicos significativos. O desenvolvimento de novos dispositivos fotônicos, de componentes semicondutores para eletrônica rápida e o desenvolvimento de novas topologias de rede $[4,5]$ alimentaram o crescimento da demanda, na medida em que permitiram a expansão dos serviços de banda larga existentes, tornando viável novos modelos de negócio. Apesar do custo elevado ainda representar desafios, as redes se expandiram e topologias como, por

exemplo, das Redes Ópticas Passivas (Passive Optical Network - PON) aproximam cada vez mais as redes ópticas da última milha. 
$\mathrm{Na}$ linha do tempo do desenvolvimento das redes ópticas, surgiram no mesmo ano (em 2010), dois padrões Ethernet de 40 G e 100 G, apesar de resultarem da superação de significativos desafios tecnológicos, aqueles padrões foram evidentemente apenas mais um passo na direção das redes ópticas de alta velocidade. O curto intervalo de tempo entre o desenvolvimento destes dois padrões [1] não freou a busca por taxas de transmissão mais altas. Houve nova explosão da demanda por banda com o surgimento de aplicações e serviços de rede como vídeo $3 D$ de alta definição, a expansão da IPTV e dos jogos eletrônicos em rede. Estes fatos sinalizam que prover novas soluções de comunicações ópticas permanece um desafio.

Para atingir taxas de dezenas de gigabits, os projetistas lançaram mão de modulações de alta ordem, uma vez que modulações binárias simples não conseguiram, em sua maioria, [2,3] superar os requisitos de desempenho para aquelas taxas. Mesmo com o obstáculo de projetar sistemas de comunicações complexos, a indústria manteve os esforços na adoção das modulações de alta ordem, indicando que o futuro imediato dos sistemas ópticos está fortemente relacionado com a melhoria da eficiência espectral [6]. Modulações baseadas em constelações vetoriais de símbolos necessitam de detecção coerente, pois os diodos fotodetectores são restringidos pela lei quadrática e, consequentemente, não preservam as informações de fase do sinal óptico. A detecção coerente também experimentou um crescimento considerável nos anos 80 [5], contudo sem as facilidades tecnológicas para fabricação de dispositivos optoeletrônicos que pudessem viabilizar a produção de sistemas comerciais em larga escala, estes sistemas perderam competitividade, pois soluções não coerentes apresentavam uma melhor relação custo benefício. A integração da eletrônica com a fotônica fez com que projetistas voltassem a considerar o desenvolvimento de sistemas coerentes para fazer frente aos novos desafios da comunicação por fibras ópticas [7]. Com esta nova onda, as modulações baseadas em chaveamento de polarização retornam à cena. O padrão IEEE P802.3ba [3], por exemplo, especifica o uso de um esquema de multiplexação/modulação denominado Polarization Division Multiplexing - Quadrature Phase Shift Keying (PDM-QPSK), também conhecida como Polarization Multiplexing - Quadrature Phase Shift Keying (PM-QPSK) ou ainda Dual-Polarization - Quadrature Phase Shift Keying (DP-QPSK). 
Neste cenário as modulações multiníveis, incluindo a PolSK emergem como candidatas para o alcance de alta eficiência espectral $[8,9,10]$, agora contemplando requisitos como chaveamento/roteamento totalmente óptico, transmissores e receptores custo-efetivo e flexibilidade para aplicação em redes locais e/ou redes de longa distância.

A complexidade dos transmissores e principalmente dos receptores ainda é onerosa para a realização de um sistema baseado unicamente em modulação por polarização. Os preços de dispositivos discretos importantes para realização de sistemas PolSK ainda são elevados, alguns dispositivos rápidos custam em torno $\$ 4,000$ [11] por unidade, no mercado internacional. A expectativa, contudo, é que os custos comecem a cair na medida em que novos dispositivos ópticos e eletroópticos surjam no mercado. Este trabalho pretende analisar questões pertinentes ao uso da modulação por chaveamento de polarização da luz e sua viabilidade como uma solução para as comunicações ópticas, no estágio tecnológico atual.

\section{1.}

\section{Fluxo do trabalho e análise}

O presente trabalho utilizou em sua metodologia o seguinte fluxo de atividades:

- Revisão bibliográfica;

- Considerações de projeto;

- Análise teórica do projeto;

- Caracterização dos componentes eletro-ópticos;

- Modelagem da constelação PolSK;

- Especificação dos chaveadores eletrônicos;

- Montagem do transmissor PolSK;

- Análise dos parâmetros de desempenho do transmissor.

A despeito da itemização das atividades, o fluxo de realização destas atividades não seguiu uma ordem definida, o nosso tema de estudo é bastante abrangente e um fluxo iterativo foi realizado onde as respostas obtidas em cada fase serviram de base para reposicionar outras. 


\section{2.}

\section{Revisão Bibliográfica}

O presente trabalho tem como referência vários trabalhos relacionados.

Uma detalhada teoria da modulação por chaveamento de polarização da luz foi estudada [12], onde os conceitos chave em torno do uso da polarização da luz como um parâmetro de modulação para telecomunicações são demonstrados. Com base em modelos probabilísticos, os limites de contorno do problema de modular e demodular sinais ópticos em polarização foram definidos e já aqui a eficiência espectral é citada como a principal vantagem obtida na adoção desta modulação/codificação. Uma contribuição desta teoria é a análise do método de detecção de uma constelação PolSK baseado no produto interno de matrizes, realizada eletronicamente, este tipo de detecção ganhou recentemente novos adeptos com o advento da tecnologia FPGA, pois a realização de operações com matrizes em hardware está cada vez mais acessível e custo-efetivo.

Os aspectos básicos da modulação em polarização [13] foram abordados até o caso mais avançado de transmissões PolSK multiníveis (M-POLSK), uma completa caracterização estatística dos parâmetros de Stokes estimados e extraídos do receptor é desenvolvida. Considerando um receptor operando na presença de ruído aditivo gaussiano (AWGN), o sistema de detecção baseado no modelo de máxima verossimilhança é analisado de modo que as regiões (do espaço de Stokes) possam ser projetadas para uma constelação genérica de sinais.

Definições genéricas do modulador e do receptor são usadas para modelar a geração de sinais no transmissor bem como as regras de decisão no receptor. As abordagens adotadas para as regras de decisão são interessantes e trabalhos recentes demonstram que as regras de decisão são de fato de grande impacto num receptor Stokes. O desempenho de esquemas POLSK e Combined Amplitude and Polarization Shift Keying (CAPSK) foi analisado, concluindo que a eficiência destes esquemas é aumentada pela cardinalidade de suas constelações e que, com base naquelas considerações, POLSK é uma boa candidata para obtenção da desejada eficiência em banda e potência. 
Uma abordagem que leva em consideração requisitos de desempenho que permanecem importantes nos dias atuais, pode ser vista numa publicação de 1990 [14], a modulação POLSK é citada como candidata para soluções tanto de Local Area Network (LAN) quanto Metropolitan Area Network (MAN). O transmissor proposto, baseado num esquema composto por moduladores de fase e beam splitters de polarização que dividem o campo óptico em componentes ortogonais, é particularmente adequado para altas taxas de transmissão, pois em dias atuais podemos encontrar dispositivos moduladores de fase rápidos operando em taxas típicas de 40 Gbit, uma limitação deste esquema é a cobertura do espaço de Stokes para transmissão de constelações grandes, como por exemplo, 8-POLSK (cubo). A estrutura do receptor observada em [12] é bastante referenciada. Uma análise da ótima configuração para a distribuição dos pontos de uma constelação POLSK sobre a esfera de Poincaré é desenvolvida, observamos que a otimização de constelações tridimensionais não pode ser resolvida analiticamente. Na maioria dos trabalhos, as coordenadas angulares na esfera de Poincaré são representadas para o caso de até 08 (níveis) estados de polarização, caso de um sistema denominado Multilevel Stokes Parameters Shift Keying (N-SPSK). Uma importante observação em relação ao receptor diz respeito à potência do ruído, pois considerar que esta potência de ruído é diretamente determinada pela largura de banda do filtro de Frequência Intermediária (FI) impõe penalidades para o desempenho do sistema de amostragem e decisão, que podem ser superadas com adoção de dispositivos integradores de sinais.

Alguns trabalhos relatam que as flutuações dos estados de polarização causadas pela birrefringência da fibra óptica, podem ser compensadas através de algoritmos eletrônicos, uma vez que estas flutuações são relativamente lentas $[14,15]$. Estes relatos concordam que a modulação em polarização é, em grande parte, insensível ao ruído de fase.

PolSK diferencial multinível é analisada em [9], onde é relatado que, apesar das fibras ópticas disponibilizarem grande largura de banda, a busca por melhor eficiência espectral se justifica pelo fato de permitir a construção de transmissores e receptores mais eficientes, principalmente em aplicações de redes locais que requerem um grande número de transceptores com boa relação custo benefício. 
Um sinal modulado em polarização sofrerá uma variação temporal randômica que muda os estados de polarização recebidos, isto implica que os receptores adotem algum tipo de seguidor de polarização, geralmente um circuito Phase Locked Loop (PLL) que auxilia no travamento de polarização do oscilador (laser) local $[16,17]$.

Um esquema de transmissão diferencial PolSK pode dispensar o uso do travamento de polarização no receptor. PolSK diferencial, contudo não é eficiente em esquemas binários devido à penalidade em potência. $\mathrm{O}$ uso de um esquema diferencial multinível denominado N-DDPolSK apresentaria vantagens ainda que incorra em novas restrições como, por exemplo, não admitir que dois símbolos paralelos no espaço de Stokes sejam transmitidos sequencialmente. Uma configuração 6-DDPolSK é particularmente apresentada como solução eficiente.

A aplicação de códigos esféricos $3 \boldsymbol{n}$-dimensionais em sistemas PolSK foi analisada [10], onde os pontos das constelações são projetados de maneira que maximizem a distância Euclidiana. Nos casos em que $\boldsymbol{n}>\mathbf{1}$, os pontos são mapeados em espaços de dimensões maiores que o espaço de Stokes, desta forma cada símbolo é formado por grupos de $\boldsymbol{n}$ estados de polarização. Simulações mostram os potenciais ganhos obtidos através do aumento da distância entre símbolos num espaço 3n-dimensional. A abordagem de códigos esféricos é particularmente importante para o mapeamento de constelações PolSK, sua inserção na teoria da modulação em polarização contribui positivamente para a realização de sistemas mais eficientes. Apesar do ganho teórico no desempenho do sistema ser obtido ao custo de um aumento na complexidade do receptor, esta complexidade pode ser reduzida com a escolha de constelações formadas por pontos com "perfeita simetria". A possibilidade de extrair pontos de constelações através de empacotamento regular (lattice packing) é considerada.

PMD e PDL são ofensores intrínsecos da PolSK, em [18] um experimento relata que sistemas PolSK operando em velocidades menores 10 Gbit podem sofrer penalidades devido a PDL induzida pela intermodulação, em [19] resultados experimentais mostram que em um enlace de fibra óptica com dispersão dos modos de polarização (PMD), o formato de transmissão (PolSK) sofre uma penalidade da sensibilidade devido ao efeito de despolarização do sinal, quando comparado com formatos de intensidade modulada. A penalidade em excesso relatada é de $3 \mathrm{~dB}$, quando a PMD é de $30 \%$ do período de bit. 
Os efeitos negativos da PDL são observados em taxas de transmissão abaixo de um determinado valor, diferente da maioria dos ofensores das modulações baseadas em intensidade modulada que frequentemente impõe restrições acima de determinadas taxas.

No caso da PMD, sua capacidade de despolarizar o sinal deve ser levada em consideração, pois a PMD de segunda ordem gera efeitos vetoriais que impactam a PolSK. Considerando que a demanda dos consumidores é por maiores taxas de transmissão e não necessariamente maiores taxas de sinalização, a PolSK apresenta pontos fortes que justificam a busca pela mitigação de seus pontos fracos. 


\section{2 \\ Sistemas de comunicações ópticas no contexto atual}

Conforme descrito em [20] os sistemas de comunicações ópticas atuais poderão entrar em saturação nos próximos anos. Por conta disto, projetistas passaram a considerar aspectos mais abrangentes em relação a estes sistemas, alguns desafios são imediatos como, por exemplo, o provimento de maior banda, outros desafios dizem respeito a novas arquiteturas, diferentes contextos de uso e parâmetros de desempenho dinâmicos. Podemos observar, contudo, que é cada vez mais tênue a separação entre limites físicos fundamentais e limitações tecnológicas.

\section{1. Requisitos para sistemas de comunicações ópticas de última geração}

A adoção de novas tecnologias utilizando modulações de alta ordem, com maior número de bits por símbolo tem exigido relações de compromisso entre o fornecimento de maior banda e a máxima distância que pode ser atingida por links de canal simples em cascata [6]. Desta forma os parâmetros de desempenho das modulações ópticas são obtidos frente a uma lista de ofensores que representam em si grandes desafios para projetistas e integradores que necessitam avaliar diferentes modelos de implantação. Neste cenário é extremamente desafiador encontrar uma solução que atenda, por exemplo, aos requisitos de links de longa de distância para backbones transoceânicos e aos requisitos das redes urbanas PON, simultaneamente.

Em longo prazo, as virtudes de determinadas modulações poderão esbarrar em limites impostos mais pelo contexto do que pela capacidade da modulação em si. Avanços tecnológicos decorrentes da integração em larga escala de dispositivos optoeletrônicos poderão, por exemplo, reduzir a complexidade de arquiteturas que atualmente são consideradas inviáveis. Num cenário deste tipo alguns dispositivos que na atualidade são extremamente caros poderão ter seus custos reduzidos quando produzidos em larga escala. 
Com a sustentabilidade em mente, fabricantes deverão produzir dispositivos baseados em materiais (metais e cristais) cujo fornecimento não seja ameaçado pela escassez $[21,22]$ e cuja possibilidade de reciclagem seja economicamente viável. Estes fatores representam em si motivações para a busca de técnicas de comunicação mais adequadas aos novos tempos, incluindo aquelas que integrem modulações em polarização (PolSK), contribuindo para o leque de soluções disponíveis aos projetistas de redes na atualidade.

Existem diversos parâmetros e requisitos de desempenho para sistemas de comunicações ópticas [6], a seguir é mostrada uma lista de alguns destes parâmetros que estão direta ou indiretamente relacionados ao tipo de modulação escolhido para determinado sistema, são eles:

- Eficiência espectral;

- Consumo reduzido de potência;

- Boa granularidade da taxa de bits;

- Suporte a múltiplas topologias de redes;

- Boa relação custo benefício;

- Interoperabilidade.

Os requisitos de desempenho estão relacionados tanto a experiência do usuário quanto a viabilidade técnica e econômica dos sistemas de comunicação. Atender simultaneamente a expectativa de clientes finais e dos provedores de acesso óptico é um desafio considerável.

\subsection{1.}

\section{Eficiência espectral e capacidade do canal óptico}

A eficiência espectral está relacionada com a capacidade de o sistema transmitir mais informação com a mesma taxa de sinalização. Sua medida é dada em bit/segundo/Hertz (bit/s/Hz). A taxa de sinalização denota a variação das características da portadora em função do sinal modulante. Em sistemas modulados em amplitude, à medida que a taxa de sinalização aumenta, os efeitos não lineares se pronunciam de forma mais acentuada e passam a representar sérias limitações para as comunicações em fibras ópticas [23]. É conveniente, portanto que cada transição do sinal transmita o máximo de informação. 
A busca por melhor eficiência espectral tem resultado em novas relações de compromisso, pois modulações compostas por constelações de símbolos mais complexas são frequentemente mais susceptíveis aos ofensores do meio óptico, quando a distância espacial entre símbolos se torna muito próxima.

A banda passante da fibra óptica padrão de telecomunicações do tipo G.652 é amplamente estudada e avaliada, de qualquer forma sabemos que esta banda é um recurso finito com limites intrínsecos que em algum momento atingirá a saturação. Pelo teorema de Shannon, a capacidade de um canal pode ser calculada através da formulação:

$$
C=B \log _{2}(1+S N R)
$$

Onde C é capacidade do canal (em bits), B é banda passante (em Hz) e SNR é a relação sinal ruído. A formulação simplificada do teorema de Shannon é baseada numa série de considerações, a principal é que o canal deve ser do tipo AWGN, ou seja, que o ruído predominante no canal seja ruído branco e cuja densidade de potência seja modelada por uma curva Gaussiana. De acordo com [24], a extensão da Teoria de Shannon para o "canal" de fibra óptica no núcleo das redes enfrenta várias dificuldades. Um importante desafio se origina da presença de três fundamentais fenômenos físicos em fibras ópticas: ruído (não necessariamente gaussiano), dispersão cromática das fibras e não linearidade Kerr instantânea. Além disso, nas redes opticamente roteadas, filtros ópticos distribuídos ao longo das redes roteiam diferentes canais (WDM) ao seu pretendido destino.

Alguns trabalhos dão conta de que a banda passante disponível em uma fibra óptica está na faixa de $10 \mathrm{THz}$ [25] a $25 \mathrm{THz}$ [20], outros levam em conta diferentes parâmetros e indicam, ao invés da banda, a máxima eficiência espectral teórica da fibra óptica em 5,6 bit/s/Hz [24], recordes experimentais recentes de transmissão em fibras ópticas e a eficiência espectral relatada por cada um são mostrados em [4]. Apesar dos recordes experimentais relatados, a eficiência espectral de sistemas comerciais atuais ainda está em torno $\mathbf{0 , 4} \mathbf{b i t} / \mathbf{s} / \mathbf{H z}$, o que nos leva a concluir que há muito por fazer. 


\begin{tabular}{|c|c|c|c|c|c|c|}
\hline $\begin{array}{c}\text { Capacidade } \\
(\text { Tbit/s) }\end{array}$ & $\begin{array}{c}\text { Distância } \\
(\mathrm{km})\end{array}$ & $\begin{array}{c}\text { Cap.x } \\
\text { Distância } \\
(\text { Pbit/s.km) }\end{array}$ & $\begin{array}{c}\text { Eficiência } \\
\text { Espectral } \\
(\mathrm{bit} / \mathrm{s} / \mathrm{Hz})\end{array}$ & Canais & $\begin{array}{c}\text { Taxa por } \\
\text { Canal } \\
(\mathrm{Gbit} / \mathrm{s})\end{array}$ & Ano \\
\hline 25,6 & 240 & 6,14 & 3,2 & 160 & 160 & 2008 \\
\hline 0,91 & 640 & 0,58 & 4,2 & 8 & 114 & 2008 \\
\hline 1,09 & 18000 & 19,62 & 0,2 & 109 & 10 & 2003 \\
\hline 0,96 & 13100 & 12,58 & 0,3 & 96 & 10 & 2004 \\
\hline 16,4 & 2550 & 41,82 & 2,0 & 164 & 100 & 2008 \\
\hline Fonte: "Exploding Data Traffic and Bandwidth Demands, " in High Order Modulation \\
for Fiber Optic Transmission.: Springer-Verlag, 2009, pp. 1-12
\end{tabular}

Tabela 1 - Recentes recordes de comunicações ópticas e respectivas eficiências espectrais.

\subsection{2.}

\section{Redução do consumo de potência}

Outro fator amplamente discutido é o consumo de energia nas redes de comunicações [26,27,28,29], esta preocupação aumenta na medida em que as redes ópticas tornam-se onipresentes e indispensáveis à vida moderna. O limite inferior de consumo das redes ópticas é determinado pelos seguintes fatores:

- Consumo dos amplificadores;

- Consumo dos transmissores e receptores;

- Capacidade do sistema de comunicação.

A capacidade do sistema de comunicação, modelada pelo teorema de Shannon [24], descreve um limite físico imposto pela sensibilidade do receptor, a sensibilidade do receptor por sua vez depende de fatores como formato de modulação, perdas das fibras ópticas, comprimento do link, ruído espontâneo (ASE) nos amplificadores ópticos e efeitos não lineares do meio, resta então aos projetistas atuar sobre variáveis sobre as quais tenham algum controle, uma vez que o aumento da potência dos transmissores [20] esbarra em limites físicos da fibra óptica. Um dos parâmetros que mais influenciam no consumo de energia é a quantidade de conversões entre o domínio óptico e o domínio eletrônico (conversões opto-eletro-óptica) [27] e as redes que reduzem ou eliminam a necessidade destas conversões são denominadas redes ópticas transparentes. 
Um roteamento transparente baseado em rótulos "labels" em conjunto com PolSK é descrito em [30], os roteadores ópticos ainda são caros e a escolha de implantar ou não roteamento totalmente óptico deverá levar conta o desempenho de determinada modulação tanto sobre redes ponto a ponto quanto em redes ponto multiponto (PON), considerando ou não o uso de amplificadores em cascata. Ótimas soluções podem servir a links com múltiplos protocolos, em enlaces de redes metropolitanas - Metropolitan Area Network (MAN) ou redes remotas Wide Area Network (WAN). A PolSK tem se mostrado flexível para atender estas exigências e, considerando que o consumo de energia dos sistemas ópticos atuais é duas vezes maior do que o limite mínimo desejável [26], concluímos que existe espaço para pesquisa e desenvolvimento nesta direção.

\subsection{3.}

\section{Granularidade da taxa de bits}

Uma boa granularidade da taxa de bits permite o fornecimento de banda sem desperdícios [31]. A banda de transmissão pode ser alocada de modo dinâmico ou estático, em qualquer dos dois casos a granularidade será determinante para o bom aproveitamento dos recursos disponíveis. O requisito de uma boa granularidade é fortemente influenciado pelo tipo de modulação e sua robustez, além de esbarrar nas limitações das interfaces, que nem sempre são capazes de suportar múltiplas taxas. Em redes de última milha, como é caso de redes PON, este requisito é extremamente importante, pois permite a precificação dos acessos com base num leque variado de opções de banda, que resultam nos pacotes de serviços, oferecidos pelos provedores de acesso. Num cenário em que as redes ópticas transparentes (sem conversão optoeletrônica) se aproximam da última milha, estas considerações são relevantes, pois a granularidade deverá estar disponível diretamente do domínio óptico [32]. 


\subsection{4. \\ Múltiplas topologias de redes}

Uma das maiores vantagens de um núcleo óptico dinâmico é a sua capacidade de fornecer informações de forma confiável num modo de roteamento qualquer-para-qualquer caminho e ainda criar e alterar estes caminhos dinamicamente. Normalmente, cada caminho óptico é independente e pode atravessar rotas completamente diferentes em relação a outras.

Encontrar um fator comum para compensação de dispersão cromática nos vários caminhos ópticos é normalmente difícil e as soluções não fornecem compensação de dispersão cromática adequada para futuros caminhos cujo início e fim ainda não são conhecidos localmente. Estas exigências acrescentam custos e tempo, além disso, podem ser impraticáveis do ponto de vista de implantação em redes já existentes.

\subsection{5. \\ Relação custo benefício}

O tempo entre o anúncio de novas soluções tecnológicas e a produção de equipamentos baseados nestas soluções é cada vez menor, em parte devido a uma demanda reprimida. Contudo a racionalização cada vez maior no uso dos recursos e a contabilização de custos ambientais indicam que as sociedades estarão mais receptivas (e investirão mais recursos) em soluções que apresentem boa relação custo benefício. Alguns parâmetros para contabilização dos custos incluem ainda requisitos como confiabilidade, disponibilidade, escalabilidade e manutenabilidade das redes de comunicações. As redes PON necessitam de equipamentos de usuário $(O N U s)$ que tenham preços competitivos, oferecendo recursos avançados como, por exemplo, independência de comprimento de onda. A grande quantidade destes equipamentos necessários para alcançar a almejada capilaridade das redes ópticas passivas justifica a necessidade de custo reduzido. 


\subsection{6. \\ Interoperabilidade}

No nível industrial, a interoperabilidade é um requisito importante para tecnologias globais como é o caso das comunicações ópticas. Fabricantes têm recorrido a "acordos de múltiplas partes" - Multisource Agreement (MSA) [33], para garantir que seus equipamentos possam efetivamente se comunicar. Este tipo de acordo é importante para reduzir o desperdício de recursos em situações onde os consumidores precisam adquirir diferentes produtos, muitas vezes subutilizando vários deles, na tentativa de prover interoperabilidade em suas redes.

Em níveis tecnológicos, a inserção de determinada solução depende da aceitação e da consequente formalização, em alguns casos resultando em padrões. Neste contexto a PolSK representa uma solução inovadora em termos de produto. O uso de polarização para multiplexação em padrões como o PDM-QPSK abre espaço para a desmistificação do uso da polarização como parâmetro de informação. Embora não tenhamos conhecimento de estudos teóricos ou experimentais sobre interoperabilidade em sistemas PolSK, podemos observar que, em níveis mais específicos, a interoperabilidade pode esbarrar em questões conforme descreve [34], onde foi observado que, para o caso dos sistemas WDM utilizando PDM-QPSK poderiam ocorrer problemas de convivência entre canais modulados em amplitude e canais modulados em polarização. Podemos observar, contudo, que a indústria continua na busca pela efetiva interoperabilidade entre equipamentos de múltiplos fornecedores [35].

\section{2.}

\section{Considerações de projeto}

Para o projeto do transmissor, consideramos os recursos disponíveis como um primeiro delimitador das condições de contorno do projeto de um enlace baseado em modulação de polarização. Desta forma obtivemos características mínimas do enlace a ser projetado. O principal limitador do projeto é a velocidade dos chaveadores eletrônicos que operam na faixa entre 20 e $100 \mathrm{MHz}$, esta limitação por sua vez está relacionada aos valores máximos das tensões de chaveamento. 
As tensões de chaveamento determinam, em parte, a quantidade de diferentes estados de polarização que podem ser alcançados. Outro fator determinante era a velocidade de resposta do controlador de polarização, pois o fabricante apenas fornece a informação de que esta resposta é muito menor que $100 n$ s. Conforme descrito em [16], e posteriormente confirmado por nossas medições, os controladores de polarização disponíveis exigem tensões relativamente elevadas para realizarem rotações satisfatórias dos estados de polarização. Em sistemas eletro-ópticos as tensões de chaveamento devem ser menores possíveis e considerando que o enlace é um sistema chaveado, investigamos a possibilidade de utilizar chaveamento eletrônico multinível com inversão das polaridades (chaveamento em ponte).

A vantagem do chaveamento eletrônico em ponte é que com ele é possível realizar excursões de tensão igual à metade daquela que seria necessária em chaveamento direto de tensão. Para o nosso chaveador de conversão eletro-óptica buscamos um modelo de transformador de polarização onde as simetrias das tensões de excitação resultassem em excursões aproximadamente simétricas dos estados de polarização, isto é extremamente desejável conforme explicado em [10], pois permite o mapeamento direto de constelações compostas por pontos simétricos no espaço $3 n$, também contribui para redução da complexidade do transmissor. Estas considerações direcionaram nossos esforços para que nas fases de análise teórica e de caracterização do transformador de polarização buscássemos modelos matemáticos e experimentais que permitissem rotações simétricas.

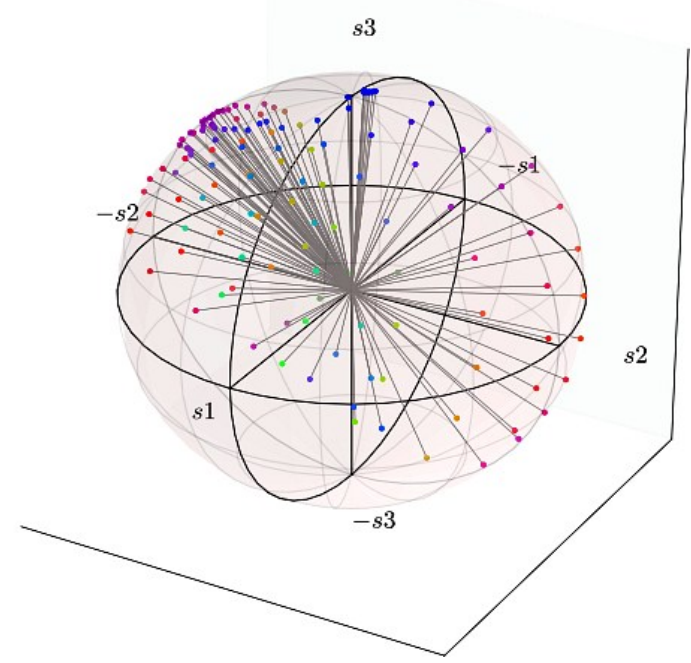

Figura 1 - Visualização de mapeamento simétrico dos estados de polarização. 


\section{3}

\section{Análise teórica dos fenômenos de polarização da luz}

$\mathrm{Na}$ nossa análise teórica necessitamos recorrer ao formalismo adequado para representação dos fenômenos de polarização da luz nas fibras ópticas.

\section{1.}

\section{Teoria e modelo matemático para a propagação da luz}

Por volta de 1820 Fresnel propôs uma teoria da luz, agora conhecida como a teoria de onda de Fresnel, que explicou completamente os três maiores fenômenos da luz: interferência, difração e polarização [36]. Além disso, Fresnel e Arago mostraram experimentalmente que o campo óptico consistia em apenas dois componentes ortogonais no plano transversal à direção de propagação. A teoria de onda de Fresnel postulava que os componentes ortogonais eram:

$$
u_{1}(r, t) \text { e } u_{2}(r, t)
$$

aos quais ele denominou perturbações ópticas. Sabemos agora, contudo, que as perturbações ópticas podem ser representadas pelas componentes do campo elétrico do campo eletromagnético. Fresnel hipotetizou que as componentes do campo são descritas por duas equações conhecidas como as equações de onda,

$$
\begin{aligned}
& \nabla^{2} E_{x}(\boldsymbol{r}, t)=\frac{1}{v^{2}} \frac{\partial^{2} E_{x}(\boldsymbol{r}, t)}{\partial t^{2}} \\
& \nabla^{2} E_{y}(\boldsymbol{r}, t)=\frac{1}{v^{2}} \frac{\partial^{2} E_{y}(\boldsymbol{r}, t)}{\partial t^{2}}
\end{aligned}
$$

Onde $\mathrm{E}_{x}(\boldsymbol{r}, t)$ e $\mathrm{E}_{y}(\boldsymbol{r}, t)$ são as componentes ópticas do campo, $\boldsymbol{r}$ é o vetor radial para um ponto no espaço medido a partir a origem de um sistema de coordenadas, $\boldsymbol{t}$ é o tempo, $\boldsymbol{v}$ é a velocidade das ondas, e $\nabla^{2}$ é o operador Laplaciano. Os dois componentes do campo na direção $\boldsymbol{k}$ formam um sistema ortogonal como mostrado. 
As soluções das equações de onda são:

$$
E_{x}(\boldsymbol{r}, t)=E_{0_{x}} \cos \left(\omega t-\boldsymbol{k} \cdot \boldsymbol{r}+\delta_{x}\right)
$$

e

$$
E_{y}(\boldsymbol{r}, t)=E_{0_{y}} \cos \left(\omega t-\boldsymbol{k} \cdot \boldsymbol{r}+\delta_{y}\right)
$$

Onde $\boldsymbol{k}$ é o número de onda (vetor) e descreve a direção de propagação, $\boldsymbol{r}$ é um ponto no campo. Na prática, o campo é tomado ao longo do eixo $\boldsymbol{z}$. As duas componentes anteriores podem ser reescritas como:

$$
E_{x}(\mathbf{z}, t)=E_{0_{x}} \cos \left(\omega t-k z+\delta_{x}\right)
$$

e

$$
E_{y}(\mathbf{z}, t)=E_{0 y} \cos \left(\omega t-k z+\delta_{y}\right)
$$

$\omega=2 \pi f$ é a frequência angular, $k=2 \pi / \lambda$ é a magnitude do vetor de onda, $E_{0_{x}}$ e $E_{0_{y}}$ são as máximas amplitudes e $\delta_{x}$ e $\delta_{y}$ são fases arbitrárias; o termo $\omega t-k z$ é denominado constante de propagação.

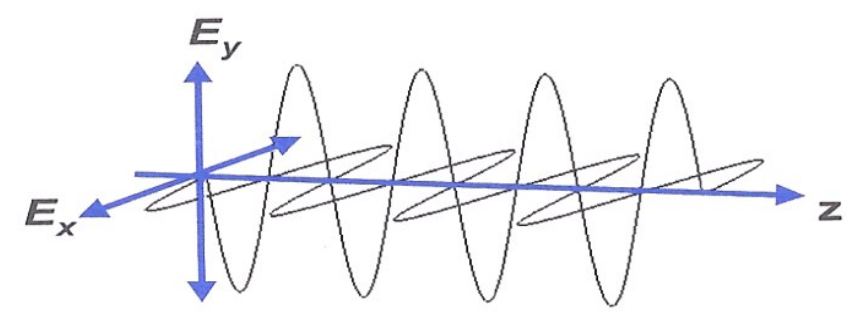

Figura 2 - Representação gráfica da propagação e seus eixos de referência.

De acordo com a teoria de Fresnel, $E_{x}(z, t)$ e $E_{y}(z, t)$ descrevem oscilações senoidais nos planos $x-z$ e $y-z$ respectivamente. Para o fenômeno de polarização, estas equações não revelam nada particular, contudo eliminando a componente espacial nas duas equações, representada pelo propagador $\boldsymbol{\omega} \boldsymbol{t}-\boldsymbol{k z}$, temos como resultado a seguinte equação da elipse,

$$
\frac{E_{x}(z, t)^{2}}{E_{0_{x}}{ }^{2}}+\frac{E_{y}(z, t)^{2}}{{E_{0 y}{ }^{2}}^{2}}-\frac{2 E_{x}(z, t) E_{y}(z, t)}{E_{0_{x}} E_{0_{y}}} \cos \delta=\operatorname{sen}^{2} \delta
$$

Onde $\delta=\delta_{x}-\delta_{y}$, 
A Equação 3.8, que descreve uma elipse em sua forma não padrão, é chamada de elipse de polarização pelo fato de se referir à luz polarizada. Nesta equação apesar do termo referente à constante de propagação ter sido explicitamente eliminado, ainda assim as componentes do campo $E_{x}(z, t)$ e $E_{y}(z, t)$ continuam a ter dependência espaço temporal. Uma representação da elipse de polarização não padronizada é mostrada a seguir:

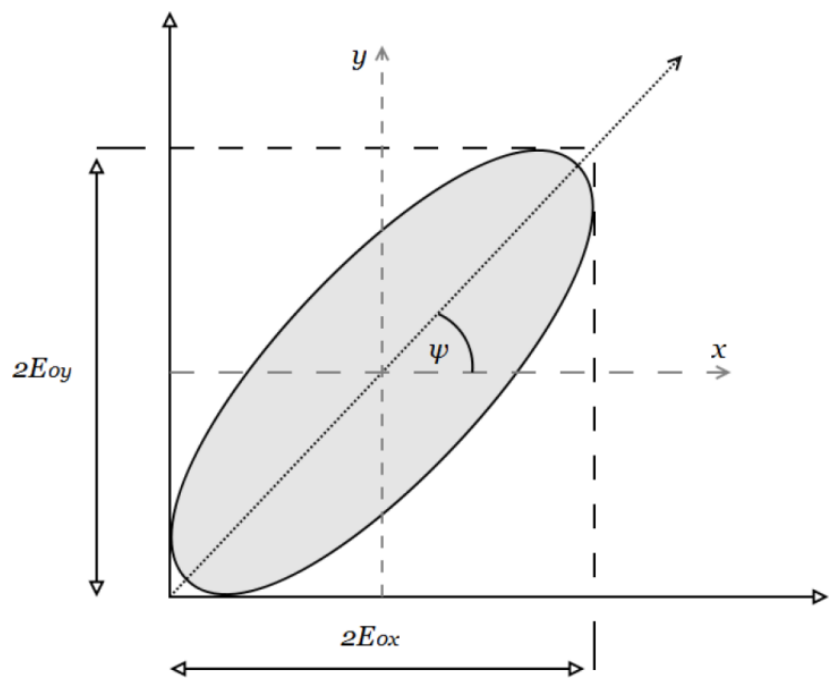

Figura 3 - Elipse de polarização (não padronizada).

A elipse de polarização pode ser expressa em função de dois parâmetros angulares: o ângulo de orientação $\boldsymbol{\psi}, \quad \psi(0 \leq \psi \leq \pi)$ e o ângulo de elipsidade $\chi, \chi(-\pi / 4<\chi \leq \pi / 4)$. Estes ângulos, por sua vez, podem ser definidos em função dos seguintes parâmetros de polarização da elipse:

$$
\begin{gathered}
\tan 2 \psi=\frac{2 E_{0_{x}} E_{0_{y}}}{E_{0_{x}}^{2}-E_{0_{y}}^{2}} \cos \delta, \quad 0 \leq \psi \leq \pi \\
\sin 2 \chi=\frac{2 E_{0_{x}} E_{0_{y}}}{E_{0_{x}}^{2}-E_{0_{y}}^{2}} \sin \delta, \quad-\pi / 4 \leq \chi \leq \pi / 4
\end{gathered}
$$

O lado direito destas equações consiste de termos algébricos e trigonométricos. 
Para melhor concisão, a equação pode ser reescrita completamente em termos trigonométricos, através da introdução de um ângulo conhecido como ângulo auxiliar $\alpha$, definido pela relação:

$$
\tan \alpha=\frac{E_{0_{y}}}{E_{0_{x}}}, \quad 0 \leq \alpha \leq \pi / 2
$$

A transformação proporcionada pelo ângulo auxiliar é muito importante e conduz as equações puramente trigonométricas:

$$
\begin{aligned}
& \tan 2 \psi=(\tan 2 \alpha) \cos \delta \\
& \sin 2 \chi=(\sin 2 \alpha) \sin \delta
\end{aligned}
$$

Nas Equações 3.12 e 3.13 as condições para os ângulos são $0 \leq \alpha \leq \pi / 2$ e $0 \leq \delta<2 \pi$.

A elipse de polarização é uma boa ferramenta matemática para tratamento da luz polarizada. Contudo, com exceção dos estados degenerados, é praticamente impossível determinar os ângulos de orientação e elipsidade a partir da visualização da elipse. Adicionalmente, o cálculo requerido para determinar novos ângulos de um feixe polarizado que se propaga através um ou mais elementos polarizadores exige considerável esforço. Para superar esta dificuldade Poincaré (1892) sugeriu o uso de uma esfera, que hoje é conhecida como esfera de Poincaré, para representar a luz polarizada. A Figura 4 mostra a esfera de Poincaré e suas coordenadas esféricas:

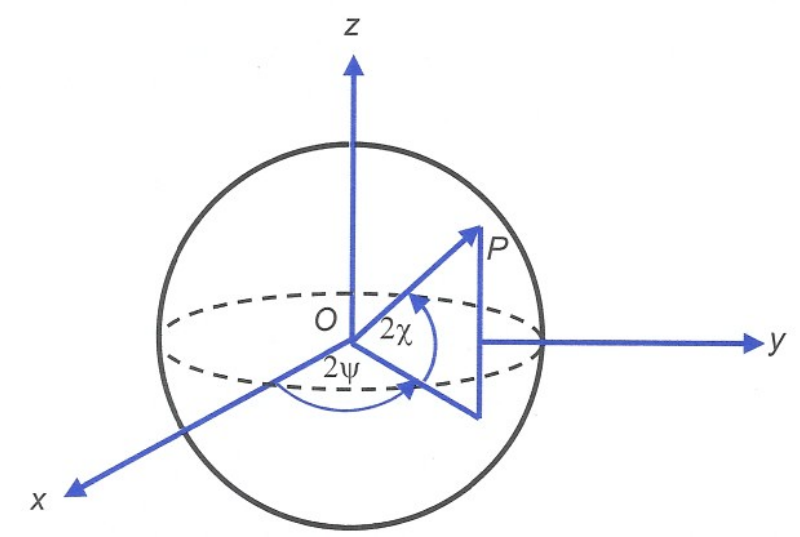

Figura 4 - Esfera de Poincaré com a representação de suas coordenadas esféricas. 
Considerando a esfera de Poincaré mostrada na Figura 4 os eixos das coordenadas cartesianas são representados por $x, y$ e $z$. $\chi \mathrm{e} \psi$ são os ângulos de orientação e de elipsidade, respectivamente oriundos da elipse de polarização. P é um ponto na superfície da esfera, onde os ângulos são representados como $2 \chi$ e $2 \psi$. Para uma esfera unitária, suas coordenadas cartesianas podem ser relacionadas às coordenadas esféricas pelas equações:

$$
\begin{aligned}
& x=\cos (2 \chi) \cos (2 \psi), \quad 0 \leq \psi<\pi \\
& y=\cos (2 \chi) \operatorname{sen}(2 \psi), \quad-\pi / 4 \leq \chi<\pi / 4, \\
& z=\operatorname{sen}(2 \chi)
\end{aligned}
$$

Onde $x^{2}+y^{2}+z^{2}=1$, para uma esfera de raio unitário.

Apesar de extremamente úteis, a esfera de Poincaré e a elipse de polarização possuem algumas características que dificultam sua realização em circuitos de comunicações, entre elas podemos citar:

1. A elipse de polarização é uma representação instantânea da luz polarizada.

2. Nem o ângulo de rotação $\psi$ nem o de elipsidade $\chi$ são diretamente mensuráveis.

Para superar estas limitações é necessário determinar os mensuráveis da luz polarizada. Isto pode ser obtido tomando uma média temporal da elipse de polarização.

$$
\frac{E_{x}(z, t)^{2}}{E_{0_{x}}{ }^{2}}+\frac{E_{y}(z, t)^{2}}{E_{0_{y}}{ }^{2}}-\frac{2 E_{x}(z, t) E_{y}(z, t)}{E_{0_{x}} E_{0_{y}}} \cos \delta=\operatorname{sen}^{2} \delta
$$

A média temporal $\left\langle E_{i}(z, t) E_{j}(z, t)\right\rangle$ é definida por:

$$
\left\langle E_{i}(z, t) E_{j}(z, t)\right\rangle=\lim _{T \rightarrow \infty} \frac{1}{T} \int_{0}^{T} E_{i}(z, t) E_{j}(z, t) d t, \quad i, j=x, y
$$


Onde $T$ é o tempo médio total. Aplicando a definição de média temporal na elipse de polarização chegamos as seguintes equações:

$$
S_{0}^{2}=S_{1}^{2}+S_{2}^{2}+S_{3}^{2}
$$

Onde,

$$
\begin{aligned}
& S_{0}={E_{0 x}}^{2}+{E_{0 y}}^{2}, \\
& S_{1}=E_{0_{x}}{ }^{2}-{E_{0 y}}^{2}, \\
& S_{2}=2 E_{0_{x}} E_{0_{y}} \cos \delta, \\
& S_{3}=2 E_{0_{x}} E_{0_{y}} \operatorname{sen} \delta,
\end{aligned}
$$

As quantidades $\boldsymbol{S}_{\mathbf{0}}, \boldsymbol{S}_{\mathbf{1}}, \boldsymbol{S}_{\mathbf{2}}$ e $\boldsymbol{S}_{\mathbf{3}}$ são os observáveis do campo polarizado. Eles foram introduzidos por Stokes (1852) e são chamados parâmetros de polarização de Stokes. Cada parâmetro de Stokes descreve quantidades específicas, associadas com potências das componentes do campo óptico.

- O parâmetro de Stokes $\boldsymbol{S}_{\mathbf{0}}$ descreve a intensidade total do feixe óptico;

- O segundo parâmetro $\boldsymbol{S}_{\mathbf{1}}$ descreve a preponderância da luz polarizada horizontal linear sobre a luz polarizada vertical linear;

- O terceiro parâmetro $\boldsymbol{S}_{2}$ descreve a preponderância da luz polarizada a $45^{\circ}$ á esquerda sobre a luz polarizada a $45^{\circ}$ á direita;

- Finalmente, $\boldsymbol{S}_{\mathbf{3}}$ descreve a preponderância da luz circularmente polarizada a direita sobre a luz circularmente polarizada a esquerda;

Uma característica interessante dos parâmetros de Stokes é o fato de que, diferentemente do formalismo de Jones, eles podem descrever não somente a luz totalmente polarizada, mas também podem descrever a luz despolarizada e parcialmente polarizada. O grau $\mathcal{P}$ de polarização da luz (em inglês DOP) é definido matematicamente na forma:

$$
\mathcal{P}=\frac{I_{\text {pol }}}{I_{\text {tot }}}=\frac{\sqrt{S_{1}^{2}+S_{2}^{2}+S_{3}^{2}}}{S_{0}}, \quad 0 \leq \mathcal{P} \leq 1
$$

Onde $I_{p o l}$ representa a intensidade de luz polarizada e $I_{\text {tot }}$ representa a intensidade total da luz. Para a luz totalmente polarizada o grau de polarização é igual a 1. 
Os parâmetros de Stokes podem ser dispostos num arranjo de vetores coluna na forma matricial, uma destas representações, mostrada na Equação 3.25, é denominada de vetores de Stokes para a luz elipticamente polarizada é.

$$
S=\left[\begin{array}{l}
S_{0} \\
S_{1} \\
S_{2} \\
S_{3}
\end{array}\right]=\left[\begin{array}{c}
E_{0_{x}}{ }^{2}+E_{0_{y}}{ }^{2} \\
E_{0_{x}}{ }^{2}-E_{0_{y}}{ }^{2} \\
2 E_{0_{x}} E_{0_{y}} \cos \delta \\
2 E_{0_{x}} E_{0_{y}} \operatorname{sen} \delta
\end{array}\right]
$$

$\mathrm{O}$ vetor de Stokes pode ser normalizado em relação à intensidade total do campo que é definida por $S_{0}$, o vetor normalizado é escrito na forma:

$$
S=\left[\begin{array}{l}
S_{1}{ }^{\prime} \\
S_{2}{ }^{\prime} \\
S_{3}{ }^{\prime}
\end{array}\right]=\left[\begin{array}{l}
S_{1} / S_{0} \\
S_{2} / S_{0} \\
S_{3} / S_{0}
\end{array}\right]
$$

Em nosso trabalho utilizaremos com mais frequência os parâmetros de Stokes normalizados, uma vez que é razoável considerar que o grau de polarização do sinal manterá um valor médio próximo da unidade. 


\subsection{1. \\ Representações das interações da luz com o meio}

Quando a luz atravessa um meio propagante ela sofre os efeitos deste meio, a polarização da luz com sua característica vetorial sofrerá uma rotação ao atravessar materiais com características polarizantes. Até aqui trabalhamos com o conceito de polarização do feixe de luz, a partir daqui devemos introduzir outro conceito de polarização associado aos materiais. De acordo com [37].

Quando nós aplicamos um campo elétrico a um material, nós puxamos os elétrons e, numa direção oposta núcleos positivamente carregados dos átomos. O movimento resultante dos elétrons e núcleos em resposta a este campo elétrico é chamado de polarização do material.

Para ser mais preciso na definição de polarização do material, nos devemos primeiro discutir a ideia de momento de dipolo. Uma típica forma de visualizar um dipolo é imaginar que nós temos um par de cargas iguais e opostas de valores $+q$ e $-q$. Nós podemos separar estas cargas por uma distância $\boldsymbol{d}$, por exemplo, na direção $\boldsymbol{z}$ empurrando a carga $+\boldsymbol{q}$ para o lado mais positivo de $\boldsymbol{z}$ e $-\boldsymbol{q}$ para o lado mais negativo de $\boldsymbol{z}$. Em geral qualquer par de cargas iguais e opostas separadas por alguma distância é chamado um dipolo. Tal separação é exatamente o que nós obtemos quando aplicamos um campo elétrico na direção $\boldsymbol{z}$ de $+\boldsymbol{v} \boldsymbol{e}$. Assim podemos dizer que nós temos um momento de dipolo de magnitude $\boldsymbol{\mu}=q \boldsymbol{d}$ apontado para direção $+\boldsymbol{v} \boldsymbol{e}$ de $\boldsymbol{z}$. Onde $\boldsymbol{v}$ é o potencial aplicado

Em geral se a carga positiva é separada da carga negativa pelo vetor $\boldsymbol{r}$, então o momento de dipolo é $\boldsymbol{\mu}=q \boldsymbol{r}$. É importante notar que o momento de dipolo $\boldsymbol{\mu}$ é uma quantidade vetorial. Embora seja típica a definição de um momento de dipolo em termos de cargas iguais e opostas, não é realmente necessário ter dois tipos de carga, a fim de ter um momento de dipolo. Poderíamos ver o movimento de uma taxa de valor $\boldsymbol{q}$ por um montante de vetor $\boldsymbol{r}$ como correspondente à adição de um dipolo. Podemos colocar a carga $-\boldsymbol{q}$ final do dipolo no topo da posição original da carga, anulando a carga original e $+\boldsymbol{q}$ final do dipolo, agora nos situamos na nova posição da carga. Conforme o consenso da eletrostática, não existe diferença entre mover a carga $\boldsymbol{q}$ por $\boldsymbol{r}$ ou criar o dipolo $\boldsymbol{\mu}=q \boldsymbol{r}$. 
Em um material real, não temos apenas duas cargas pontuais simples. Em vez disso, temos muitos pequenos elementos de carga, possivelmente de distribuição contínua, na verdade, para cada elemento que está sendo movido é como se aplicáseemos o campo elétrico. Muitas vezes, nós nem sequer sabemos exatamente como a carga é distribuída para começar a trabalhar com o material. O que nós realmente sabemos é que, quando olhamos numa escala bem acima do tamanho dos átomos, há algum momento de dipolo induzido quando se aplica um campo elétrico. Um dos aspectos muito convenientes sobre os momentos de dipolo é que podemos adicioná-los como vetores para obter um momento de dipolo efetivo maior. $\mathrm{Na}$ verdade, na nossa escala macroscópica, nós realmente não temos idéia do que todos os pequenos momentos de dipolo são - o que vemos são momentos de dipolo eficazes para alguns pequenos volumes. Para alguns volumes que são grandes em comparação com os átomos, mas pequenos quando comparados com dimensões macroscópicas, podemos, de maneira simplista, considerar esta soma vetorial dos momentos de dipolo como sendo o momento de dipolo efetivo desse volume. É então conveniente definir outra quantidade, que é o momento de dipolo por unidade de volume, e cujo vetor quantidade é chamado a polarização $\boldsymbol{P}$. Frequentemente e especificamente para pequenos campos elétricos $\boldsymbol{E}$ aplicados, a polarização $\boldsymbol{P}$ é aproximadamente proporcional ao campo elétrico e desta forma nós podemos definir uma constante proporcional $\chi$ chamada susceptibilidade. Formalmente descrita na forma:

$$
P=\varepsilon_{0} \chi E
$$

Esta notação é útil quando nós consideramos materiais não lineares, neste caso nós poderíamos expandir $\chi$ em uma série de potencia. A constante elétrica $\varepsilon_{0}$ (permissividade do espaço livre embora não tenha real significado físico permanece na equação por razões históricas associadas com a definição das unidades). Em eletromagnetismo, o campo de deslocamento elétrico $\boldsymbol{D}$, é definido como:

$$
D=\varepsilon_{0} E+P
$$


A partir das equações de Maxwell, as relações entre campos e densidades de fluxo são dadas por:

$$
\begin{aligned}
& D=\varepsilon_{0} E+P \\
& B=\boldsymbol{\mu}_{\mathbf{0}}(H+M)
\end{aligned}
$$

$\boldsymbol{B}$ é a densidade de fluxo magnético, $\boldsymbol{\mu}_{\mathbf{0}}$ é a constante magnética ou permeabilidade do espaço livre, da mesma forma que a constante elétrica não tem real significado físico e permanece na equação por razões históricas associadas com a definição das unidades. $\boldsymbol{M}$ é a magnetização e representa a resposta magnética do material ao campo magnético $\boldsymbol{H}$. Em meios isotrópicos, o momento de dipolo elétrico $\boldsymbol{P}$ e o momento de dipolo magnético $\boldsymbol{M}$ têm a mesma direção do campo correspondente.

\subsection{2. \\ Efeito eletro-óptico linear}

Nos materiais reais os deslocamentos eletromagnéticos não são estritamente proporcionais aos campos aplicados [25]. Uma investigação mais detalhada mostrará comportamentos não lineares. A relação $B=\boldsymbol{\mu}_{\mathbf{0}} H$ adere às características do meio óptico, o deslocamento elétrico por sua vez necessita ser reescrito na forma:

$$
D=\varepsilon_{0}\left(\left(1+\chi^{(1)}\right) E+\chi^{(2)}: E E+\chi^{(3)} \vdots E E E+\cdots\right)
$$

O termo proporcional ao campo elétrico $\boldsymbol{E}$ descreve comportamentos lineares incluindo a anisotropia, enquanto os outros termos descrevem dependências quadráticas e cúbicas. Nos cristais, o tensor $\chi^{(2)}$ geralmente tem elementos não nulos e os termos associados representam contribuições para $\boldsymbol{D}$ mais importantes que $\chi^{(3)}$. Em contraste, na sílica, que é um material amorfo, $\chi^{(2)}$ desaparece e $\chi^{(3)}$ é a mais importante não linearidade. O desenvolvimento da Equação 3.31 mostra que $\boldsymbol{D}$ contém termos proporcionais a:

$$
E_{3}^{2}=\left(E_{D C}^{2}+\frac{1}{2} E_{0}^{2}\right)+2 E_{D C} E_{0} \cos \omega t+\frac{1}{2} E_{0}^{2} \cos \omega t
$$


O primeiro termo do lado direito desta equação causa um deslocamento dielétrico estático, o terceiro uma contribuição relacionada ao dobramento da frequência óptica e o segundo é proporcional a ambos o campo estático e o campo óptico. Em outras palavras, esta é a contribuição para $\boldsymbol{D}$ que é linear no campo óptico e pode ser controlada por um campo eletrostático. Este é o efeito eletroóptico linear, também chamado de efeito Pockels. Um exemplo de material que exibe este efeito é o Niobato de Litio $\left(\mathrm{LiNbO}_{3}\right)$.

$\mathrm{O} \mathrm{LiNbO}_{3}$ é um material transparente, de propriedades cristalinas, não condutivo, pertencente ao grupo de simetria $3 m$. É um material sintético cuja principal matéria prima, o Nióbio tem o Brasil como maior fornecedor mundial [22]. É um cristal uniaxial com índices de refração $n_{X}=n_{Y}=n_{0}=$ $2,21283, n_{Z}=n_{e}=2,13739$. O tensor eletro-óptico contém na maioria zeros e sobre seus oito elementos não nulos exibem igualmente uns, o que deixa somente quatro coeficientes independentes.

$$
\left[r_{i j}\right]=\left[\begin{array}{ccc}
0 & r_{12} & r_{13} \\
0 & -r_{12} & r_{13} \\
0 & 0 & r_{33} \\
0 & r_{51} & 0 \\
r_{51} & 0 & 0 \\
r_{12} & 0 & 0
\end{array}\right]
$$

O transformador de polarização que utilizamos é um guia de onda de óptica integrada, composto por oito estágios de compensadores Soleil-Babinet [16] feitos em $\mathrm{LiNbO}_{3}$ [38]. Os autovetores normalizados de Stokes deste retardador podem ser calculados e a equação da elipse para este dispositivo pode ser escrita na forma Hermitiana. Os autovalores e o primeiro de dois autovetores ortogonais são:

$$
\begin{gathered}
\lambda_{1,2}=n_{0}^{-2} \pm r_{12} \sqrt{E_{2}{ }^{2}+E_{1}{ }^{2}} \\
{\left[\begin{array}{l}
X_{1} \\
Y_{1}
\end{array}\right]=\left[\begin{array}{c}
-E_{1} \\
E_{2}-\sqrt{E_{2}{ }^{2}+E_{1}}
\end{array}\right]}
\end{gathered}
$$


Os índices de refração são:

$$
n_{1,2}=\lambda_{1,2}^{-1 / 2} \approx n_{0}\left(1 \mp\left(n_{0}^{2} / 2\right) r_{12} \sqrt{E_{2}^{2}+E_{1}^{2}}\right)
$$

O retardo é dado por:

$$
\delta=\left(n_{2}-n_{1}\right) L
$$

O vetor normalizado de Stokes de um dos automodos é:

$$
V=\frac{1}{\sqrt{{E_{2}{ }^{2}+E_{1}^{2}}^{2}}}\left[\begin{array}{c}
E_{2} \\
E_{1} \\
0
\end{array}\right]
$$

$\mathrm{O}$ retardo do segundo automodo, $-\mathrm{V}$, em relação a $\mathrm{V}$ é:

$$
\delta=\left(n_{0}^{3} r_{12} \sqrt{E_{2}{ }^{2}+E_{1}{ }^{2}}-n_{1}\right) L
$$

Se atribuirmos $\pi=n_{0}^{3} r_{12} \Gamma_{2}\left(\mathrm{U}_{2, \pi} / \mathrm{d}\right) \mathrm{L}=n_{0}^{3} r_{12} \Gamma_{1}\left(\mathrm{U}_{1, \pi} / \mathrm{d}\right) \mathrm{L}$ para definir as voltagens $U_{2, \pi}$ e $U_{1, \pi}$ as quais se aplicadas sozinhas, geram um retardo igual a $\pi$. Isto resulta em:

$$
\begin{gathered}
V=\frac{\pi}{\delta}\left[\begin{array}{c}
U_{2} / U_{2, \pi} \\
U_{1} / U_{1, \pi} \\
0
\end{array}\right]=\left[\begin{array}{c}
\cos 2 \alpha \\
\sin 2 \alpha \\
0
\end{array}\right], \\
\delta=\pi \sqrt{\left(U_{2} / U_{2, \pi}\right)^{2}+\left(U_{1} / U_{1, \pi}\right)^{2}},
\end{gathered}
$$

Onde $\alpha$ é o ângulo de azimute do automodo linearmente polarizado descrito na Equação 3.37. É então conveniente escrever a seguinte relação:

$$
V=\frac{1}{\sqrt{\left(U_{2} / U_{2, \pi}\right)^{2}+\left(U_{1} / U_{1, \pi}\right)^{2}}}\left[\begin{array}{c}
U_{2} / U_{2, \pi} \\
U_{1} / U_{1, \pi} \\
0
\end{array}\right]
$$

É importante notar que mesmo na ausência de voltagens existe uma birrefringência TE-TM por conta da ausência de simetria na seção cruzada do guia de onda. 
Isto explica a necessidade da tensão de offset que é adicionada à $U_{2}$ e que aparece na formula do EOSPACE dada pelo fabricante com o nome de VBIAs. A matriz de Jones deste dispositivo é dada por:

$$
J=\left[\begin{array}{cc}
\cos \delta / 2+j \cos 2 \alpha \sin \delta / 2 & j \sin 2 \alpha \sin \delta / 2 \\
j \sin 2 \alpha \sin \delta / 2 & \cos \delta / 2-j \cos 2 \alpha \sin \delta / 2
\end{array}\right]
$$

A matriz de Mueller de um retardador sem perdas pode ser dada na forma:

$$
M=\left[\begin{array}{ccccc}
1 & \vdots & 0 & 0 & 0 \\
\cdots & \cdots & \cdots & \cdots & \cdots \\
0 & \vdots & & & \\
0 & \vdots & & G & \\
0 & \vdots & & &
\end{array}\right], \quad G \cdot G^{T}=1
$$

Na Equação 3.43 a submatriz $\boldsymbol{G}$ é do tipo $3 \times 3$ ortogonal.

De acordo com [25], um compensador Soleil-Babinet pode ser representado através de uma matriz de Mueller fazendo uso da submatriz $\boldsymbol{G}$ da Equação 3.43. Combinando as matrizes de Jones e Mueller do compensador Soleil-Babinet (CSB) [25] temos que a matriz $\boldsymbol{G}$ é da forma:

$$
\operatorname{CSB}(\delta, 2 \alpha)=\boldsymbol{G}=\left[\begin{array}{ccc}
V_{1}^{2}+V_{2}^{2} \cos \delta & V_{1} V_{2}(1-\cos \delta) & V_{2} \sin \delta \\
V_{1} V_{2}(1-\cos \delta) & V_{2}^{2}+V_{1}^{2} \cos \delta & -V_{1} \sin \delta \\
-V_{2} \sin \delta & V_{1} \sin \delta & \cos \delta
\end{array}\right]
$$

Para o caso de um feixe de luz circularmente polarizada ser utilizado como entrada, na saída do estágio de um compensador Soleil-Babinet o feixe de luz terá nova polarização definida pelo seguinte vetor:

$$
S=\operatorname{CSB}(\delta, 2 \alpha)\left[\begin{array}{l}
0 \\
0 \\
1
\end{array}\right]=\left[\begin{array}{c}
V_{2} \sin \delta \\
-V_{1} \sin \delta \\
\cos \delta
\end{array}\right]
$$




\section{4 \\ O transmissor PolSK}

\subsection{1. Eficiência espectral teórica do transmissor PoISK}

Um transmissor PolSK é eficiente na medida em que codifica os estados de polarização da luz a taxas de transmissão compatíveis com os requisitos de banda do sistema, adicionalmente estes estados de polarização deverão possuir distância de Hamming tal que permita a sua discriminação no receptor. As taxas de transmissão poderão ser aumentadas através do incremento da taxa de sinalização ou de forma mais eficiente através do aumento da quantidade de estados de polarização (símbolos) transmitidos. Considerando que no transmissor PolSK, os símbolos transmitidos estão associados a estados de polarização da luz devemos formalizar e adotar um espaço de códigos adequado, previamente definido e especificado. Conforme descrito na seção 3.1, vetores de Stokes são diretamente mensuráveis e por isto são apropriados para realização em sistemas físicos. Ao espaço formado pelos vetores de Stokes denominamos "espaço de Stokes". As vantagens de se trabalhar neste espaço de três coordenadas são várias, entre elas podemos citar:

- A distância de Hamming decai com menor velocidade no espaço de Stokes que no $\mathbb{R}^{2}[10,9]$, para uma mesma ordem de constelação de símbolos.

- A máxima eficiência espectral teórica que pode ser atingida [39], para quatro estados de polarização distintos é de $2 \mathrm{bit} / \mathrm{s} / \mathrm{Hz}$ e com 16 diferentes estados de polarização obteríamos uma eficiência espectral de $4 \mathrm{bit} / \mathrm{s} / \mathrm{Hz}$.

- A modulação PolSK pode apresentar amplitude praticamente constante [40], minimizando efeitos não lineares de propagação em fibras ópticas.

Constelações PolSK podem ser mapeadas diretamente no espaço de Stokes ou em espaços de dimensões maiores. Métodos de empacotamento regular (lattice packing) podem melhorar o projeto de sistemas PolSK, principalmente através da escolha de constelações compostas por pontos simétricos no espaço definido. 
De acordo com a teoria de códigos esféricos apresentada em [10], um ponto de sinal oriundo do espaço de dimensão $3 n$ e denotado por $X=$ $\left(x_{1}, x_{2}, \ldots, x_{3 n}\right) \cdot$, pode ser transmitido como uma combinação de $n$ estados de polarização em $n$ consecutivos intervalos de sinalização. Os três primeiros elementos de uma dada tupla $(X, 3 n)$ podem representar os valores dos parâmetros de Stokes durante o primeiro período de sinalização. No próximo intervalo de tempo, o estado de polarização definido pelos próximos três elementos de $X$ podem ser transmitidos a assim consecutivamente. Na forma definida, um símbolo de dimensão $3 n$ é composto de $n$ sub-símbolos. Cada sub-símbolo está associado a um diferente estado de polarização. No receptor cada estado de polarização é independentemente detectado e armazenado até que todo o símbolo seja completado. Em termos teóricos constelações ótimas, compostas por até 360 pontos, podem ser geradas. Obviamente à medida que os pontos se acomodam em posições próximas o trabalho de demodulação dos estados de polarização independentes pode se tornar impraticável devido às perturbações sofridas pelo canal óptico.

\subsection{2. \\ Conversão eletro-óptica no transmissor PoISK}

O transmissor PolSK experimental é composto de um laser $\mathrm{CW}$, que é o gerador do sinal óptico, um controlador de polarização lento que transforma o sinal CW para um sinal de polarização circular esquerda que é lançado através um transformador de polarização eletro-óptico composto por 04 estágios de compensadores Soleil-Babinet de $\mathrm{LiNbO}_{3}$ (EOSPACE). A escolha do número de estágios decorre das seguintes considerações:

1. O dispositivo integrado que utilizamos é composto de oito estágios logo, podemos construir o polarizador lento e o transformador no mesmo dispositivo;

2. Com quatro estágios é possível construir várias configurações equivalentes de transformadores qualquer-para-qualquer estado de polarização;

3. É esperado que a associação de um número maior de estágios incorra num aumento da capacitância da carga efetiva para os chaveadores MOSFET, forçando a redução da velocidade máxima que poderia ser atingida com menor número de estágios em paralelo. 
A consideração 3 é baseada no fato de que à medida que a capacitância de uma carga chaveada aumenta, a energia acumulada durante o chaveamento aumenta proporcionalmente ao quadrado da tensão de chaveamento, esta característica limita a velocidade de chaveamento de cargas capacitivas, pois a reatância capacitiva tende a diminuir com o aumento da frequência levando à correntes de pico elevadas que podem destruir os MOSFET.

Em [41,42,36] encontramos detalhadas e rigorosas abordagens sobre configurações de transformadores de polarização baseados em retardadores (waveplates). Em [43], observamos importantes considerações sobre a configuração Quarter Half Quarter (QHQ), em [44] duas variantes do QHQ, Half Quarter Quarter (HQQ) e Quarter Quarter Half (QQH) são reportadas como configurações de transformadores qualquer-para-qualquer estado de polarização. $\mathrm{Na}$ fase de caracterização do controlador de polarização, avaliamos o uso das diversas configurações observadas na bibliografia de referência.

Concluímos após análise teórica e experimental, que devido ao fato do EOSPACE possuir um eixo comum de propagação da luz para todos os seus estágios (waveplates), isto restringe as eventuais vantagens que seriam obtidas de uma configuração sobre a outra. Desta forma utilizamos um modelo de transformador próprio baseado em resultados experimentais.

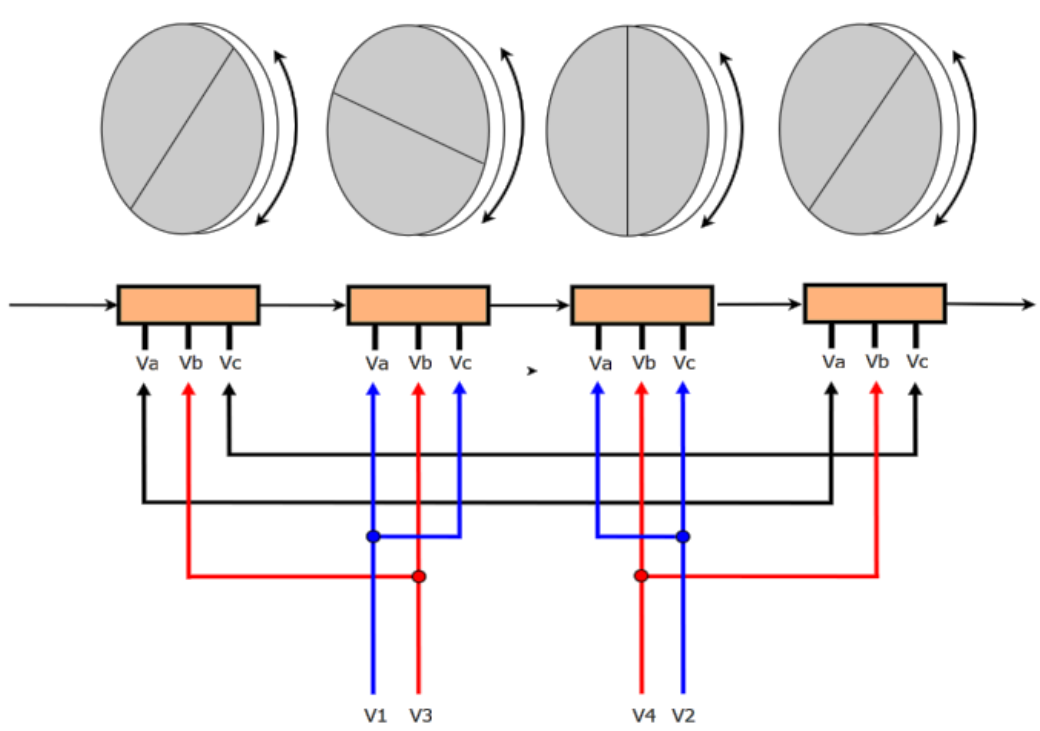

Figura 5 - Transformador de polarização experimental composto de 04 estágios. 
O transformador de polarização da Figura 5 apresentou um desempenho mais adequado para chaveamento em ponte, pois as inversões de polaridade das tensões resultaram, em alguns casos, em mudanças aproximadamente simétricas dos estados de polarização. Além disso, o mapeamento do espaço de Stokes foi relativamente maior do que foi obtido em outras configurações testadas, utilizando a mesma quantidade de estágios.

\subsection{3.}

\section{O cálculo matricial de Jones}

O cálculo de Jones é uma formulação matricial da luz polarizada que consiste de vetores $2 \times 1$, denominados vetores de Jones, utilizados para descrever as componentes do campo e matrizes $2 \times 2$ que descrevem componentes polarizadores, denominadas matrizes de Jones. A formulação 2x2 é mais simples que a matriz de Mueller, porém a formulação de Jones é limitada ao tratamento da luz totalmente polarizada, uma matriz de Jones não pode a principio, descrever luz despolarizada ou parcialmente polarizada.

Por conta disto, a formulação de Jones é mais utilizada em problemas que tratam interferências ou onde as amplitudes dos campos precisam ser superpostas. Considerando uma onda de luz monocromática, polarizada no plano $(x, y)$, mas com um estado de polarização arbitrário naquele plano. O estado de polarização é definido por um vetor do campo elétrico $\boldsymbol{E}$, formado a partir de amplitudes complexas (fasor de amplitudes) das componentes $x, y$ de polarização, $E x$ e $E y$ como se segue:

$$
\vec{E}=\left(\begin{array}{c}
E_{x} \\
E_{y}
\end{array}\right)=\left[\begin{array}{c}
E_{0 x} e^{i \delta_{x}} \\
E_{0 y} e^{i \delta_{y}}
\end{array}\right]
$$

Onde $E_{0 x}$ e $E_{0 y}$ são as amplitudes, $\delta_{x}$ e $\delta_{y}$ são as fases, e $i=\sqrt{-1}$. Observamos que as componentes $E_{x}$ e $E_{y}$ são quantidades complexas.

É possível, respeitando-se as restrições, representar a matriz de Jones em função de outras notações. Para efeito deste trabalho não utilizamos cálculo de Jones, pois o formalismo de Stokes se mostrou mais adequado para mapeamento de símbolos. 


\subsection{4.}

\section{Matrizes de Mueller}

Para representar a transmitância de um feixe de luz polarizada através de um polarizador é comum utilizar a notação matricial dos parâmetros de Stokes. Esta notação matricial é denominada Matriz de Mueller. Considerando os parâmetros de Stokes $S$ como uma descrição das componentes de campo elétrico de um feixe incidente sobre um dispositivo polarizador. Após atravessar o dispositivo o feixe emergente pode ser descrito por um novo conjunto de parâmetros de Stokes $S^{\prime}$. Se $S^{\prime}$ puder ser escrito como uma combinação linear dos quatro parâmetros de Stokes do feixe incidente resulta no seguinte conjunto de equações lineares:

$$
\begin{aligned}
& S_{0}^{\prime}=m_{00} S_{0}+m_{01} S_{1}+m_{02} S_{2}+m_{03} S_{3} \\
& S_{1}^{\prime}=m_{10} S_{0}+m_{11} S_{1}+m_{12} S_{2}+m_{13} S_{3} \\
& S_{2}^{\prime}=m_{20} S_{0}+m_{21} S_{1}+m_{22} S_{2}+m_{23} S_{3} \\
& S_{3}^{\prime}=m_{30} S_{0}+m_{31} S_{1}+m_{32} S_{2}+m_{33} S_{3}
\end{aligned}
$$

Este sistema linear pode ser reescrito na forma matricial:

$$
\left[\begin{array}{l}
S_{0}^{\prime} \\
S_{1}^{\prime} \\
S_{2}^{\prime} \\
S_{3}^{\prime}
\end{array}\right]=\left[\begin{array}{llll}
m_{00} & m_{01} & m_{02} & m_{03} \\
m_{10} & m_{11} & m_{12} & m_{13} \\
m_{20} & m_{21} & m_{22} & m_{23} \\
m_{30} & m_{31} & m_{32} & m_{33}
\end{array}\right]\left[\begin{array}{l}
S_{0} \\
S_{1} \\
S_{2} \\
S_{3}
\end{array}\right]
$$

Ou de forma simplificada:

$$
S^{\prime}=M . S
$$

A matriz $\mathrm{M}$ de dimensão $4 \times 4$ é conhecida como matriz de Mueller e sua forma matemática:

$$
M=\left[\begin{array}{llll}
m_{00} & m_{01} & m_{02} & m_{03} \\
m_{10} & m_{11} & m_{12} & m_{13} \\
m_{20} & m_{21} & m_{22} & m_{23} \\
m_{30} & m_{31} & m_{32} & m_{33}
\end{array}\right]
$$

A seguir são mostradas matrizes de alguns dispositivos ópticos. 
A Matriz de Mueller para um retardador genérico é dada na forma:

$$
M=\left[\begin{array}{cccc}
1 & 0 & 0 & 0 \\
0 & 1 & 0 & 0 \\
0 & 0 & \cos \phi & -\sin \phi \\
0 & 0 & \sin \phi & \cos \phi
\end{array}\right], \quad \phi=\frac{2 \pi}{\lambda}\left(n_{0}-n_{e}\right) d
$$

Para um retardador de quarto de onda em que $\phi=\pi / 2$ :

$$
M=\left[\begin{array}{cccc}
1 & 0 & 0 & 0 \\
0 & 1 & 0 & 0 \\
0 & 0 & 0 & -1 \\
0 & 0 & 1 & 0
\end{array}\right]
$$

Para um retardador de meia onda em que $\phi=\pi$ :

$$
M=\left[\begin{array}{cccc}
1 & 0 & 0 & 0 \\
0 & 1 & 0 & 0 \\
0 & 0 & -1 & 0 \\
0 & 0 & 0 & -1
\end{array}\right]
$$




\section{5}

\section{Teoria do receptor PoISK}

Para a avaliação dos requisitos do receptor consideramos os efeitos impostos pela fibra óptica ao sinal modulado, para tanto é útil analisar como os estados de polarização da luz evoluem à medida que o sinal se propaga no meio óptico. Em nosso projeto de transmissor, um sinal óptico de um laser CW é polarizado circularmente e lançado através um transformador de polarização eletro-óptico composto por 04 estágios de compensadores Soleil-Babinet de $\mathrm{LiNbO}_{3}$ (EOSPACE) [38]. Na sequência o sinal modulado em polarização é lançado na fibra óptica até o receptor (analisador).

Para descrever os fenômenos que acontecem na fibra óptica, necessitamos recorrer, de forma sucinta, ao adequado formalismo. Em [45] e [41] encontramos análises detalhadas destes fenômenos. Uma importante característica da PolSK é sua robustez diante do ruído de fase do laser transmissor [14]. Além disso, o fato desta modulação produzir um sinal de envoltória praticamente constante torna-a menos suscetível aos efeitos de propagação não lineares em fibras ópticas. Uma conhecida desvantagem da PolSK é a baixa sensibilidade do receptor e é interessante notar que a sensibilidade, relativamente baixa, dos receptores PolSK está justamente associada à intensidade constante do sinal transmitido. Para aumentar a sensibilidade dos receptores, alguns autores sugerem a PolSK multinível como uma solução viável na medida em que ela permite estabelecer uma relação de compromisso entre os indesejáveis efeitos não lineares provocados pelas variações rápidas de amplitude do sinal e o ganho de sensibilidade.

A PolSK multinível é assim chamada em função da quantidade de níveis dentro do espaço de Stokes. É importante notar que para uma onda totalmente polarizada, a modulação (chaveamento) dos estados de polarização será mapeada sobre o modelo matemático de uma casca esférica (esfera de Poincaré), que denota necessariamente um nível de amplitude constante. Como amplitude constante num canal óptico é uma abstração matemática é preciso levar em conta que a luz transmitida nem sempre estará idealmente polarizada. 
A Figura 6 ilustra três tipos de constelações PolSK que possuem respectivamente dois, quatro e oito níveis.

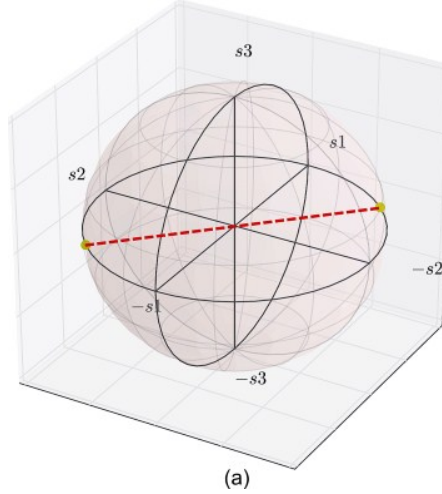

Figura 6 - Constelações PolSK

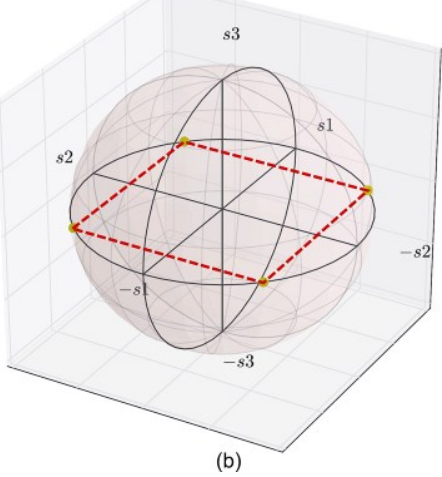

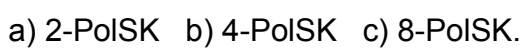

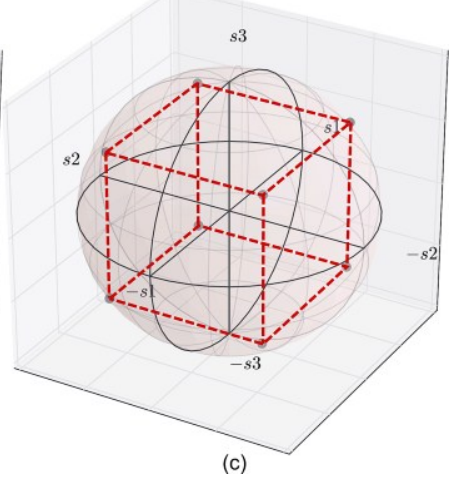

(c)

A constelação em forma de hexaedro mostrada na Figura 6-c, apesar de harmônica, não proporciona uma distância euclidiana ótima [12], contudo existe certa vantagem ao utilizá-la devido à simetria de seus pontos, fato este que facilita o método de recepção baseado no produto interno de vetores.
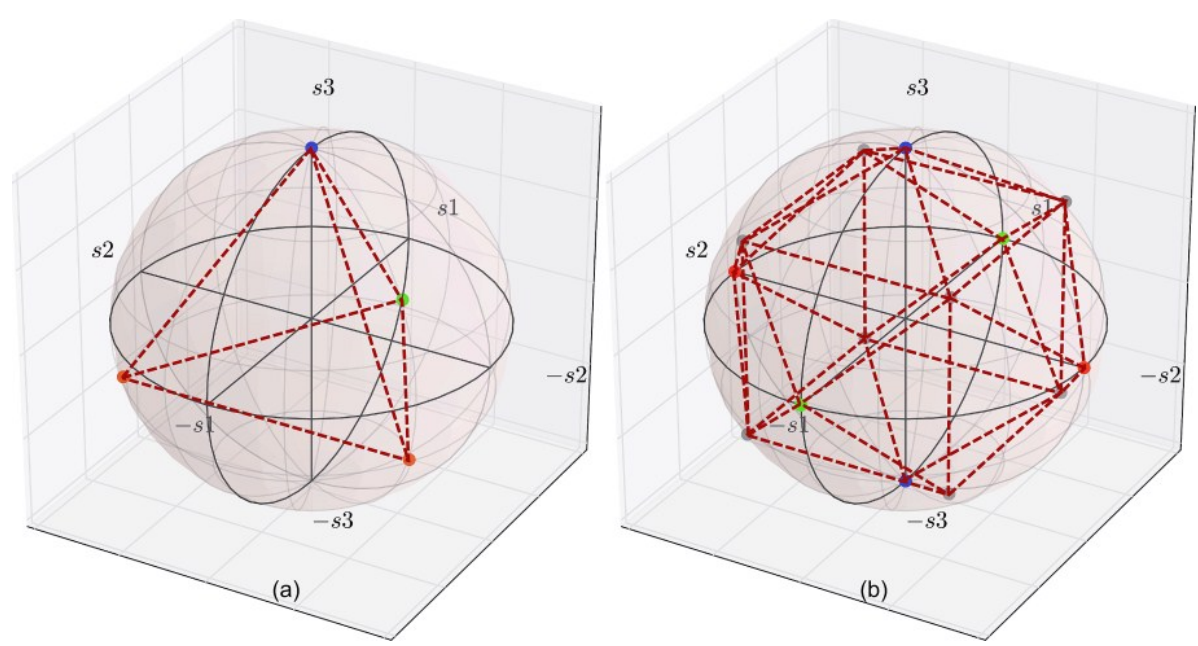

Figura 7 - a) Constelação do Tetraedro regular b) Constelação do Poliedro composto por um hexaedro e um octaedro.

Uma constelação que proporciona uma distância euclidiana ótima é o tetraedro regular mostrado na Figura 7-a. Um exemplo de uma constelação mais complexa é mostrado na Figura 7-b, formada por um hexaedro igual ao mostrado na Figura 6-c e um octaedro composto por seis estados de polarização degenerados, o poliedro resultante possui 14 vértices que podem ser mapeados. 
A especificação do transmissor é realizada, em grande parte, como função dos parâmetros de desempenho do receptor, desta forma é necessário tomar conhecimento de quais são os parâmetros do receptor a fim de garantirmos que a informação transmitida seja recuperada eficientemente.

Para efeito deste trabalho, um receptor Stokes é um receptor coerente, heteródino ou homódino, que extrai os parâmetros de Stokes de um sinal de frequência intermediária (FI). A demodulação e detecção do sinal modulado em polarização podem ser obtidas através da análise dos estados de polarização do sinal recebido. Conforme mencionado anteriormente, um estado de polarização pode ser completamente descrito através do conhecimento dos parâmetros de Stokes [41,12]. É importante notar que uma abordagem mais rigorosa do formalismo dos parâmetros de Stokes, baseada na mecânica quântica, pode considerar os estados quânticos da luz polarizada e efeitos que escondem os estados de polarização. Para a nossa abordagem é suficiente considerar os efeitos clássicos e deste modo assumir que os parâmetros de Stokes extraídos irão descrever de maneira unívoca cada estado de polarização da luz.

\section{1. Requisitos de desempenho do receptor PolSK com detecção coerente}

Conforme descrito anteriormente, na detecção coerente, o sinal óptico recebido é misturado com o sinal de um oscilador local (caso do receptor heteródino, $\operatorname{com} \Delta \omega \neq 0$ ) ou com o próprio sinal recebido atrasado (caso do receptor homódino, com $\Delta \omega=0$ ). O objetivo da detecção coerente é produzir uma frequência intermediária, comumente chamada de FI, que translada a informação do domínio óptico para frequências na faixa de RF, permitindo que o sinal onde esteja contida a informação seja processado eletronicamente. No caso de o sinal ser misturado num dispositivo acoplador com razão de divisão de $50 \% \mathrm{e}$ após o batimento deste sinal recebido com o laser local, a corrente no fotodiodo pode ser descrita pela equação:

$$
I(t)=\Re\left|E_{1}(t)\right|^{2}=\frac{\Re}{2}\left\{\left|E_{S}(t)\right|^{2}+\left|E_{L O}\right|^{2}+E_{S}(t) E^{*}{ }_{L O}+E_{S}^{*}(t) E_{L O}\right\}
$$


Onde $E_{\mathrm{S}}$ e $E_{\mathrm{LO}}$ são o campo óptico complexo e o oscilador local, respectivamente. Desconsiderando as contribuições da detecção direta, a parte útil da foto corrente que produz a componente de FI é representada pelo termo cruzado.

$$
i(t)=\frac{\Re}{2}\left[E_{S}(t) E^{*}{ }_{L O}(t)+E^{*}{ }_{S}(t) E_{L O}(t)\right]
$$

A multiplicação no domínio do tempo entre o sinal recebido e o oscilador local, equivale a convolução entre os dois espectros ópticos no domínio da frequência. Desta forma a densidade espectral de potência da FI é dada por:

$$
S_{I F}(\omega) \propto S_{p, s}(\omega) \otimes S_{p, L O}(-\omega)
$$

Onde $S_{p, s}$ e $S_{p, L O}$ são a densidade espectral de potência do sinal recebido e do oscilador local, respectivamente. Supondo que estas duas potências espectrais sejam ambas modeladas por uma distribuição de Lorenz, temos que:

$$
\begin{aligned}
S_{p, S}(f) & =\frac{1}{1+\left(\frac{f-f_{s 0}}{\Delta v_{s} / 2}\right)^{2}} \\
S_{p, L O}(f) & =\frac{1}{1+\left(\frac{f-f_{L O 0}}{\Delta v_{L O} / 2}\right)^{2}}
\end{aligned}
$$

Onde $\Delta v_{s}$ e $\Delta v_{L O}$ são as larguras a meia altura das bandas espectrais de linha e $f_{s 0}$ e $f_{L O 0}$ são as frequências centrais do sinal recebido e do oscilador local, respectivamente. A densidade espectral de potência normalizada da FI medida por um analisador de espectro deve ser:

$$
S_{F I}(f)=\frac{1}{1+\left(\frac{f-f_{F I}}{\left(\Delta v_{S}+\Delta v_{L O}\right) / 2}\right)^{2}}
$$

Onde $f_{F I}=\left|f_{s 0}-f_{L O 0}\right|$ é a freqüência central do sinal heteródino da FI. Conforme podemos observar, a largura de linha no domínio elétrico é a soma das larguras de linha do sinal recebido e do oscilador local, ou seja:

$$
\Delta v_{F I}=\Delta v_{s}+\Delta v_{L O}
$$


A necessidade de utilizar um oscilador local na detecção coerente heteródina resulta em requisitos rigorosos para que o receptor funcione de forma adequada, o ajuste de parâmetros do laser local como frequência, fase e polarização necessita, frequentemente, de sofisticados esquemas de realimentação e controle.

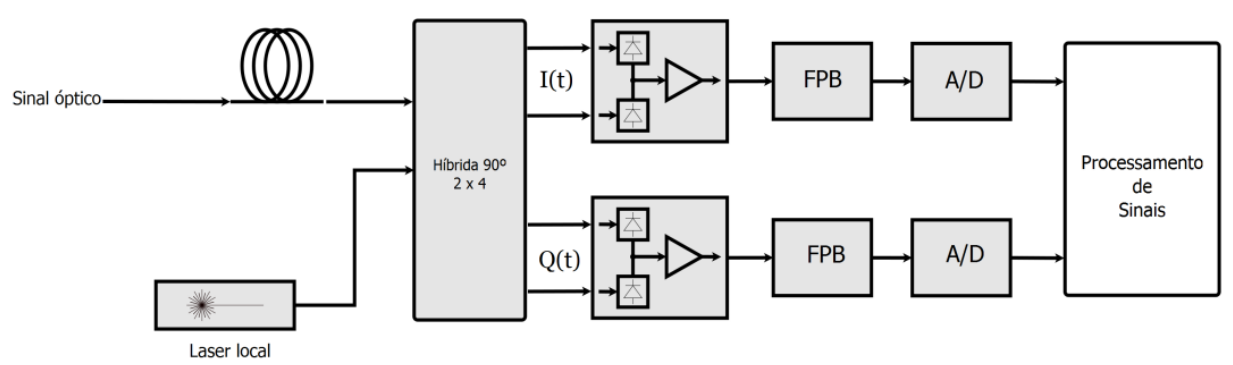

Figura 8 - Diagrama de blocos simplificado de um receptor coerente heteródino.

No diagrama de blocos mostrado na Figura 8, o batimento do sinal óptico com o laser local é realizado com auxílio de uma híbrida óptica de $90^{\circ}$ com duas entradas e quatro saídas. Os sinais ópticos em fase e quadratura $I(t) e Q(t)$ são convertidos em sinais elétricos com o auxilio de dois conjuntos fotodetectores balanceados, as componentes do sinal passam por filtros passa baixas antes da conversão analógica digital. Uma vez convertido em informação digital, o sinal pode ser processado de diversas maneiras.

Uma alternativa ao método heteródino é a detecção auto-homódina. Este tipo de detecção elimina a necessidade de uso de um oscilador local e o sinal recebido é misturado com versão de si mesmo atrasado. Considerando este esquema de detecção, a corrente em cada fotodiodo pode ser descrita pela equação:

$$
I(t)=\Re\left|E_{T}(t)\right|^{2}=\Re\left\{P_{1}+P_{2}+2 \sqrt{P_{1} \cdot P_{2}} \cos [\omega \Delta t+\Delta \phi(t)]\right\}
$$

A densidade espectral de potencia normalizada da FI, medida por um analisador de espectro, deve ser a autoconvolução do sinal densidade de potência espectral denotada por:

$$
S_{F I}(f)=S_{p, s}(f) \otimes S_{p, L O}(-f)=\frac{1}{1+\left(\frac{f}{\Delta v_{s}}\right)^{2}}
$$


É importante notar que, neste caso, a FI é centrada na frequência zero $\left(\mathrm{f}_{\mathrm{FI}}=0\right)$. A largura de linha resultante deveria ser o dobro da largura de linha do espectro óptico, contudo como o centro do pico de RF é na frequência zero, a parte negativa do espectro será espelhada na parte positiva, teremos efetivamente que a largura de linha do espectro em banda simples é igual à largura de linha do sinal óptico recebido. O esquema auto-homódino apesar de relaxar as exigências em relação à largura de linha do sinal óptico recebido, apresenta alguns desafios que devem ser encarados na construção de um receptor eficiente. Para um adequado funcionamento do receptor auto-homódino precisamos garantir que o retardo nos dois braços do dispositivo acoplador (interferômetro) obedeça a uma relação de compromisso com o comprimento de coerência do laser emissor. Quanto menor a largura de linha da fonte emissora, maior será o caminho que o sinal deve percorrer para que este seja equivalente ao comprimento de coerência dado por:

$$
L_{c o h}=c /(n \Delta v)
$$

Se $\Delta_{\tau} \gg \mathrm{t}_{\text {coh }}$ um interferômetro do tipo Mach-zehnder irá operar no regime incoerente, se $\Delta_{\tau} \ll t_{\text {coh }}$, o interferômetro irá operar no regime coerente. Especificamente, o regime incoerente é mais estável. O fato de a frequência central ser zero na detecção auto-homódina impõe penalidades na relação sinal ruído no detector, pois o ruído de intensidade laser é maior em baixas frequências. Para melhorar o desempenho da detecção auto-homódina é interessante mover a frequência central para longe do nível DC e manter $f_{F I}>\Delta v$ a fim de melhorar a acurácia na região de baixa frequência. Num detector auto-homódino com FI deslocada, a densidade espectral de potencia normalizada da FI medida por um analisador de espectro deve ser:

$$
S_{F I}(f)=S_{p, s}\left(f-f_{F I}\right) \otimes S_{p, s}(-f)=\frac{1}{1+\left(\frac{f-f_{F I}}{\Delta v_{s}}\right)^{2}}
$$


Com base na análise teórica, o receptor PolSK auto-homódino apresenta a melhor relação custo benefício, pois suas principais desvantagens podem ser compensadas através de técnicas que necessitam de recursos cada vez mais acessíveis como componentes de eletrônica rápida, dispositivos integrados optoeletrônicos e processamento digital de sinais.

A Figura 9 mostra o diagrama de blocos simplificado de um receptor coerente homódino. A escolha deste tipo de receptor impõe explicitamente uma relação entre a largura de linha do laser transmissor e a FI do receptor, descrita pela Equação 5.11. Adicionando a esta equação o fato de que existe uma proporção definida entre a FI e os filtros passa baixa (FPB) do receptor, temos que a banda passante do receptor deve ser especificada principalmente em função da largura de linha do laser transmissor.

De acordo com [12], a largura de banda do filtro de FI deve ser suficientemente grande para evitar a conversão entre o ruído de fase e o ruído de amplitude.

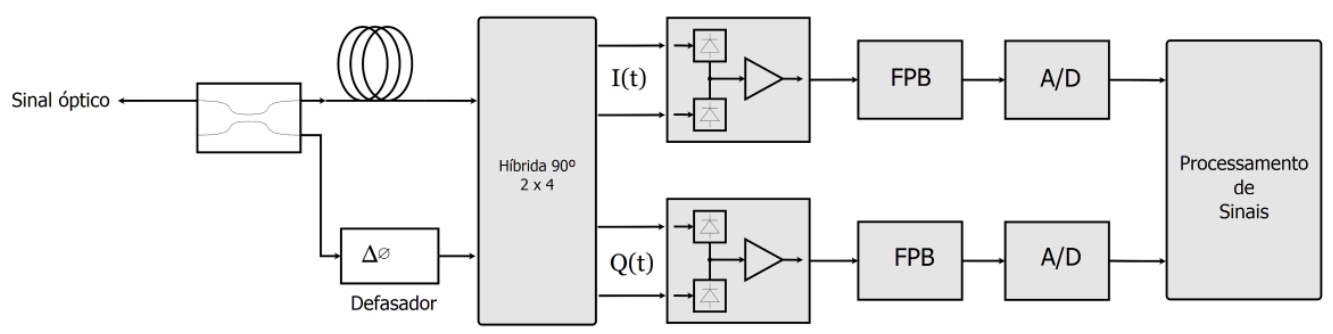

Figura 9 - Diagrama de blocos simplificado de um receptor coerente homódino. 


\section{6 \\ Caracterização dos componentes eletro-ópticos}

\section{1. O controlador de polarização}

Controladores ou transformadores de polarização eletro-ópticos são uma escolha natural para serem utilizados como moduladores de polarização por sua praticidade e facilidade de uso. O principal bloco funcional dos controladores ou retardadores de polarização é construído a partir de cristais birrefringentes formados por materiais como Rutile and Yttrium Orthovanade $\left(\mathrm{YVO}_{4}\right)$ ou Lithium Niobate $\left(\mathrm{LiNbO}_{3}\right)$.

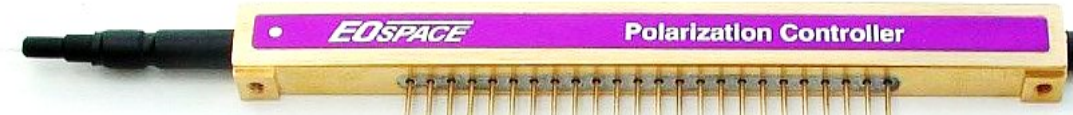

Figura 10 - Controlador de polarização multiestágio.

Uma waveplate, também conhecida como retardador, tem um eixo rápido e um eixo lento [16]. Se uma onda plana passa através de um retardador, a componente do campo elétrico ao longo do eixo rápido se propaga com menor índice de refração em relação a componente ao longo do eixo lento. Esta característica é conhecida como birrefringência ou dupla refração. Na saída do retardador, um relativo atraso de fase é introduzido entre os dois componentes (modos ortogonais). Este atraso depende da espessura do cristal e um retardador fracionário é definido como uma fração do comprimento de onda. Apesar de materiais $\mathrm{YVO}_{4}$ apresentarem elevada birrefringência [38] por questões práticas, o $\mathrm{LiNbO}_{3}$ é o cristal mais utilizado devido a sua menor dependência com a temperatura. A Figura 10 mostra um exemplo de dispositivo baseado em $\mathrm{LiNbO}_{3}$. 
Apesar das facilidades, alguns dispositivos têm a desvantagem de necessitar de tensões da ordem $50 \mathrm{~V}$ [16], o que na prática inviabiliza seu uso como moduladores de alta frequência.

Estes dispositivos com resposta linear não impõem, a priori, restrições em relação às polaridades das tensões de excitação. Contudo, o grau de liberdade para estas tensões não é ilimitado. Para o dispositivo mostrado na Figura 10, por exemplo, existe uma restrição para o máximo valor das voltagens que podem ser submetidas aos estágios adjacentes, naquele caso o típico valor máximo é de $80 \mathrm{~V}$ [38]. Cada estágio pode se comportar como linhas de retardo de $\lambda / 2, \lambda / 4$ ou $\lambda / 8$, de acordo com as tensões aplicadas em seus terminais. Entre as técnicas de controle possíveis para este dispositivo podemos, por exemplo, utilizar um único estágio do dispositivo para operar como um retardador de $\boldsymbol{\delta}$ comprimentos de onda e com ângulo de orientação $\boldsymbol{\alpha} / \mathbf{2}$, as tensões de operação necessárias são:

$$
\begin{aligned}
& V_{A}=2 \cdot V_{0} \cdot \delta \sin (\alpha)-V_{\pi} \cdot \delta \cos (\alpha)+V_{A, B I A S} \\
& V_{B}=0 \mathrm{~V} \\
& V_{C}=2 \cdot V_{0} \cdot \delta \sin (\alpha)-V_{\pi} \cdot \delta \cos (\alpha)+V_{C, B I A S}
\end{aligned}
$$

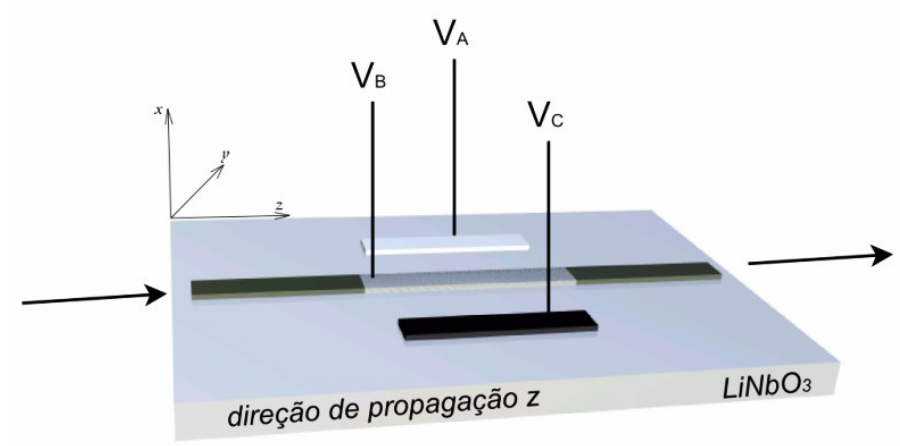

Figura 11 - Representação do guia de onda equivalente para cada estágio do EOSPACE.

Para mapear o espaço de Stokes podemos utilizar vários arranjos com linhas de retardo de $\lambda / 2$ onda e/ou $\lambda / 4$ de onda, cujos comportamentos serão completamente determinados pela escolha das tensões $V_{A}, V_{B}$ e $V_{C}$. 


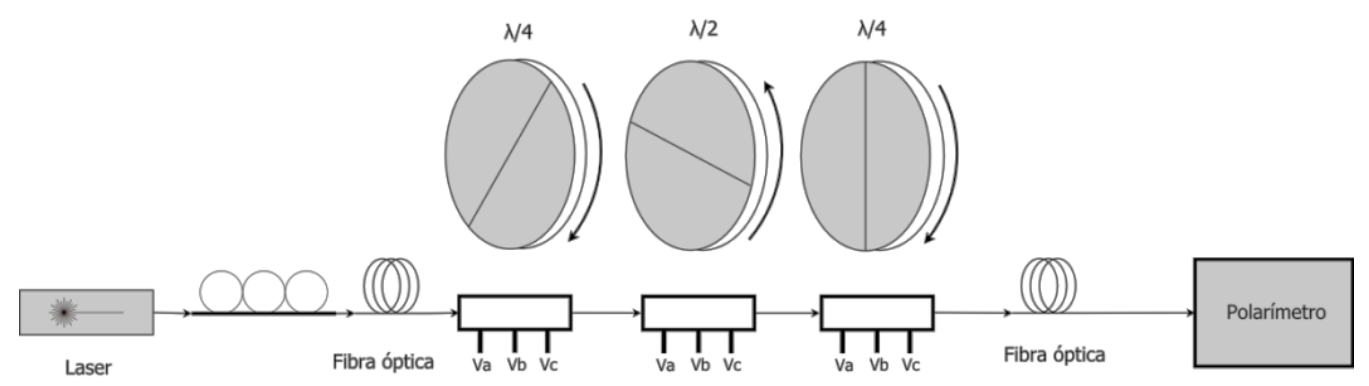

Figura 12 - Arranjo de retardadores compondo um transformador de polarização arbitrário para arbitrário.

A Figura 12 mostra uma configuração, descrita em [38], que apresenta um grau de liberdade bastante amplo. Este arranjo, composto de um retardador (waveplate) de $\lambda / 4$ de onda, seguido de um de $\lambda / 2$ e outro de $\lambda / 4$, pode transformar um estado de polarização linear de entrada para um estado de polarização arbitrário de saída. Para explorar o máximo do espaço de bit disponível e excitar o arranjo citado, o dispositivo que atua como chaveador eletrônico deverá ser capaz de chavear quatro tensões, duas a duas, com valores e polaridades independentes. Devido aos requisitos de alta velocidade e tensões relativamente altas para a faixa de frequência desejada, chaveadores MOSFET são uma opção de projeto. 


\section{2.}

\section{Aquisição, armazenamento e processamento dos dados}

Para caracterizar o controlador de polarização desenvolvemos um módulo de software para automação de duas fontes de tensão e de um equipamento A2000 da Adaptif Photonics (atual Agilent). O A2000 reúne num único equipamento polarímetro e controlador de polarização que podem ser controlados por interfaces USB e GPIB. Um microcomputador foi montado exclusivamente para controle e aquisição dos dados, nele foi instalada uma placa PCI 82350, esta placa é uma controladora GPIB completa. A caracterização foi realizada em duas fases, na primeira fase realizamos sequências combinatórias de valores de tensão, esta fase foi demorada, pois a fonte de tensão E3631A, quando controlada pela interface GPIB, possui um tempo de estabilização relativamente longo em torno de $250 \mathrm{~ms}$, tempo necessário para alterar o valor de saída e medi-lo com seu voltímetro interno na sequência. As combinações de tensão geraram sequências muito longas. Para exemplificar, se desejássemos verificar de forma exaustiva todos os possíveis estados de polarização que poderiam ser gerados considerando o intervalo de tensão 0-25 V e -25-0 V com um grau de liberdade 4, ou seja, quatro fontes independentes de tensão (duas negativa e duas positivas), em intervalos de 1 Volt, teríamos uma sequência de:

$25 \times 25 \times 25 \times 25=25^{4}=390625$ possíveis estados de polarização.

Considerando um intervalo de $100 \mathrm{~ms}$ entre cada comando GPIB o tempo total para gerar somente esta sequência seria em torno de 38 horas. As sequências longas produziam estados de polarização próximos uns dos outros, gerados por diferentes combinações das tensões, desta forma quanto mais densa a combinação maior é o grau de liberdade na escolha das tensões de chaveamento que o driver MOSFET vai utilizar. O tempo necessário para gerar estas sequências deve ser levado em conta, pois foi muito superior ao que havíamos previsto. $\mathrm{O}$ uso de fontes chaveadas ou conversores $\mathrm{D} / \mathrm{A}$ pode ser uma solução, pois este tipo de fonte, geralmente, necessita de um tempo muito menor para estabilização das tensões de saída. 


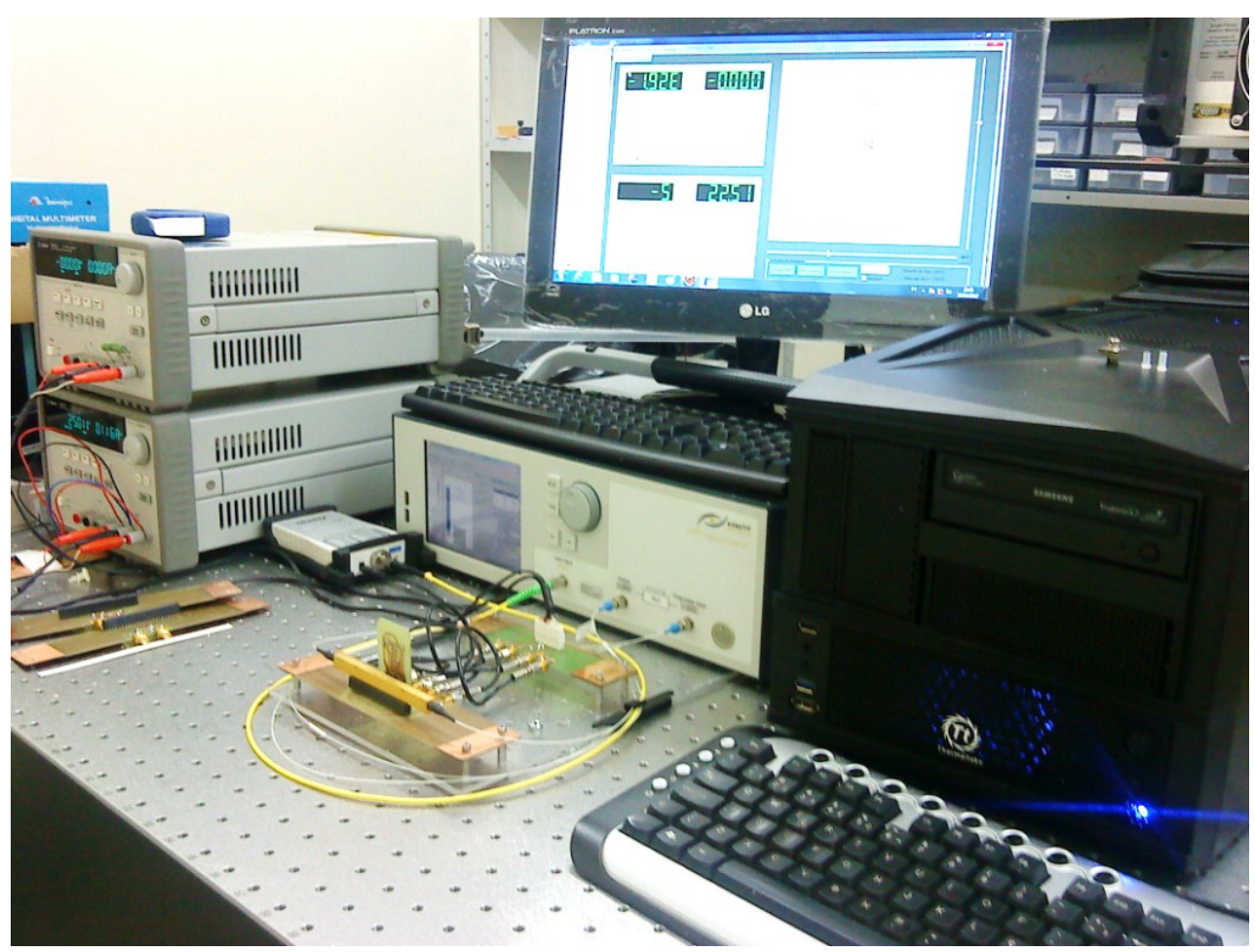

Figura 13 - Foto do "setup" inicial de caracterização do controlador de polarização.

Na primeira fase de caracterização, associamos cada conjunto de tensões, com o respectivo estado de polarização na saída do EOSPACE. A aquisição de dados medidos foi sincronizada entre as tensões aplicadas ao EOSPACE e os estados de polarização na saída deste dispositivo, desta forma os valores das tensões juntamente com as componentes normalizadas do estado de polarização e o grau de polarização foram armazenados em nós de arquivos XML com uma estrutura (modelo de dados) especificamente criada para esta finalidade.

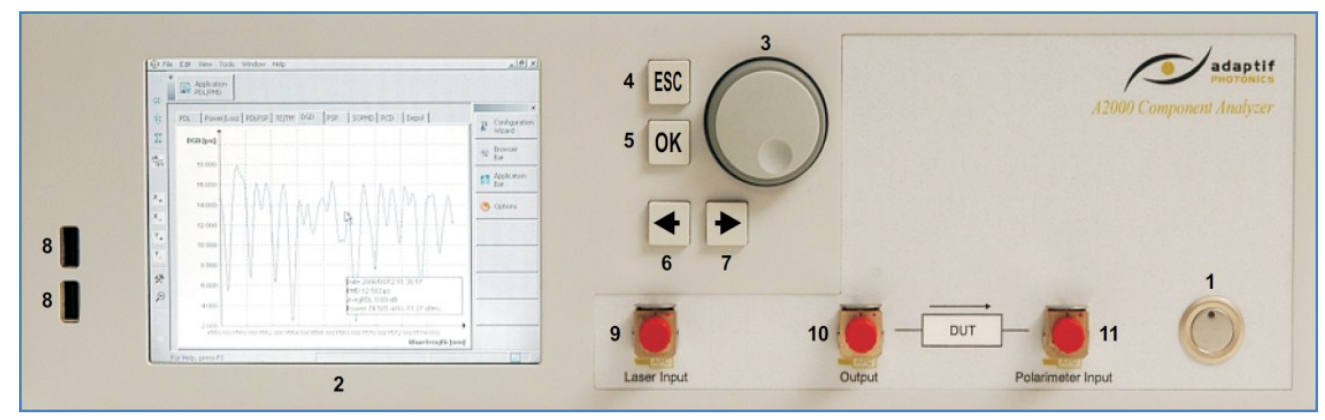

Figura 14 - Vista frontal do equipamento A2000. 


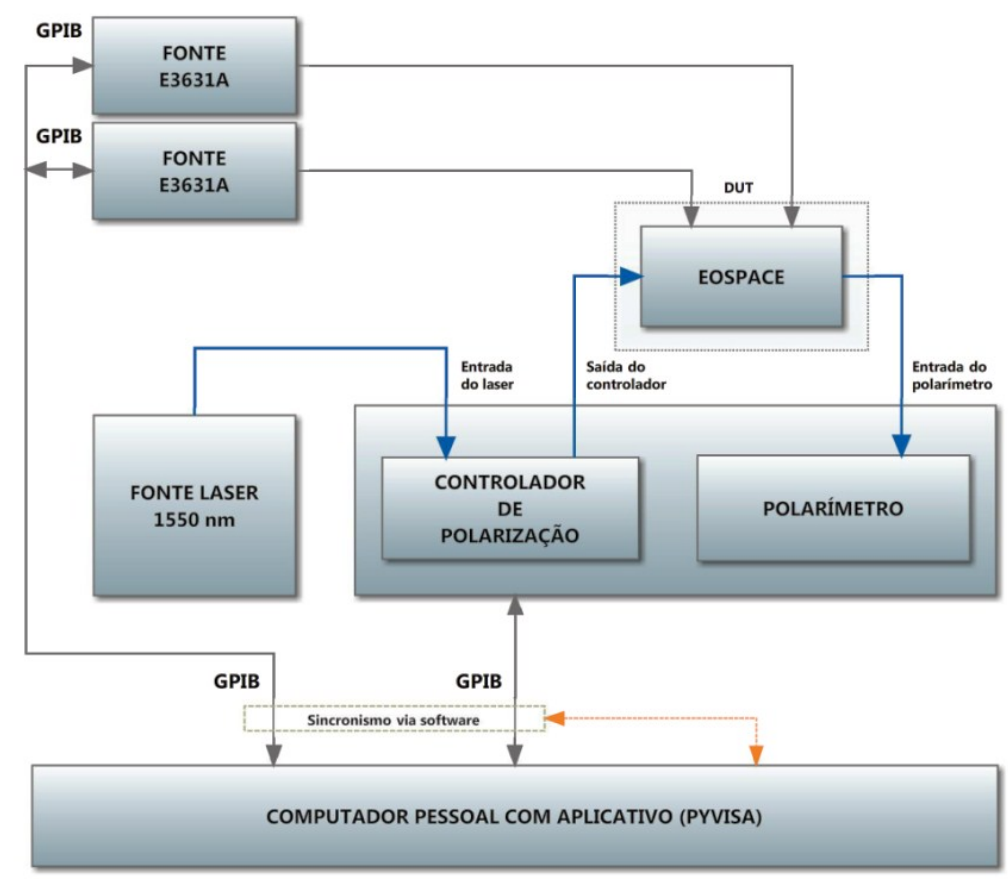

Figura 15 - Diagrama em blocos do aparato de caracterização do EOSPACE.

$\mathrm{O}$ armazenamento sincronizado das medidas permitiu recuperar os valores de tensão aplicados aos terminais da fonte de alimentação nos instantes em que o polarímetro media os estados de polarização. Por simplicidade foi considerado que valor de tensão medido nos terminais de cada fonte de alimentação era o mesmo valor aplicado aos terminais do EOSPACE, com esta simplificação foi possível utilizar o voltímetro interno da própria fonte E3631A e desta forma a automação dos valores de tensão de saída e as medidas destas tensões puderam ser realizadas com a mesma interface GPIB. Cuidados foram tomados no sentido de garantir que as conexões físicas dos cabos que ligavam as fontes de alimentação ao controlador de polarização estavam íntegras, pois se houvesse ruptura dos cabos, o voltímetro interno da fonte continuaria a indicar a tensão nominal de saída presente nos terminais da fonte.

Durante a caracterização do EOSPACE verificamos que a inversão da polaridade da tensão $V_{B}$ em relação às tensões $V_{A}$ e $V_{C}$ podem gerar rotações interessantes, que podem melhorar o rendimento dos circuitos de chaveamento. Tal comportamento pode ser deduzido do sistema de Equações 6.1 a 6.3.

Para inverter a polaridade das voltagens aplicadas aos terminais do EOSPACE construímos um conversor analógico digital simplificado e de baixa velocidade. 
A tensão de controle para o conversor A/D foi fornecida pela saída de $6 \mathrm{~V}$ de uma das fontes E3631A, esta saída é totalmente independente das demais saídas e foi programada para gerar quatro níveis de voltagens. Com este recurso a capacidade de mapeamento do aparato de caracterização foi multiplicada por quatro, além disso, nos permitiu analisar a relação entre as inversões de polaridade das tensões e os correspondentes estados de polarização. A lógica resultante da adição deste recurso é mostrada na Tabela 2.

\begin{tabular}{|c|c|c|c|c|c|c|c|}
\hline \multirow{2}{*}{$\begin{array}{c}\text { Saída de 6V } \\
\text { Fonte } 1 \\
\text { E3631A }\end{array}$} & \multirow{2}{*}{\multicolumn{2}{|c|}{$\begin{array}{c}\text { Saídas } \pm 25 \mathrm{~V} \\
\text { Fonte } 1 \\
\text { E3631A } \\
\end{array}$}} & \multirow{2}{*}{\multicolumn{2}{|c|}{$\begin{array}{c}\text { Saídas } \pm 25 \mathrm{~V} \\
\text { Fonte } 2 \\
\text { E3631A }\end{array}$}} & \multicolumn{2}{|c|}{$\begin{array}{c}\text { Lógica binária } \\
\text { equivalente }\end{array}$} & \multirow{3}{*}{$\begin{array}{c}\text { Sequência } \\
1 \\
\end{array}$} \\
\hline & & & & & \multirow{2}{*}{$\begin{array}{c}\mathrm{Q}_{1} \\
0\end{array}$} & \multirow{2}{*}{$\begin{array}{c}\mathrm{Q}_{0} \\
0 \\
\end{array}$} & \\
\hline $0-1 \mathrm{~V}$ & $+\mathrm{V}$ & $+\mathrm{V}$ & $+\mathrm{V}$ & $+\mathrm{V}$ & & & \\
\hline $1.25-2 \mathrm{~V}$ & $+\mathrm{V}$ & $-\mathrm{V}$ & $+\mathrm{V}$ & $-\mathrm{V}$ & 0 & 1 & 2 \\
\hline $2.25-3 \mathrm{~V}$ & $-\mathrm{V}$ & $+\mathrm{V}$ & $-\mathrm{V}$ & $+\mathrm{V}$ & 1 & 0 & 3 \\
\hline $3.25-4 \mathrm{~V}$ & $-\mathrm{V}$ & $-\mathrm{V}$ & $-\mathrm{V}$ & $-\mathrm{V}$ & 1 & 1 & 4 \\
\hline
\end{tabular}

Tabela 2 - Mapeamento de tensões com o uso do circuito chaveador de polaridade de tensão.

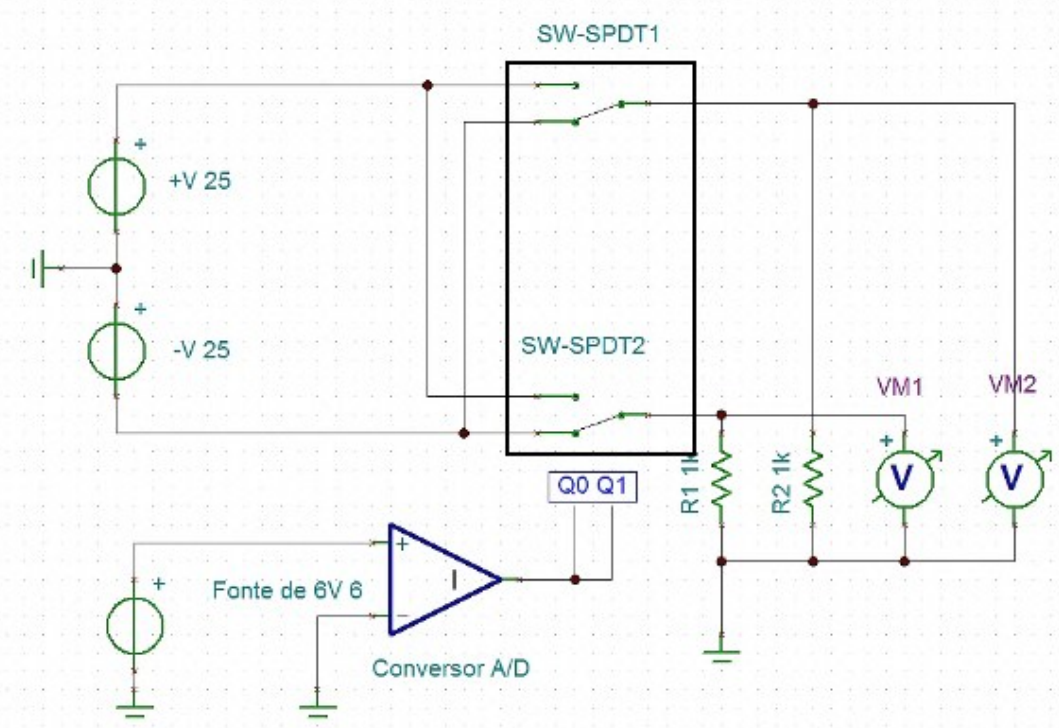

Figura 16 - Circuito equivalente do chaveador de polaridade para tensões das fontes. 


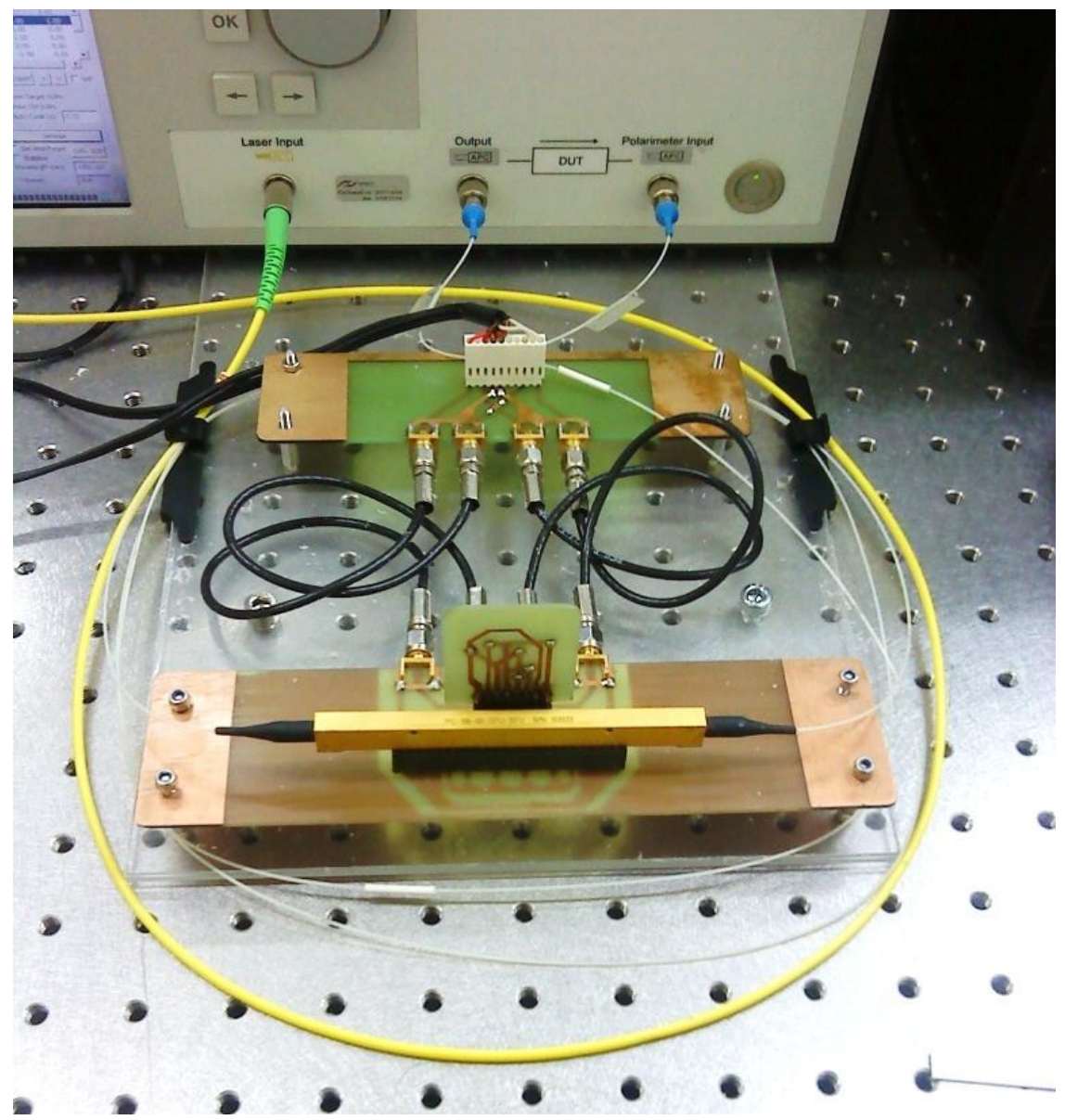

Figura 17 - Placa de circuito para conexão do EOSPACE com as fontes de alimentação.

Além da questão de confiabilidade das conexões, a placa de circuito impresso mostrada na Figura 17 foi confeccionada para resolver outro problema relacionado com a parte óptica do dispositivo controlador de polarização. Para efeito da caracterização do EOSPACE, as medições em polarização são extremamente sensíveis ao movimento da fibra óptica nas proximidades do dispositivo e por isto necessitávamos uma forma de mudar a configuração elétrica do controlador sem alterar fisicamente a disposição física do rabicho "pig tail". Para esta finalidade o "conector adaptador", em destaque na Figura 17, teve a finalidade de permitir a alteração do circuito elétrico da configuração. A alteração é feita através de uma placa de conexão auxiliar que conecta os quatro valores de tensão (02 positivos e 02 negativos) aos pinos de 04 estágios do EOSPACE. Com esta associação de circuitos é possível mudar a configuração elétrica apenas com a troca do adaptador mantendo a placa principal (que suporta o EOSPACE) no mesmo lugar. 
A Figura 18 mostra detalhes dos adaptadores auxiliares.
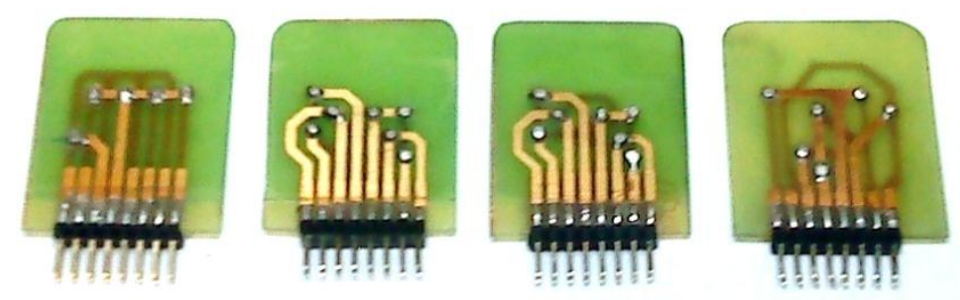

Figura 18 - Exemplo de placa de circuito impresso de conexão auxiliar.

A fase de caracterização do controlador de polarização foi de extrema importância para a compreensão das possibilidades de projeto do transmissor PolSK. Nesta fase foram definidos os valores máximos de tensão necessários para geração da constelação de estados de polarização. Escrito em linguagem Python [46] o módulo de software permitiu que várias funcionalidades fossem desenvolvidas dentro da mesma aplicação, a grande quantidade de bibliotecas de software disponíveis na linguagem Python reduziu consideravelmente a complexidade do processo de caracterização do controlador de polarização. As vantagens obtidas compensaram o tempo investido no desenvolvimento desta aplicação de software, que possui aplicabilidade mais ampla na caracterização de componentes eletro-ópticos em geral. A seguir mostramos uma lista das principais bibliotecas Python que foram utilizadas no processo de automação das medidas, listamos juntamente suas respectivas funcionalidades:

- $\boldsymbol{P y} Q \boldsymbol{T}$ - Python QT é um módulo Python para criação de interfaces gráficas e foi utilizado para expandir os recursos de visualização das fontes de alimentação e do polarímetro.

As fontes de tensão que utilizamos para a caracterização do EOSPACE são do modelo E33631A da Agilent. Estas fontes possuem 03 saídas de tensão controladas pela interface GPIB sendo que duas saídas são simétricas com tensões máximas de $\pm 25 \mathrm{~V}$. Apesar da facilidade de controle, este modelo de fonte não permite a visualização simultânea dos valores das tensões de saída, para superar esta limitação foi criada, dentro do módulo de software, uma interface gráfica com visualização simultânea dos valores de tensão. 
A visualização simultânea contribuiu positivamente para a monitoração do processo de caracterização do controlador de polarização, pois expandiu os recursos originais de visualização do equipamento E33631A e do polarímetro A2000. No exemplo mostrado na Figura 19, a esfera de Poincaré representa vários estados de polarização gerados com a combinação de 04 tensões providas pelas fontes E3631A (visualizadas simultaneamente).

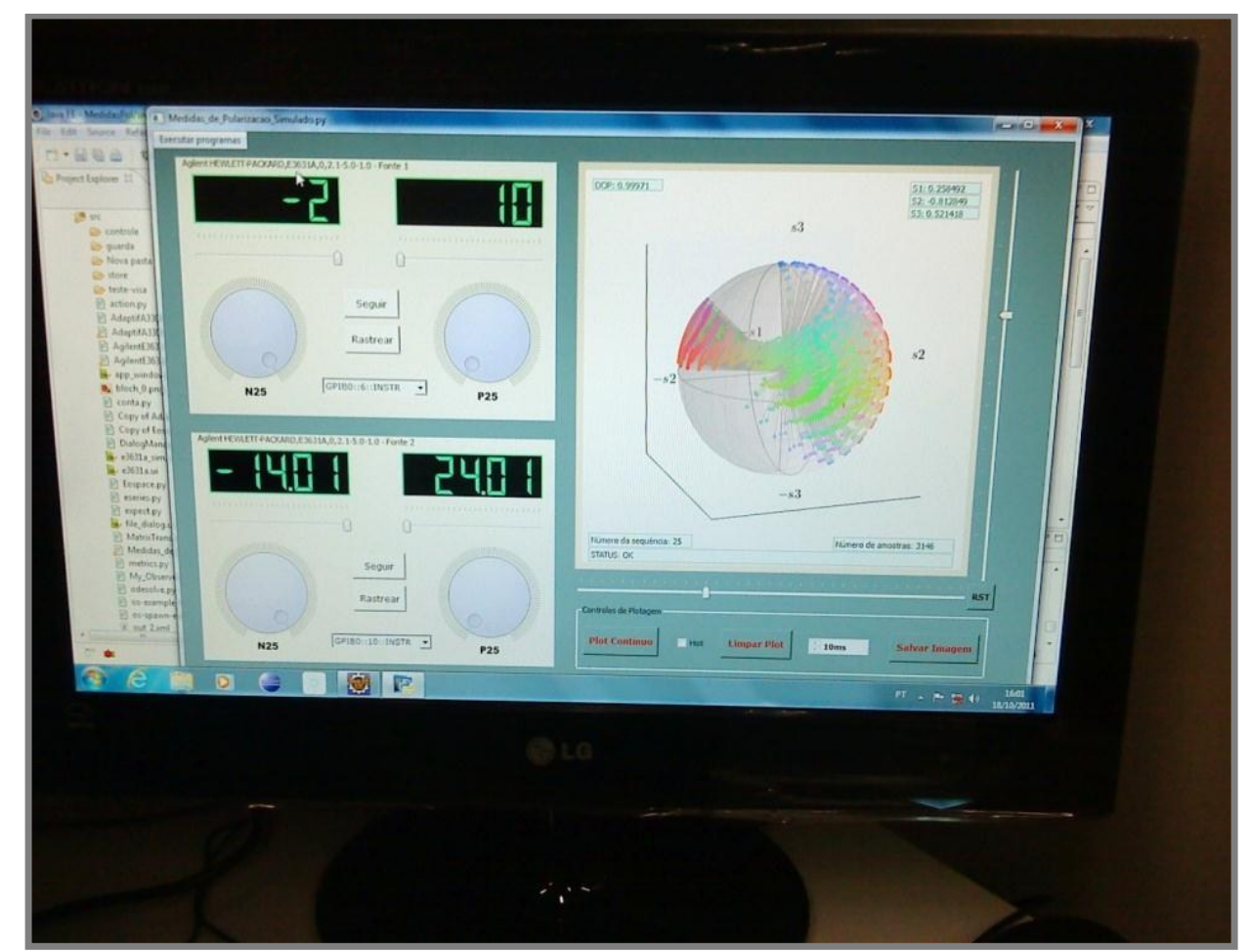

Figura 19 - Visualização da interface gráfica utilizada na caracterização do EOPSACE.

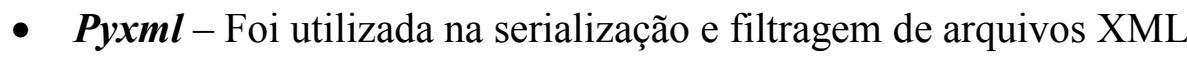

- $\quad \boldsymbol{l} \boldsymbol{x} \boldsymbol{m} \boldsymbol{l}$ - Foi utilizada na serialização em modo streaming e armazenamento de arquivos XML. O modo streaming permitiu a aquisição de dados em modo contínuo e gravação em fluxo discreto por períodos longos. Os dados medidos eram transferidos da memória para o arquivo XML em quantidades predefinidas de 100 medidas por nó XML.

- Matplotlib - Biblioteca utilizada para plotagem de dados em 3D (Esfera de Poincaré);

- Numpy - Biblioteca utilizada para operações com matrizes. A biblioteca Numpy [47] permitiu o tratamento numérico de operações envolvendo matrizes, esta biblioteca tem como base algoritmos utilizados em softwares comerciais como, por exemplo, MATLAB; 
- PyVisa - A biblioteca PyVisa (Python VISA) permite o controle via interface GPIB, USB e/ou Serial de qualquer equipamento compatível com o padrão de controle VISA. Esta biblioteca de software foi primordial para a aquisição de dados em modo sincronizado, adicionou grande flexibilidade no controle das fontes de tensão e principalmente na aquisição dos dados do polarímetro. Seguindo o paradigma da orientação a objetos, expandimos as funcionalidades da classe legada da biblioteca PyVisa e denominada Instrument. A classe Instrument disponibiliza vários métodos de acesso para funções de automação via interfaces GPIB, USB ou Serial.

- Scipy - Biblioteca utilizada para cálculos matemáticos avançados;

- Qutip - A biblioteca Quantum Toolbox in Python possui uma classe para plotagem da esfera de Bloch, esta classe Bloch foi modificada para que pudesse representar a esfera de Poincaré. A Figura 20 mostra a plotagem de estados de polarização (feita em tempo real) a partir de dados medidos com o polarímetro A2000, com auxilio da biblioteca Qutip.

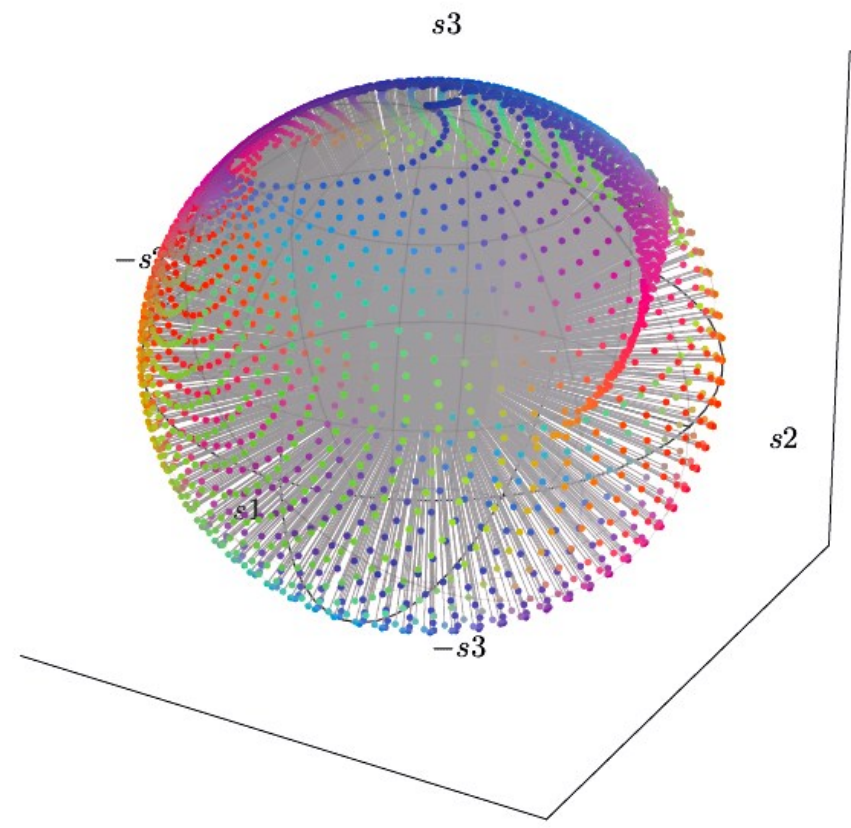

Figura 20 - Plotagem de estados de polarização feita em tempo real.

Para melhorar o efeito de profundidade da esfera, os pontos que representam os estados de polarização foram plotados em cores. As componentes do código de cores RGB foram normalizadas com valores dos módulos dos vetores de Stokes. Desta forma, pontos pertencentes ao mesmo eixo são representados com a mesma cor. 
A normalização seguiu a seguinte fórmula: Sejam $S_{1}, S_{2}, S_{3}$, as componentes dos estados de polarização normalizados, medidos através do polarímetro A2000. Para um ponto qualquer associado ao estado de polarização, a cor deste ponto representada pelo código RGB será:

$$
\boldsymbol{R}=\left|S_{1}\right| .255, \quad \boldsymbol{G}=\left|S_{2}\right| .255, \quad \boldsymbol{B}=\left|S_{3}\right| .255
$$

Desta forma, o vetor de Stokes $[0,0,1]$ é representado pelo código $(0,0,255)$ que corresponde a cor azul, da mesma forma o vetor $[0,0,-1]$ é representado pelo mesmo código $(0,0,255)$ e consequentemente pela mesma cor azul. Os vetores deste exemplo são diametralmente opostos e estes vetores possuem significado especial na esfera de Poincaré, são estados de polarização antipodais e estão associados aos autovetores e autovalores. Com o recurso das cores foi possível observar, de forma qualitativa, a densidade de pontos antipodais.

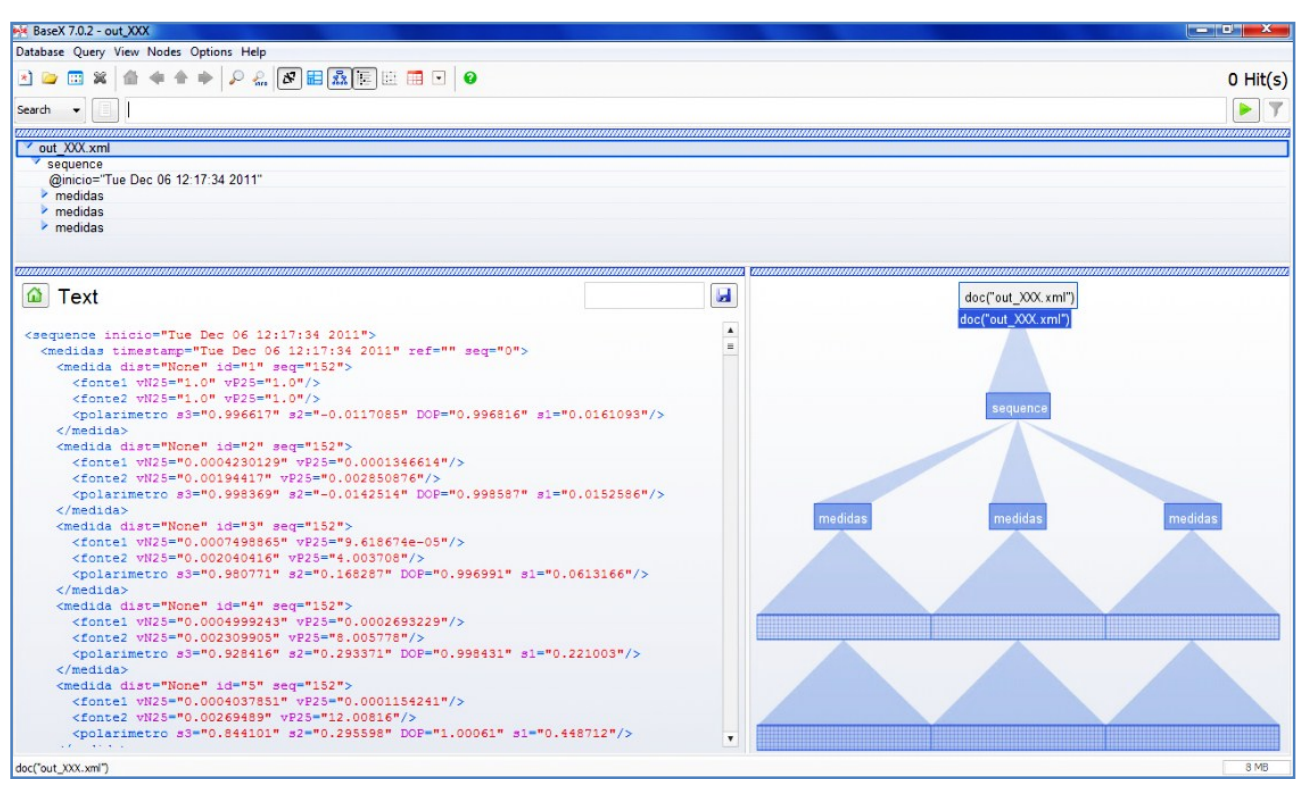

Figura 21 - Detalhe da estrutura de dados utilizada para armazenar as medidas de polarização.

Para validar os dados adquiridos foi gerada uma constelação de símbolos de referência. Foram escolhidos 18 vetores de modo a formar uma constelação factível em telecomunicações, seis vetores representam os estados de polarização degenerados, oito vetores formam a figura de um cubo (hexaedro) e os outros quatro vetores formam a figura de um tetraedro. Os vetores do hexaedro foram gerados com base na Equação 6.5, onde $S_{0}$ foi considerado igual a 1 (um). 
A Tabela 3 mostra a lista dos vetores e os respectivos valores de $\chi$ e $\psi$ que foram utilizados para gerá-los.

$$
\text { Stokes }=\left[\begin{array}{c}
S_{0} \cos (2 \chi) \cos (2 \psi) \\
S_{0} \cos (2 \chi) \sin (2 \psi) \\
S_{0} \sin (2 \chi)
\end{array}\right],-\pi / 4 \leq \chi<\pi / 4 \text { e } \psi(0 \leq \psi \leq \pi)
$$

Com base no espaço de Stokes coberto e no método descrito na Ilustração 1, testamos diferentes valores dos ângulos $\chi$ e $\psi$ para verificar quais valores forneciam a maior quantidade de pontos dentro dos cones de aceitação, formados pelos vetores cuja distância angular fosse menor ou igual ao ângulo de aceitação $\theta$ descrito na Equação 6.9. Os valores testados foram $\chi=15^{\circ}, \chi=17,63^{\circ}$ e $\chi=22,5^{\circ}$ com $\psi_{\text {inicial }}=0^{\circ}$ e $\psi_{\text {inicial }}=45^{\circ}$. Em alguns casos, a mudança do angulo $\psi_{\text {inicial }}$ proporcionou um aumento do número de pontos que aderiram aos cones de aceitação. Este recurso de girar a constelação de referência pode ser utilizado para "driblar" os buracos encontrados no espaço de Stokes, assim não é necessário ter toda a esfera de Poincaré preenchida. 


\subsection{1.}

\section{Dados sobre a geometria das constelações PolSK}

Considerando o hexaedro uma das constelações PolSK mais emblemáticas, a seguir descrevemos alguns aspectos da geometria do cubo (hexaedro regular) inscrito numa esfera unitária: $\mathrm{O}$ cubo de face $A^{2}$ inscrito numa esfera unitária possui diagonal igual a $A \sqrt{3}=2$, logo a face deste cubo equivale a um quadrado de lado $l=A=\frac{2}{\sqrt{3}}$. Considerando o grande círculo onde está contida a diagonal do cubo, temos a projeção mostrada na Figura 22:

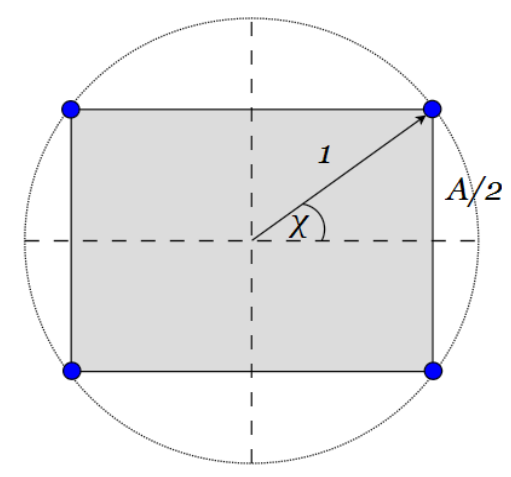

Figura 22 - Representação gráfica do plano que contém a diagonal do cubo inscrito na esfera.

O seno do ângulo de inclinação entre o equador da esfera e a face superior do cubo será calculado através da regra de Pitágoras.

$$
\sin \chi=\frac{\frac{A}{2}}{1}=\frac{A}{2}
$$

O ângulo de inclinação $\chi$ define a posição das faces superior e inferiror da constelação em forma de cubo e será dado na forma:

$$
\chi= \pm \frac{\sin ^{-1}\left(\frac{1}{\sqrt{3}}\right)}{2}
$$

Para um cubo regular $\chi=17,63$ graus $\left(2 \chi=35,26^{\circ}\right)$. O angulo $\psi$ foi calculado a partir do vetor $S_{1}$, com intervalos de 22,5 graus $\left(2 \psi=45^{\circ}\right)$. 


\begin{tabular}{|c|c|c|c|c|c|c|c|}
\hline \multirow{2}{*}{ Ordem } & \multirow{2}{*}{$\begin{array}{c}\text { Ângulo } \\
2 \chi \\
\text { (deg) }\end{array}$} & \multirow{2}{*}{$\begin{array}{c}\text { Ângulo } \\
2 \boldsymbol{\psi} \\
(\mathrm{deg})\end{array}$} & \multicolumn{5}{|c|}{ Vetor Stokes } \\
\hline & & & $S_{0}=1$ & $S_{1}$ & $S_{2}$ & $S_{3}$ & \\
\hline 1 & $0^{\circ}$ & $0^{\circ}$ & 1 & 1 & 0 & 0 & \multirow{6}{*}{ 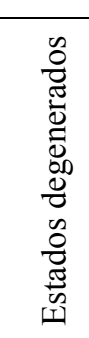 } \\
\hline 2 & $0^{\circ}$ & $45^{\circ}$ & 1 & 0 & 1 & 0 & \\
\hline 3 & $45^{\circ}$ & $0^{\circ}$ & 1 & 0 & 0 & 1 & \\
\hline 4 & $0^{\circ}$ & $90^{\circ}$ & 1 & -1 & 0 & 0 & \\
\hline 5 & 0 & $135^{\circ}$ & 1 & 0 & -1 & 0 & \\
\hline 6 & -45 & 0 & 1 & 0 & 0 & -1 & \\
\hline 7 & 35,26 & $0^{\circ}$ & 1 & 0,707 & 0 & 0,707 & \multirow{8}{*}{ 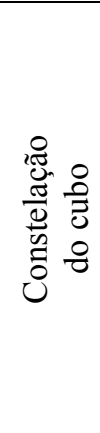 } \\
\hline 8 & 35,26 & $45^{\circ}$ & 1 & 0 & 0,707 & 0,707 & \\
\hline 9 & 35,26 & $90^{\circ}$ & 1 & $-0,707$ & 0 & 0,707 & \\
\hline 10 & 35,26 & $135^{\circ}$ & 1 & 0 & $-0,707$ & 0,707 & \\
\hline 11 & $-35,26$ & $0^{\circ}$ & 1 & 0,707 & 0 & $-0,707$ & \\
\hline 12 & $-35,26$ & $45^{\circ}$ & 1 & 0 & 0,707 & $-0,707$ & \\
\hline 13 & $-35,26$ & $90^{\circ}$ & 1 & $-0,707$ & 0 & $-0,707$ & \\
\hline 14 & $-35,26$ & $135^{\circ}$ & 1 & 0 & $-0,707$ & $-0,707$ & \\
\hline 15 & - & - & 1 & $-\sqrt{ }(2 / 3)$ & $-\sqrt{ }(6 / 3)$ & $-1 / 3$ & \multirow{4}{*}{ 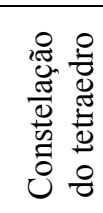 } \\
\hline 16 & - & - & 1 & $2 \sqrt{ }(2 / 3)$ & 0 & $-1 / 3$ & \\
\hline 17 & - & - & 1 & $-\sqrt{ }(2 / 3)$ & $\sqrt{ }(6 / 3)$ & $-1 / 3$ & \\
\hline 18 & - & - & 1 & 0 & 0 & 1 & \\
\hline
\end{tabular}

Tabela 3 - Vetores Stokes e seus respectivos ângulos geradores.

Após a fase de aquisição e armazenagem, os dados foram processados e validados. O processamento dos dados foi realizado utilizando os 18 vetores de Stokes da Tabela 3, seguindo os critérios demonstrados na Ilustração 1. 


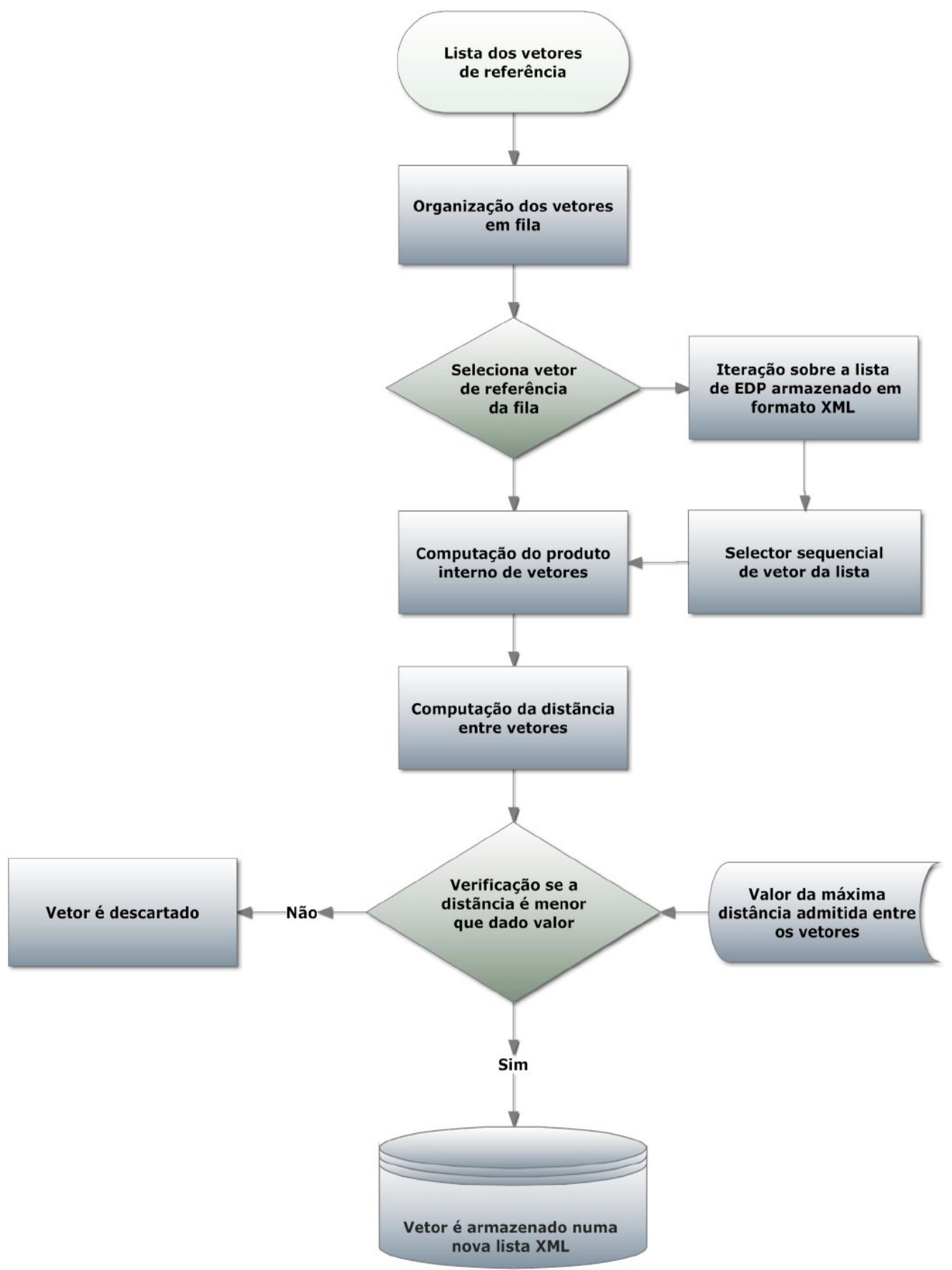

Ilustração 1 - Fluxo de processamento dos vetores de Stokes em comparação com a constelação de referência. 
O algoritmo de software utilizado, representado na Ilustração 1, pode ser descrito da seguinte forma:

a) Tomando cada vetor de referência, efetuou-se uma iteração sobre todos os nós XML das sequências de medidas armazenadas e para cada par (vetor referência - vetor armazenado) foi calculado o produto interno entre estes dois vetores.

b) De posse do valor do produto interno calculou-se a distância entre os vetores do par (vetor referência - vetor armazenado), a seguir estabeleceuse uma regra de decisão baseada na distância angular de referência $d_{r e f}=$ 0,1 radianos.

c) O ângulo de aceitação $\theta_{a c}$ é igual a $2 d_{r e f}$. A figura geométrica gerada pela revolução do angulo de aceitação ao redor do vetor de referência forma um cone de decisão onde todos os vetores dentro do referido cone foram escolhidos para posterior validação. Os valores selecionados foram armazenados em novo arquivo no formato XML.

O cálculo da distância entre dois vetores $x$ e $y$ no $\mathcal{R}^{3}$, mapeados sobre uma casca esférica é dado pelo comprimento do arco formado entre os pontos de interseção destes vetores com a casca esférica. Primeiro calculamos o ângulo entre estes dois vetores, o ângulo $\theta$ é dado por:

$$
\boldsymbol{\theta}=\arccos \left(\frac{\boldsymbol{x} \cdot \boldsymbol{y}}{|x||y|}\right), \quad 0<\boldsymbol{\theta}<\pi
$$

O ângulo $\theta$ será calculado sobre um grande círculo de raio 1 (na esfera unitária) cujo perímetro $p$ é dado por $p=2 \pi r=2 \pi$. A norma dos vetores é unitária logo o cálculo é realizado apenas em função do produto interno $\boldsymbol{x} \cdot \boldsymbol{y}$ :

$$
\boldsymbol{\theta}=\arccos (\boldsymbol{x} \cdot \boldsymbol{y}), \quad 0<\boldsymbol{\theta}<\pi
$$

Os cálculos descritos nas Equações 6.8 e 6.9 são os mesmos que devem ser realizados pelo hardware do receptor Stokes para discriminar os vetores recebidos. Para todos os vetores que chegam no discriminador, serão aceitos aqueles cujo ângulo de aceitação $\theta_{a c}$ seja menor ou igual a $2 d_{r e f}$. 

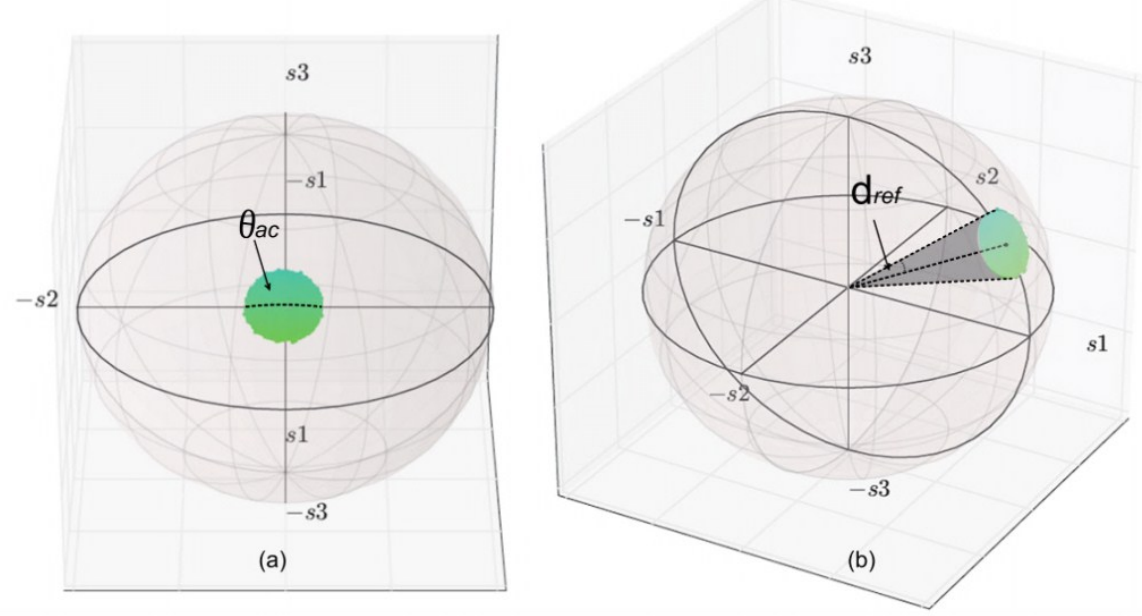

Figura 23 - Representação gráfica do cone de decisão.

Na Figura 23, $\theta_{a c}$ é o ângulo de aceitação e $d_{r e f}$ é a distância angular de referência. Uma constelação de referência pode ser vista na Figura 24.

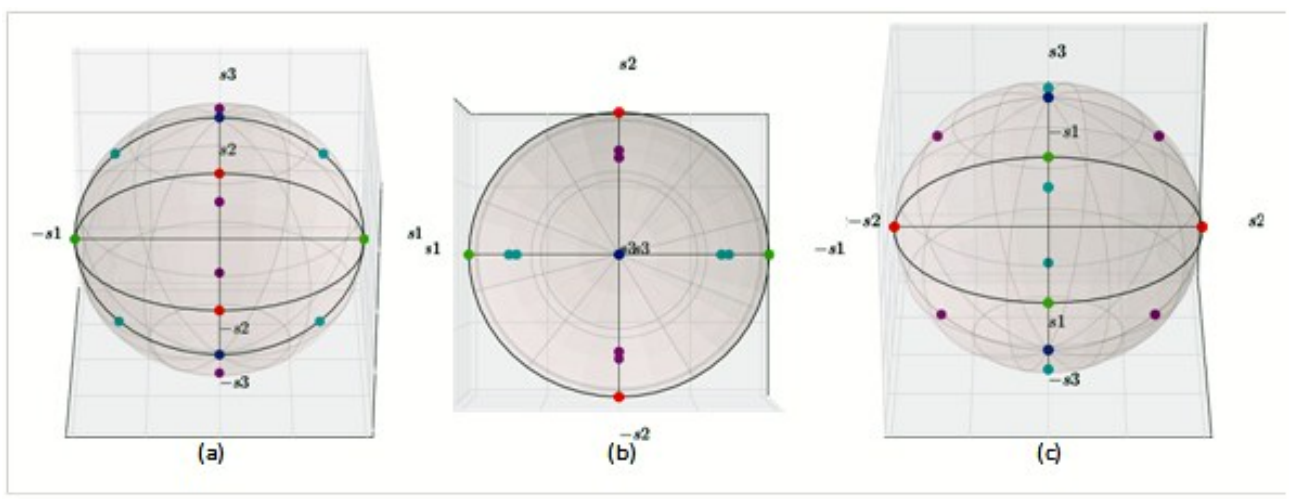

Figura 24 - Constelação para $\chi=\mathbf{1 5}^{\boldsymbol{0}}=\frac{\pi}{12}$ nos estados elípticos.

Para validar os valores selecionados na fase de processamento um novo algoritmo de software foi utilizado. O fluxo deste algoritmo, representado na Ilustração 2, pode descrito da seguinte forma:

- Uma iteração foi efetuada sobre todo o documento XML, obtido na fase de processamento, de maneira que todos os valores das tensões armazenadas foram recuperados.

- Uma nova sequência de chaveamento de polarização foi realizada, desta vez utilizando os valores de tensão selecionados na fase de processamento.

- Os valores obtidos foram considerados válidos quando os estados de polarização obtidos permaneceram associados aos vetores de referência, mantendo-se dentro do cone de decisão. 


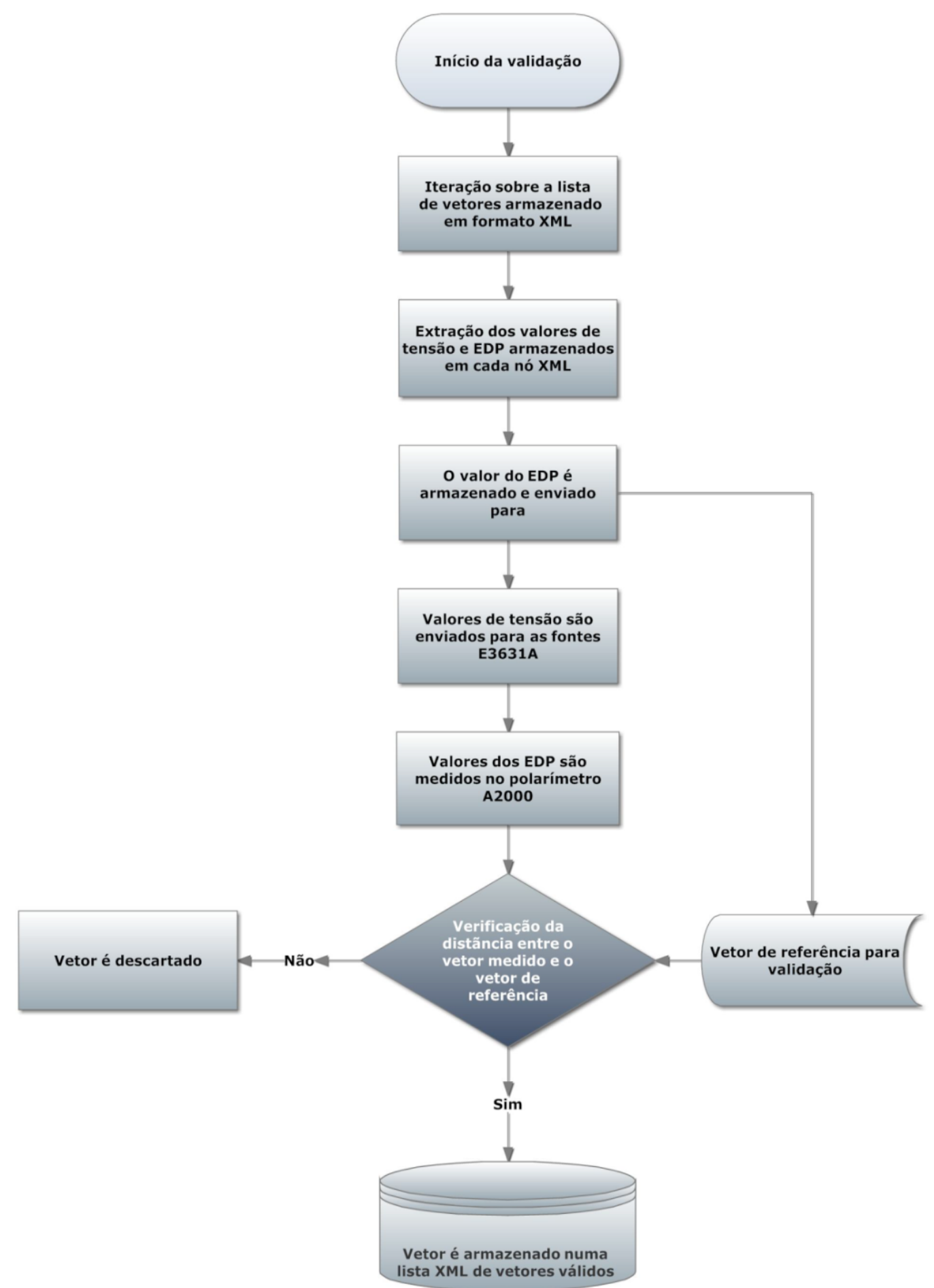

Ilustração 2 - Fluxo de validação dos valores de tensão e o respectivo estado de polarização de saída do controlador.

A Figura 25 mostra a plotagem, durante o processamento dos dados, de estados de polarização que aderiram às constelações de referência para um ângulo de aceitação de $11,4^{\circ}$ (0,2 radianos). Na Figura 25-a temos um tetraedro, na Figura 25-b um hexaedro obtido com $\chi=17,63^{\circ}$ e $\Delta \psi=22,5^{\circ}$. 

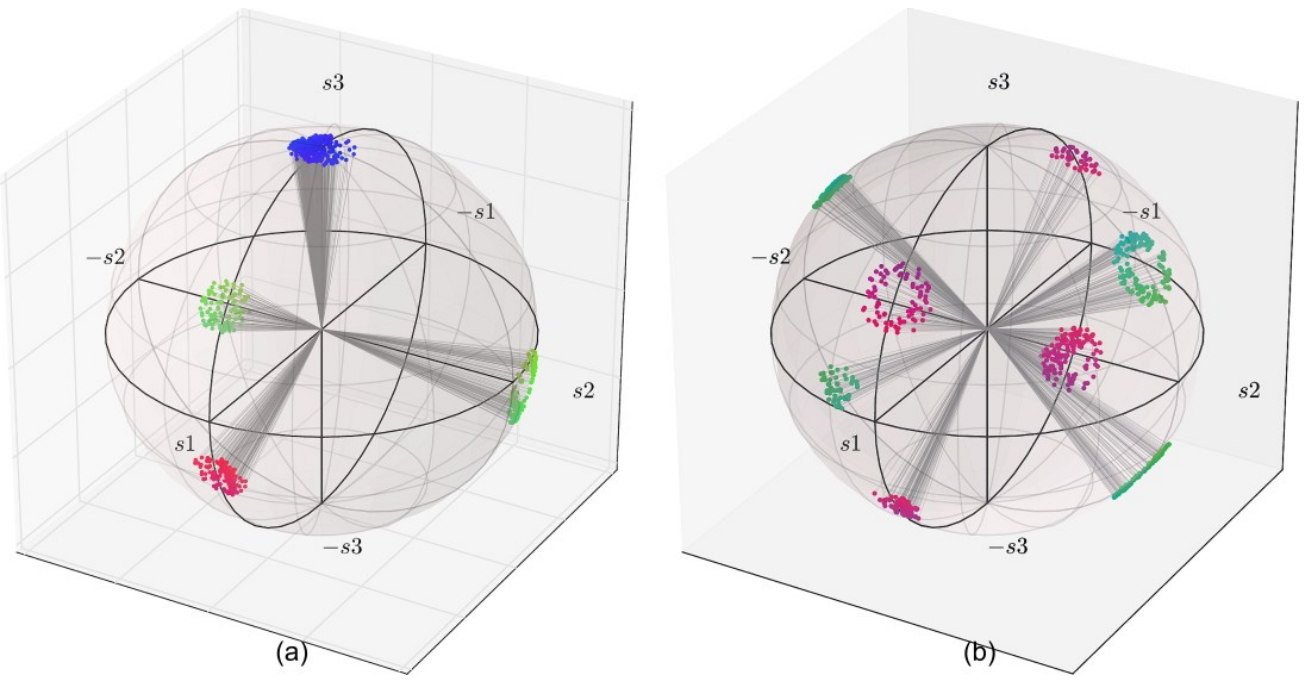

Figura 25 - Visualização de estados de polarização que aderiram às constelações de referência para um ângulo de aceitação de $11,4^{\circ}(0,2$ radianos) .

Após a validação dos dados, realizamos uma análise qualitativa da cobertura do espaço de Stokes, Esta análise serviu para que pudéssemos inspecionar graficamente buracos no espaço de Stokes não cobertos pela configuração do transformador de polarização. A Figura 26 mostra uma destas rotações sobre o eixo $S_{3}$, onde "buracos" no espaço mapeado foram visualizados com mais clareza numa determinada perspectiva da esfera de Poincaré.

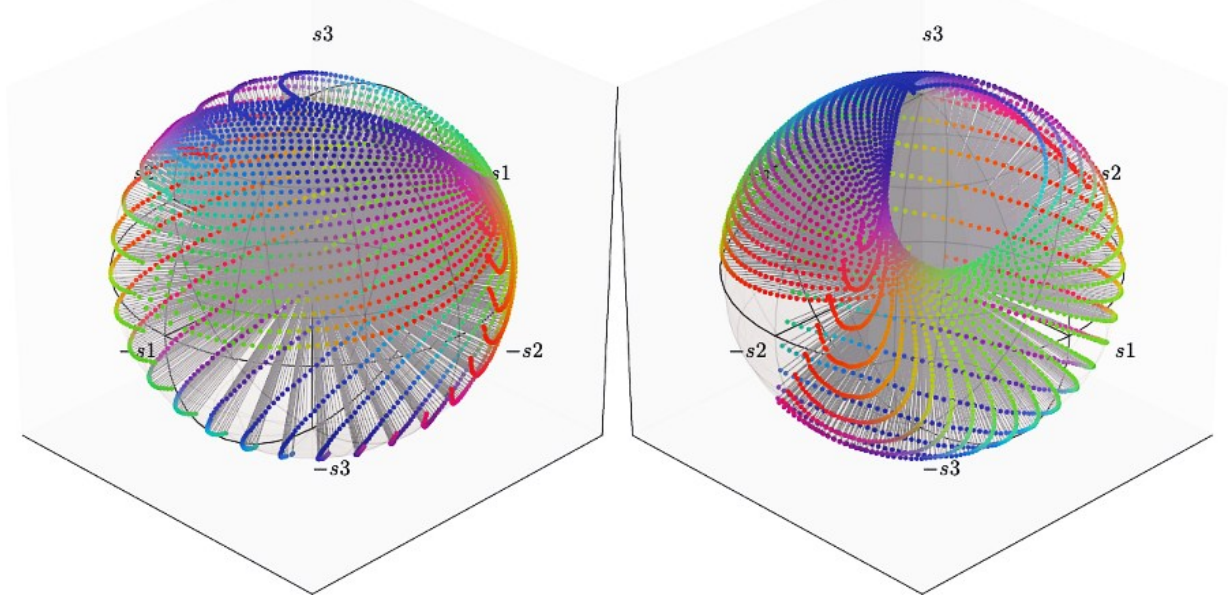

Figura 26 - Visualização de uma sequência densa com 5000 pontos, onde "buracos" no espaço mapeado foram visualizados.

Os buracos no espaço de Stokes são resultado das condições de projeto do nosso transmissor que requer que a tensão utilizada para chavear o EOSPACE seja a menor possível. 


\subsection{2.}

\section{Mapeamento e codificação no espaço de Stokes}

Para o projeto do transmissor precisamos definir os esquemas de codificação passíveis de serem utilizados. De posse do mapeamento do espaço de Stokes, obtido na caracterização do transformador de polarização, partimos então para a codificação associada aos símbolos das constelações. A Figura 27-c mostra um exemplo de codificação binária para a constelação 8-PolSK. Como pode ser observado, cada um dos oito vértices do hexaedro está associado a uma palavra de código binário de 3 bits levando a uma eficiência espectral bruta de $3 \mathrm{bit} / \mathrm{s} / \mathrm{Hz}$, obviamente num receptor comercial será necessário a inserção de códigos de redundância para garantir que a taxa de erro de bit (BER) fique dentro das especificações, a eficiência espectral final será, portanto menor.
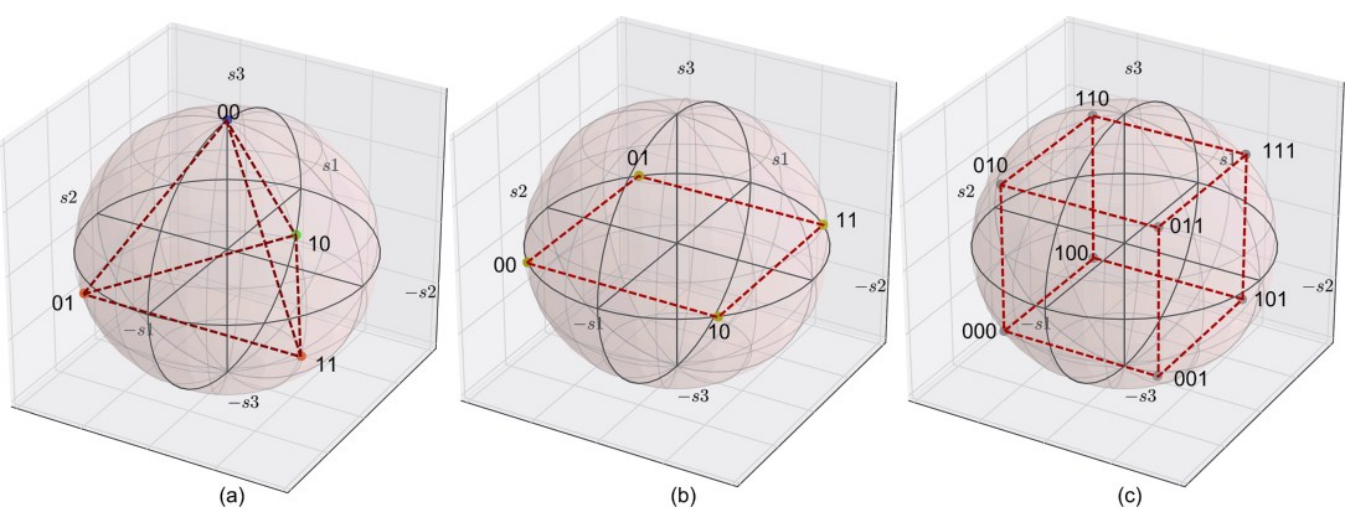

Figura 27 - Exemplo de codificação binária. a) 4-PolSK (tetraedro), b) 4-PolSK (quadrado) c) 8PolSK (cubo).

O esquema de codificação do transmissor é descrito com maiores detalhes na seção 7.2.1. Este esquema associa palavras binárias a valores discretos de tensão que por sua vez estão associados a rotações conhecidas de polarização da luz geradas pelo EOSPACE. A Tabela 4 mostra a associação entre código binário e os vetores de Stokes da constelação 8-PolSK com $\chi=17,63^{\circ}, \psi_{\text {inicial }}=22,5^{\circ} \mathrm{e}$ $\Delta \psi=22,5^{\circ}$.. 


\begin{tabular}{|c|c|c|c|c|c|c|c|}
\hline \multirow{2}{*}{ Ordem } & \multirow{2}{*}{ Q2 } & \multirow{2}{*}{ Q1 } & \multirow{2}{*}{ Q0 } & \multicolumn{3}{|c|}{ Vetor Stokes } & \\
\hline & & & & $S_{1}$ & $S_{2}$ & $S_{3}$ & \multirow{5}{*}{ 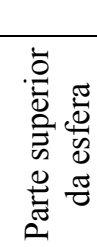 } \\
\hline 1 & 0 & 0 & 0 & 0,707 & 0 & 0,707 & \\
\hline 2 & 0 & 0 & 1 & 0 & 0,707 & 0,707 & \\
\hline 3 & 0 & 1 & 0 & $-0,707$ & 0 & 0,707 & \\
\hline 4 & 0 & 1 & 1 & 0 & $-0,707$ & 0,707 & \\
\hline 5 & 1 & 0 & 0 & 0,707 & 0 & $-0,707$ & \multirow{4}{*}{ 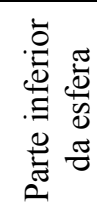 } \\
\hline 6 & 1 & 0 & 1 & 0 & 0,707 & $-0,707$ & \\
\hline 7 & 1 & 1 & 0 & $-0,707$ & 0 & $-0,707$ & \\
\hline 8 & 1 & 1 & 1 & 0 & $-0,707$ & $-0,707$ & \\
\hline
\end{tabular}

Tabela 4 - Exemplo de código binário e vetores de Stokes da codificação 8-PolSK.

Conforme descrito em [10], a utilização de códigos esféricos permite a criação de esquemas mais complexos de codificação. Códigos desta natureza conferem maior robustez à comunicação, contudo existe uma relação de compromisso entre robustez e eficiência espectral. A Figura 28 mostra o mapeamento binário para um hipercubo de dimensão 4, descrito em [48]. $\mathrm{O}$ mapeamento consiste de 16 vetores binários de tamanho 4 , estes vetores binários e os respectivos grafos deste espaço de código podem ser associados a vetores de Stokes com o auxílio de códigos esféricos.

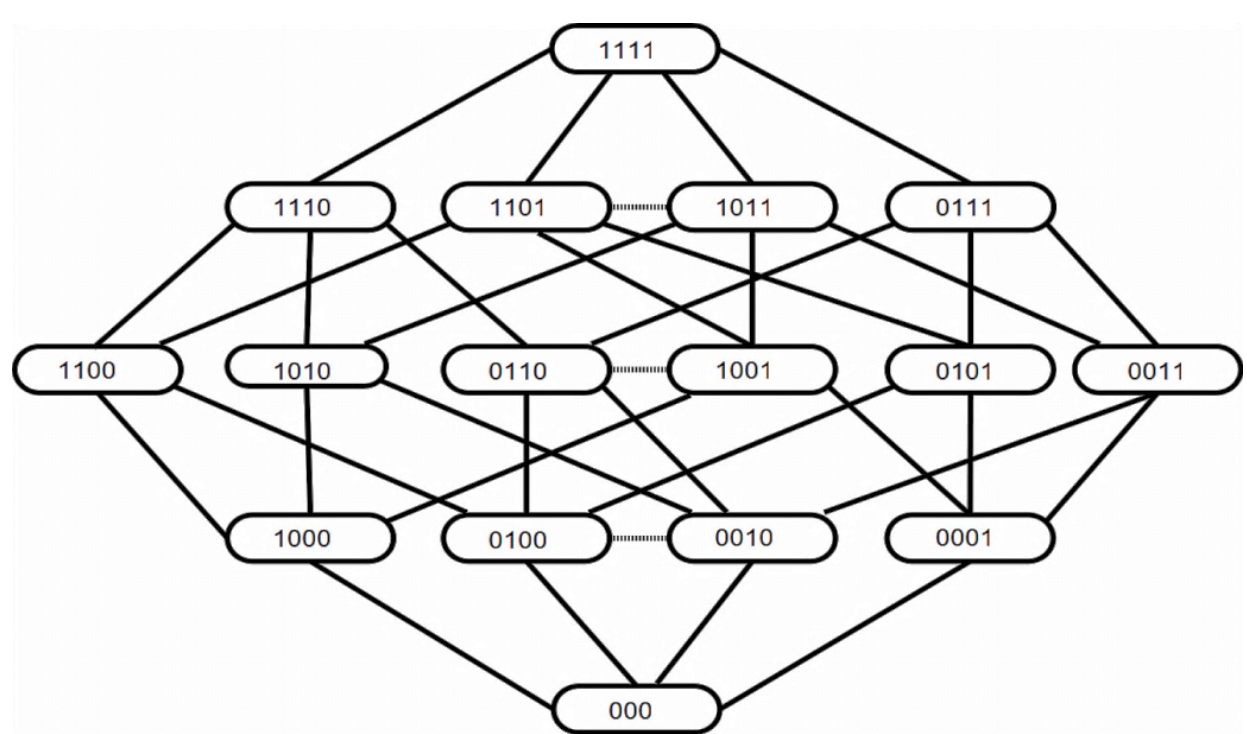

Figura 28 - Exemplo de código binário para mapeamento de um hipercubo. 


\section{Especificação e projeto do transmissor}

\section{1.}

\section{Especificação e projeto dos chaveadores eletrônicos}

A partir da relação dos valores de tensão que geraram os estados de polarização desejados, realizamos o mapeamento das tensões necessárias para alimentar os módulos MOSFET do transmissor PolSK. Uma informação particularmente importante consistiu em obter o maior valor de tensão necessário para cobrir o espaço de Stokes de modo que a constelação de símbolos (estados de polarização) estivesse nele contida. Obtivemos valores máximos de $18 \mathrm{~V}$ para as constelações do hexaedro e do poliedro irregular, para a constelação do tetraedro o valor máximo necessário foi $15 \mathrm{~V}$. Estes valores de tensão foram obtidos por conta da configuração de chaveamento em ponte, desta forma para obter um parâmetro de comparação é necessário considerar o máximo diferencial de voltagem aplicado aos terminais do arranjo transformador de polarização que neste caso foi de $32,5 \mathrm{~V}$.

\subsection{1.}

\section{Chaveadores MOSFET rápidos}

Para chavear tensões da ordem de $20 \mathrm{~V}$ em taxas de 20, 40 ou $100 \mathrm{MHz}$ nós utilizamos chaveadores MOSFET comumente utilizados como drivers para dispositivos piezelétricos, para simplificar a montagem lançamos mão de placas de demonstração modelos MD1822DB3 e MD1711DB2 produzidas pela empresa Supertex, estas placas são capazes de chavear até $\pm 100 \mathrm{~V}$ (em DC, até $\pm 12 \mathrm{~V}$ ), com três e cinco níveis respectivamente. As placas possuem ainda sinais de controle, sincronismo e relógio, desta forma podemos controlar as formas de onda de saída através de lógica binária simples. Os níveis de sinais de entrada são do tipo LVCMOS de 3,3 V. A configuração que utilizamos para o transmissor PolSK gera um estado de polarização para cada combinação de 04 de tensões aplicadas aos terminais do conjunto transformador de polarização. 
Quanto maior o número de níveis de tensão maior será a quantidade de possíveis estados polarização que poderão ser codificados. De modo geral as especificações dos chaveadores MOSFET deveriam atender aos seguintes requisitos:

- Tensão de chaveamento maior que $20 \mathrm{~V}$, na frequência de trabalho;

- Tempo de subida < 10ns;

- Tempo de apagamento $\leq 10 \mathrm{~ns}$;

- Frequência de trabalho > $20 \mathrm{MHZ}$;

- Níveis de tensão $\geq 03$;

- Lógica de controle LVCMOS.

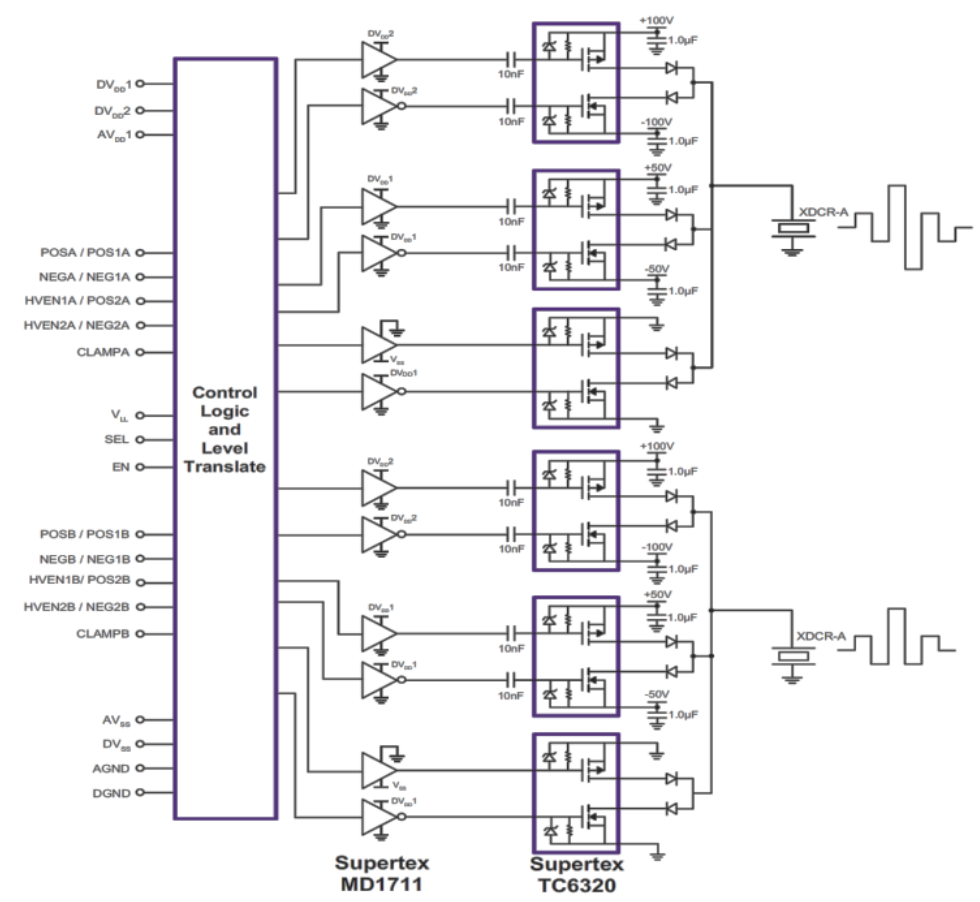

Figura 29 - Estágio de saída do chaveador MOSFET MD1711DB2.

O módulo MD1711DB2 é um chaveador MOSFET de duplo canal que pode gerar até 05 níveis de tensão por canal, com ele é possível codificar até 25 combinações de voltagens distintas, contudo nem todas as combinações serão utilizadas, pois a placa de demonstração fornece tensão de alimentação comum aos dois canais, assim o canal A é sempre uma réplica do canal B. A Figura 29 mostra um detalhe do estágio de saída deste módulo. 
Apesar das limitações, com recursos de controle e sincronismo este módulo permite gerar padrões de onda adequados para interfaces eletro-ópticas que necessitam de voltagens elevadas. Utilizamos ambos os módulos MD1822DB3 e MD1711DB2 e para conexão destes módulos com as tensões de alimentação e sinais controle, confeccionamos uma placa de circuito impresso específica para esta finalidade. Uma fonte de tensão múltipla foi também confeccionada, pois os módulos necessitam de diferentes valores de alimentação para sua lógica interna. A fonte foi realizada de maneira que pudesse atender aos requisitos de alimentação de todos os módulos logo teve 08 saídas, $\pm 12 \mathrm{~V}, \pm 10 \mathrm{~V},+5 \mathrm{~V}$ e $+3,3$ $\mathrm{V}$, esta última usada para alimentar a lógica LVCMOS. As placas de demonstração foram úteis durante a fase de caracterização. Para gerar os valores de tensão necessários para as constelações maiores foi necessário construir módulos de chaveamento adicionais.

\section{2. \\ Montagem experimental do transmissor PoISK}

Um transmissor PolSK experimental foi construído, o diagrama de blocos do transmissor pode ser visto na Figura 30.

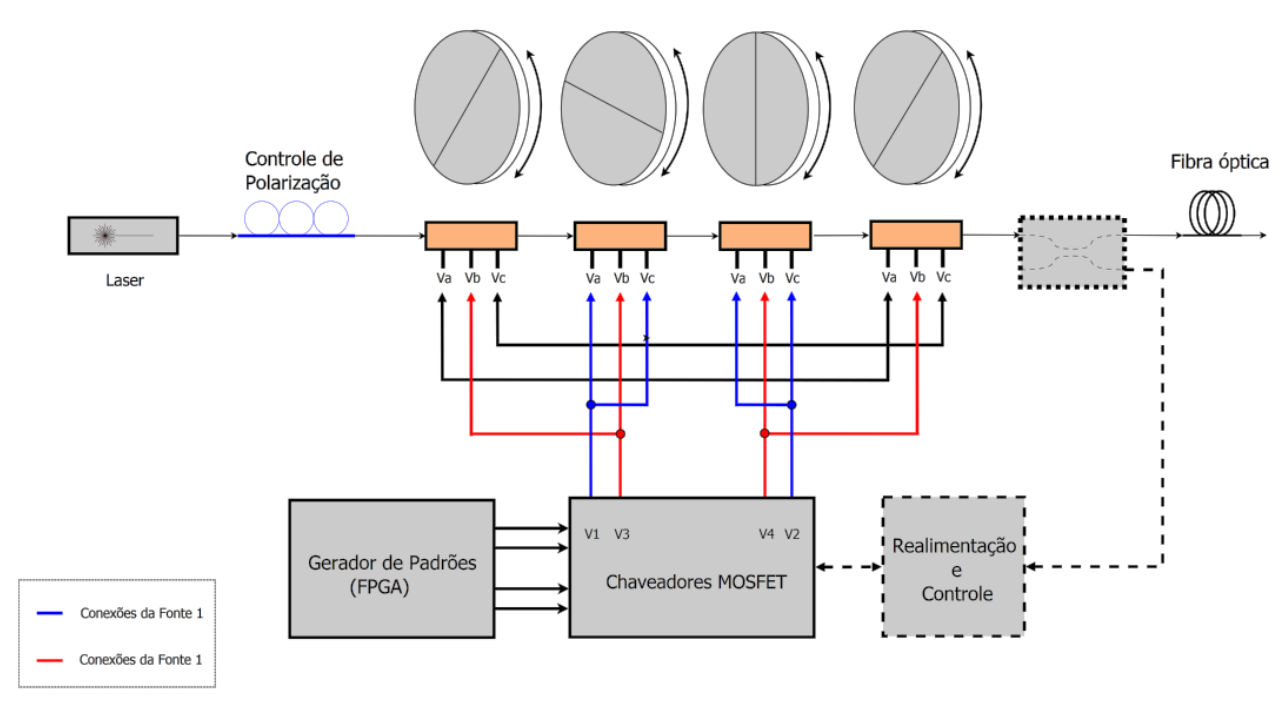

Figura 30 - Diagrama de blocos do transmissor PolSK.

O bloco de realimentação e controle não foi realizado, apesar disso na construção dos outros blocos consideramos a previsão de sinais de controle para esta finalidade. A seguir descrevemos as principais características dos principais blocos. 


\subsection{1.}

\section{O gerador de padrões (FPGA)}

A montagem experimental do transmissor PolSK precisava prover flexibilidade suficiente para que pudéssemos realizar as necessárias investigações sobre as características do sinal modulado em polarização. Para viabilizar uma montagem flexível, o gerador de sinais de modulação consistiu de uma placa FPGA Xilinx Spartan 3-AN. Esta placa possui vários tipos de interface de saída, incluindo saídas do tipo LVCMOS (CMOS de baixa voltagem), a interface LVCMOS é justamente a que é utilizada pelos chaveadores MOSFET da Supertex. Os chaveadores MOSFET funcionam como estágio de potência do transmissor PolSK e podem operar de modo autônomo ou em pares. Para que os módulos possam funcionar em pares é necessário o fornecimento de sinais de sincronismo, a placa FPGA cumpriu esta finalidade fornecendo adicionalmente os sinais de relógio e sincronismo.

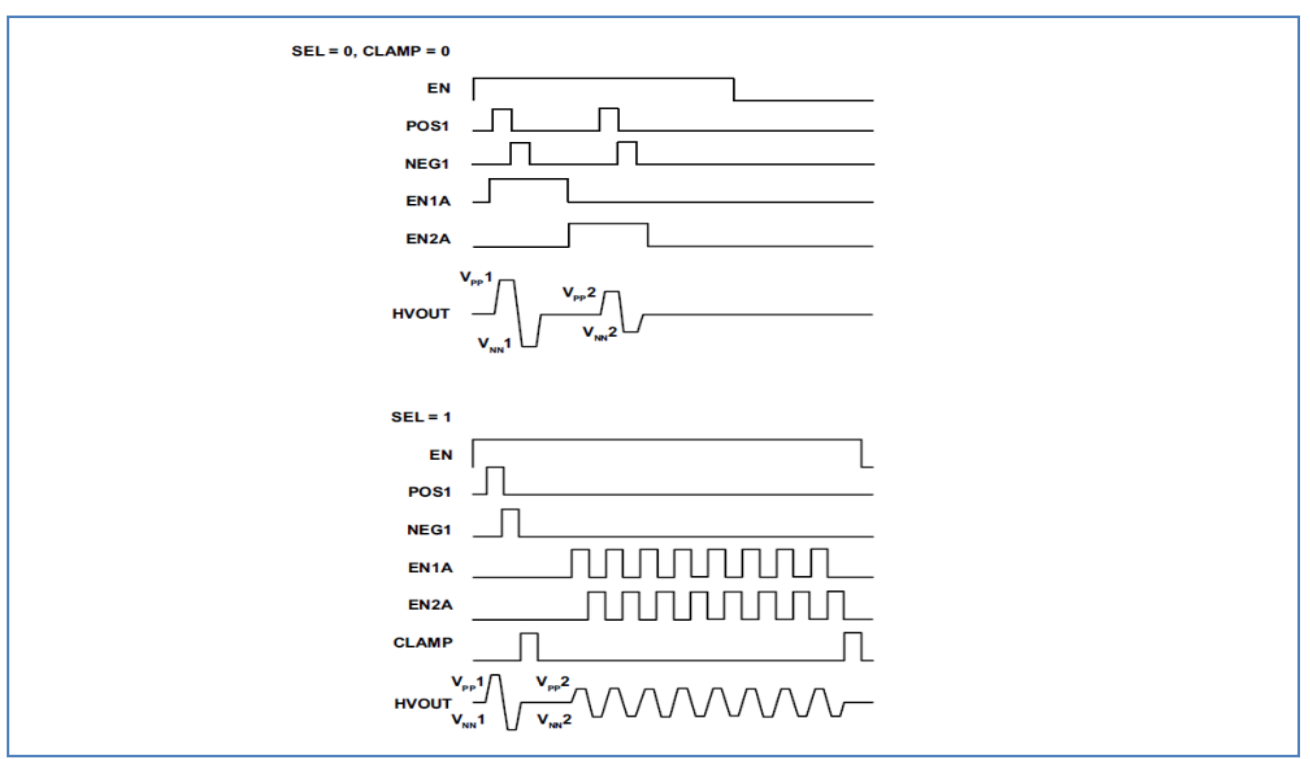

Figura 31 - Forma de onda teórica que é gerada na saída de um canal do módulo MD1711DB2 em função dos sinais de entrada.

Uma sequência pseudoaleatória contendo 65536 palavras binárias de 8 bits foi armazenada numa memória ROM. No ciclo de leitura da ROM, cada palavra de 8 bits foi segmentada em dois bits para se adaptar a lógica da placa MD1711. Para esta finalidade, utilizamos um decodificador 2-4 onde cada dois bits se transformaram numa palavra de controle de 4 bits. 


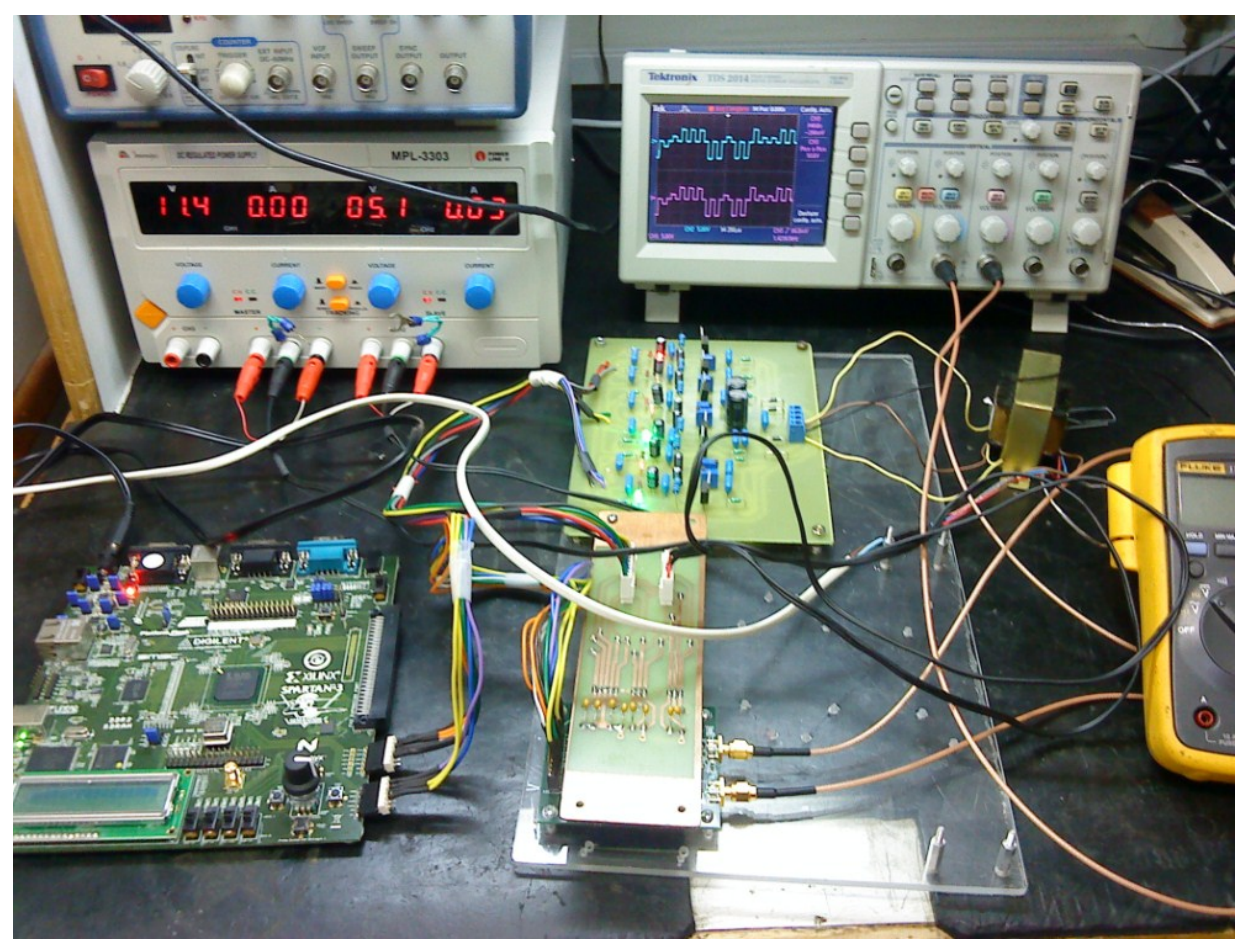

Figura 32 - Placas de circuito da montagem experimental do transmissor PolSK

As palavras de 2 bits foram multiplexadas com o sinal SEL formando uma nova palavra de dados de 3 bits, sincronizadas com o relógio interno do FPGA, com esta conversão binária era possível modificar o contorno da onda gerada, pois o sinal SEL define qual canal do módulo MD1711 será ativado.

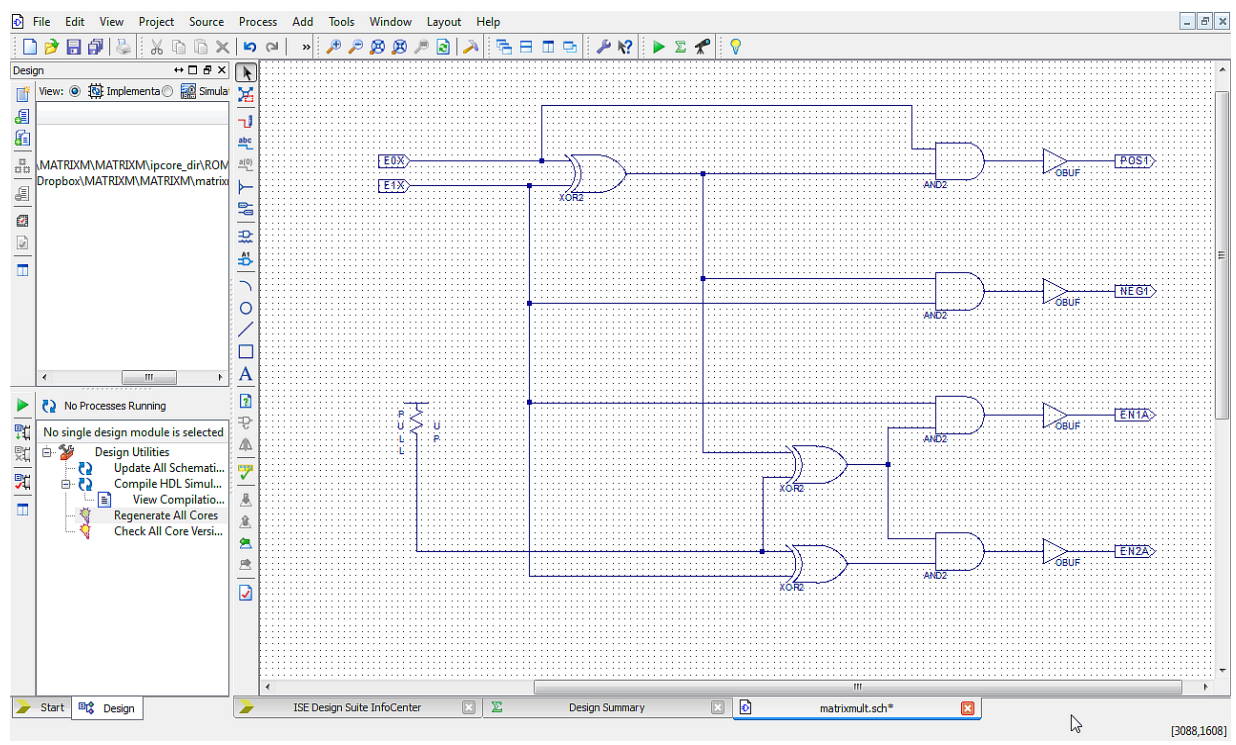

Figura 33 - Detalhe do circuito do decodificador 2-4. 
O decodificador mostrado na Figura 33 foi descrito em linguagem VHDL e sintetizado na placa FPGA Xilinx Spartan 3-AN, desta forma sua lógica poderia ser modificada em função de diferentes códigos de teste para as sequências pseudoaleatórias.

\begin{tabular}{|c|c|c|c|c|c|c|c|c|c|c|}
\hline \multicolumn{3}{|c|}{$\begin{array}{l}\text { Entrada do } \\
\text { codificador }\end{array}$} & \multicolumn{5}{c|}{ Canal 1 } & \multicolumn{4}{c|}{ Canal 2 } \\
\hline Bit0 & Bit1 & SE & POS1 & NEG & EN1 & EN2 & POS & NEG1 & EN1 & EN2 \\
\hline 0 & 0 & 0 & 1 & 0 & 0 & 0 & 0 & 0 & 0 & 1 \\
\hline 0 & 1 & 0 & 0 & 1 & 0 & 0 & 0 & 0 & 1 & 0 \\
\hline 1 & 0 & 0 & 0 & 0 & 1 & 0 & 0 & 1 & 0 & 0 \\
\hline 1 & 1 & 0 & 0 & 0 & 0 & 1 & 1 & 0 & 0 & 0 \\
\hline 0 & 0 & 1 & 0 & 0 & 0 & 1 & 1 & 0 & 0 & 0 \\
\hline 0 & 1 & 1 & 0 & 0 & 1 & 0 & 0 & 1 & 0 & 0 \\
\hline 1 & 0 & 1 & 0 & 1 & 0 & 0 & 0 & 0 & 1 & 0 \\
\hline 1 & 1 & 1 & 1 & 0 & 0 & 0 & 0 & 0 & 0 & 1 \\
\hline
\end{tabular}

Tabela 5 - Tabela verdade do codificador para o MD1711

Na Tabela 5 os sinais POS1, NEG1, EN1A e EN2A representam as entradas do chip MD1711.

\section{3.}

\section{Análise de desempenho dos chaveadores MOSFET}

O transmissor gerou oito níveis de tensões discretas (incluindo o zero) que podiam ser chaveadas em função da lógica de controle. Alguns módulos da Supertex não possuem retorno a zero este é o caso do MD1213DB1 que é o módulo mais rápido que utilizamos. Cada canal alimentava uma associação de estágios do EOSPACE com uma forma de onda de 05 níveis. Os estados de polarização gerados foram codificados com base em lógica binária descrita em código VHDL. Um divisor de sinal de relógio permitiu a mudança da frequência dos sinais independente da lógica.

Cuidados tiveram de ser tomados com tensões DC, pois os chaveadores MOSFET das placas não suportam tensões contínuas acima de $12 \mathrm{~V}$. O sinal modulado em polarização foi medido num polarímetro rápido e as constelações geradas foram analisadas. 


\section{8 \\ Resultados obtidos}

8.1.

Resultados para a constelação do tetraedro
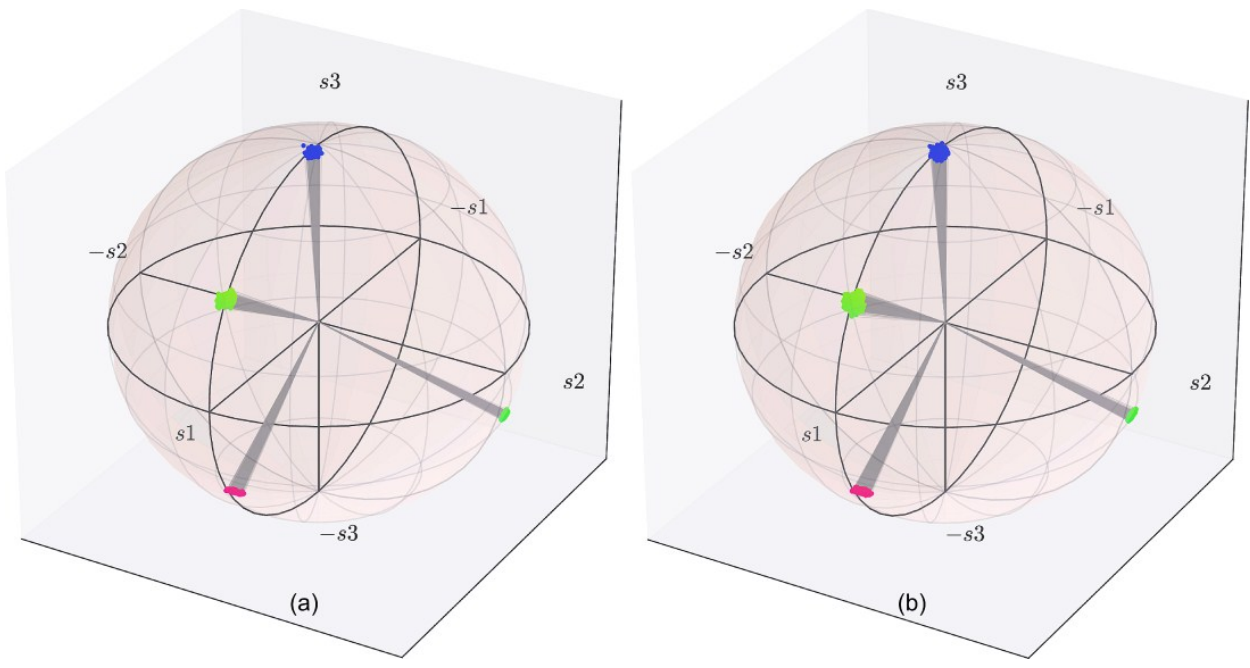

Figura 34 - Resultado de uma sequência pseudoaleatória de 4096 símbolos transmitidos para a constelação do tetraedro regular a) após 1024 símbolos recebidos b) após 4096 símbolos recebidos.

\begin{tabular}{|c|c|c|c|c|c|c|c|c|c|c|}
\hline \multirow{3}{*}{$\begin{array}{l}\frac{0}{8} \\
\text { है } \\
\text { 的 }\end{array}$} & \multicolumn{2}{|c|}{ Fonte 1} & \multicolumn{2}{|c|}{ Fonte 2} & \multirow{2}{*}{\multicolumn{3}{|c|}{$\begin{array}{l}\text { Vetores de Stokes } \\
\text { gerados } \\
\text { pelo transmissor }\end{array}$}} & \multicolumn{3}{|c|}{ Vetores de referência } \\
\hline & \multirow{2}{*}{ N25 } & \multirow{2}{*}{ P25 } & \multirow{2}{*}{$\mathrm{N} 25$} & \multirow{2}{*}{$\mathrm{P} 25$} & & & & & & \\
\hline & & & & & s1 & $\mathrm{s} 2$ & s3 & s1 & s2 & s3 \\
\hline 1 & -5 & 0 & -16 & 4 & $-0,440$ & $-0,830$ & $-0,332$ & $-0,471$ & $-0,816$ & $-0,333$ \\
\hline 2 & -5 & 0 & -10 & 14 & 0,931 & 0,055 & $-0,357$ & 0,942 & 0 & $-0,33$ \\
\hline 3 & 0 & 10 & -11 & 11 & $-0,379$ & 0,849 & $-0,381$ & $-0,471$ & 0,816 & $-0,33$ \\
\hline 4 & 0 & 0 & -3 & 10 & $-0,018$ & 0,049 & 0,999 & 0 & 0 & 1 \\
\hline
\end{tabular}

Tabela 6 - Estados de polarização da constelação de 04 estados e os respectivos valores de voltagem fornecidos pelo chaveador.

A constelação do tetraedro apresentou a melhor repetibilidade, conforme pode ser observado na Figura 34, o desvio angular máximo é quase imperceptível entre 1024 e 4096 símbolos transmitidos. As tensões para gerar esta constelação ,que possui distância de Hamming otimizada, também exibem relativa simetria. 


\section{2.}

\section{Resultados para a constelação do hexaedro (cubo)}
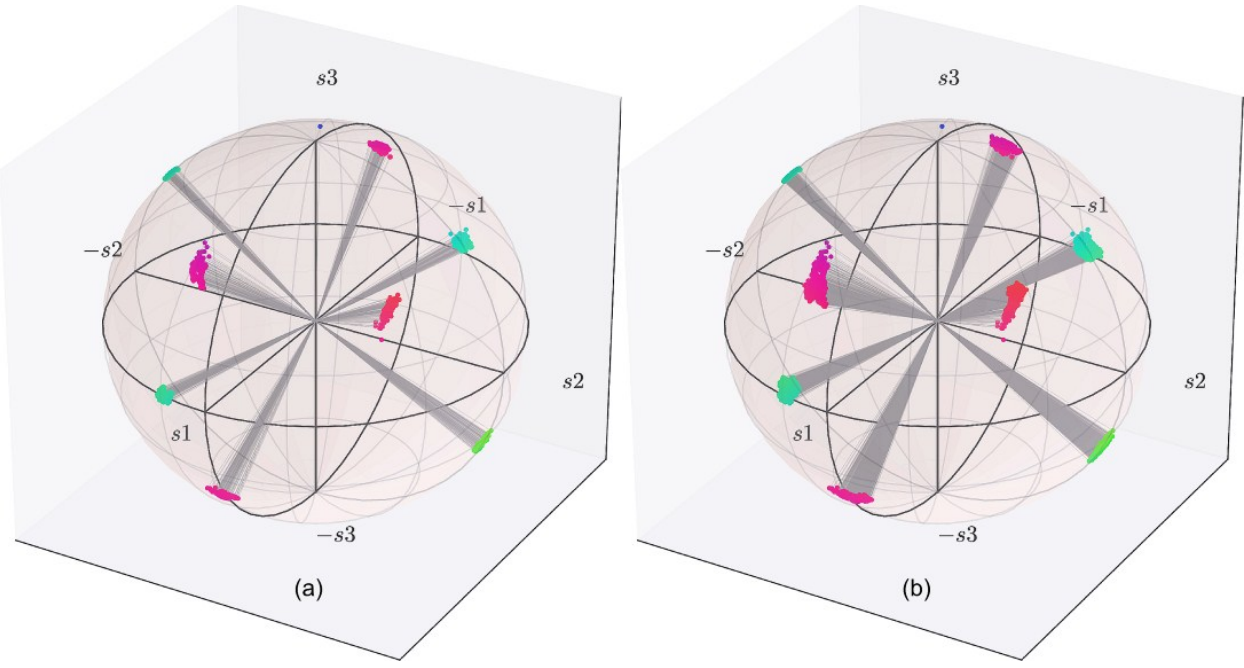

Figura 35 - Resultado de uma sequência pseudoaleatória de 8192 símbolos transmitidos para a constelação do cubo. a) após 1024 símbolos recebidos b) após 8192 símbolos recebidos.

\begin{tabular}{|c|c|c|c|c|c|c|c|c|c|c|}
\hline \multirow{3}{*}{ 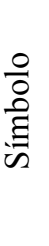 } & \multicolumn{2}{|c|}{ Fonte 1} & \multicolumn{2}{|c|}{ Fonte 2} & \multicolumn{3}{|c|}{$\begin{array}{l}\text { Vetores de Stokes } \\
\text { gerados } \\
\text { pelo transmissor }\end{array}$} & \multicolumn{3}{|c|}{ Vetores de referência } \\
\hline & \multirow{2}{*}{ N25 } & \multirow{2}{*}{ P25 } & & & & & & & & \\
\hline & & & N25 & $\mathrm{P} 25$ & s1 & s2 & s3 & s1 & s2 & s3 \\
\hline 1 & -15 & 0 & -9 & 15 & 0,787 & $-0,064$ & 0,617 & 0,816 & 0 & 0,577 \\
\hline 2 & 0 & 10 & -4 & 18 & $-0,009$ & 0,844 & 0,537 & 0 & 0,816 & 0,577 \\
\hline 3 & -5 & 0 & -18 & 18 & $-0,811$ & $-0,024$ & 0,577 & $-0,816$ & 0 & 0,577 \\
\hline 4 & 0 & 5 & -4 & 17 & 0 & $-0,805$ & $-0,591$ & 0 & $-0,816$ & 0,577 \\
\hline 5 & -15 & 5 & -18 & 11 & 0,828 & 0 & $-0,55$ & 0,816 & 0 & $-0,577$ \\
\hline 6 & 0 & 10 & -16 & 12 & $-0,076$ & 0,856 & 0,519 & 0 & 0,816 & $-0,577$ \\
\hline 7 & 0 & 15 & -5 & 5 & $-0,800$ & $-0,026$ & $-0,598$ & $-0,816$ & 0 & $-0,577$ \\
\hline 8 & -15 & 0 & -9 & 15 & 0,007 & $-0,822$ & $-0,561$ & 0 & $-0,816$ & $-0,577$ \\
\hline
\end{tabular}

Tabela 7 - Estados de polarização da constelação de 08 estados e os respectivos valores de voltagem fornecidos pelo chaveador.

Esta constelação apresentou repetibilidade mediana, conforme pode ser observado na Figura 35, o desvio angular máximo é menor que 0,2 radianos entre 1024 e 8092 símbolos transmitidos. Este desvio é também função da variação do estado de polarização de entrada. Um ponto próximo de $\mathrm{S}_{3}$ indica que o estado de polarização de entrada não estava exatamente com polarização circular a esquerda (vetor $[0,0,1])$. 


\section{3.}

\section{Resultados para a constelação do poliedro irregular}
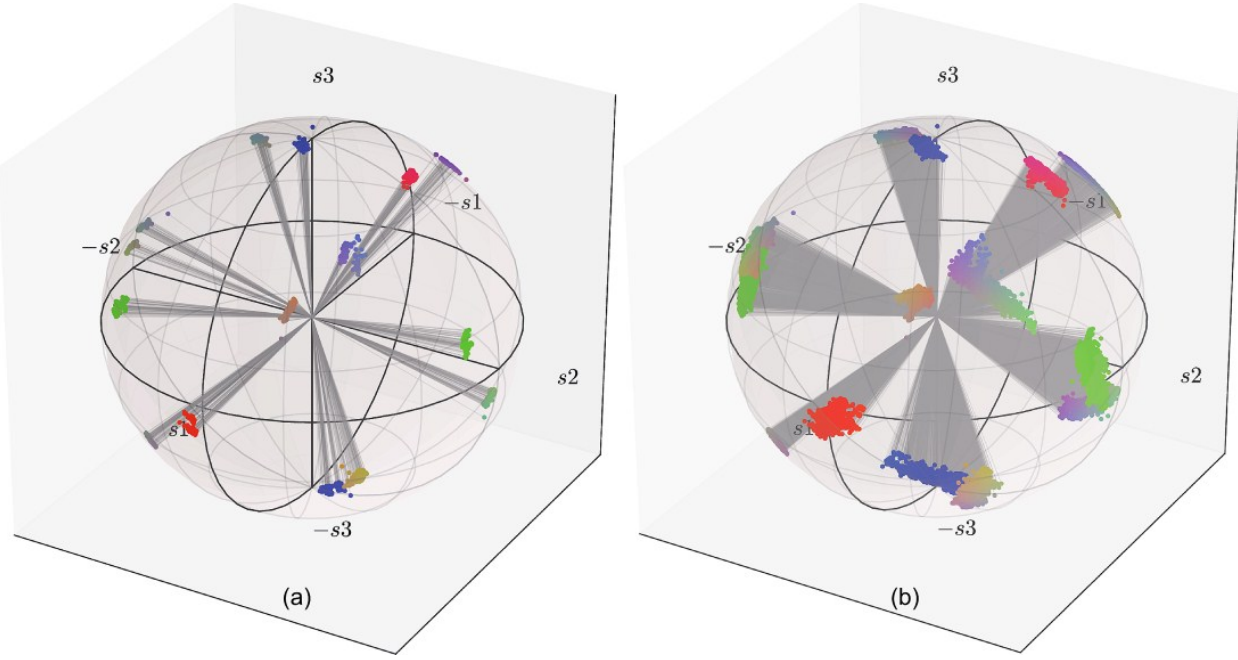

Figura 36 - Resultado de uma sequência pseudoaleatória de 14336 símbolos transmitidos para a constelação do poliedro irregular de 14 vértices. a) após 1024 símbolos recebidos b) após 14336 símbolos recebidos.

\begin{tabular}{|c|c|c|c|c|c|c|c|c|c|c|}
\hline \multirow{3}{*}{$\begin{array}{l}\frac{0}{0} \\
\text { 音 } \\
\text { in }\end{array}$} & \multicolumn{2}{|c|}{ Fonte 1} & \multicolumn{2}{|c|}{ Fonte 2} & \multirow{2}{*}{\multicolumn{3}{|c|}{$\begin{array}{c}\text { Vetores de Stokes } \\
\text { gerados } \\
\text { pelo transmissor }\end{array}$}} & \multirow{2}{*}{\multicolumn{3}{|c|}{ Vetores de referência }} \\
\hline & \multirow{2}{*}{$\mathrm{N} 25$} & \multirow{2}{*}{$\mathrm{P} 25$} & \multirow{2}{*}{ N25 } & \multirow{2}{*}{$\mathrm{P} 25$} & & & & & & \\
\hline & & & & & s1 & s2 & s3 & s1 & s2 & s3 \\
\hline 1 & -10 & 0 & -2 & 16 & 0,999 & $-0,034$ & $-0,016$ & 1 & 0 & 0 \\
\hline 2 & -10 & 15 & -9 & 16 & $-0,998$ & 0,016 & $-0,002$ & -1 & 0 & 0 \\
\hline 3 & -5 & 10 & -17 & 11 & 0,115 & 0,999 & 0,035 & 0 & 1 & 0 \\
\hline 4 & -5 & 15 & -18 & 4 & $-0,005$ & $-0,998$ & 0,018 & 0 & -1 & 0 \\
\hline 5 & 0 & 0 & -3 & 11 & $-0,018$ & 0,049 & 0,999 & 0 & 0 & 1 \\
\hline 6 & -5 & 0 & -2 & 18 & $-0,011$ & $-0,013$ & $-0,995$ & 0 & 0 & -1 \\
\hline 7 & -15 & 0 & -9 & 15 & 0,787 & $-0,064$ & 0,617 & 0,816 & 0 & 0,577 \\
\hline 8 & -10 & 0 & -11 & 8 & 0,108 & 0,848 & 0,531 & 0 & 0,816 & 0,577 \\
\hline 9 & -5 & 0 & -18 & 18 & $-0,811$ & $-0,024$ & 0,577 & 0 & 0 & 0,577 \\
\hline 10 & -15 & 0 & 0 & 18 & 0,007 & $-0,775$ & 0,625 & 0 & $-0,816$ & 0,577 \\
\hline 11 & -10 & 10 & -1 & 7 & 0,115 & 0,999 & 0,035 & 0,816 & 0 & $-0,577$ \\
\hline 12 & 0 & 10 & -16 & 12 & $-0,005$ & $-0,998$ & 0,018 & 0 & 0,816 & $-0,577$ \\
\hline 13 & -10 & 10 & -8 & 10 & $-0,018$ & 0,049 & 0,999 & 0 & 0 & $-0,577$ \\
\hline 14 & 0 & 14 & -18 & 3 & $-0,011$ & $-0,013$ & $-0,995$ & 0 & $-0,816$ & $-0,577$ \\
\hline
\end{tabular}

Tabela 8 - Estados de polarização da constelação de 14 estados e os respectivos valores de voltagem fornecidos pelo chaveador. 
A constelação do poliedro irregular (com 14 símbolos) apresentou a pior repetibilidade, conforme mostra a Figura 36. O desvio angular máximo entre 1024 e 14336 símbolos transmitidos é também função da variação do estado de polarização de entrada, ocorre que sua magnitude é bem maior que o desvio observado para as constelações do tetraedro e do hexaedro, excedendo o ângulo de aceitação de 0,2 radianos, consequentemente a rigidez da constelação foi quebrada com a modificação da posição relativa entre os símbolos. Considerando que a polarização de entrada foi a mesma para o hexaedro, acreditamos que o maior desvio se deve ao maior número de excursões (pseudoaleatórias) entre estados de polarização uma vez que o EOSPACE não "zera" completamente após ser submetido a diferentes voltagens. Adicionalmente devemos considerar que devido a necessidade de gerar voltagens próximas de zero, o chaveador não manteve a tensão de polarização $\mathrm{V}_{\mathrm{BI} A S}$.

\section{4. \\ Dados relativos à caracterização do sinal modulado}

O polarímetro A1000 foi utilizado como detector e discriminador dos sinais modulados em polarização. Este instrumento possui a máxima frequência de amostragem limitada a $1 \mathrm{MHz}$, por conta disto foi necessário reduzir a velocidade do chaveador e utilizar a funcionalidade de processamento de sinais do polarímetro para uma sequência de 20.000 (vinte mil) amostras, pois mesmo utilizando a função de disparo (trigger) não foi possível medir variações acima de $5 \mathrm{MHz}$. Como estávamos mais interessados na capacidade de mapeamento da configuração de que na velocidade de chaveamento isto não foi um problema naquele momento. Assim foi gerada a sequência mostrada na Tabela 6, correspondente ao tetraedro. Esta constelação foi escolhida por ser a mais fácil de ser gerada com os módulos MD1213DB1 da Supertex que alcançam a velocidade de $100 \mathrm{MHz}$, mas também podem trabalhar em velocidades inferiores. Os pontos observados na Figura 37 foram visualizados diretamente através da interface do software Polarization Navigator da Adaptif Photonics (atual Agilent). Apesar de não apresentarem boa noção de profundidade, é possível notar a correspondência com o tetraedro observado na Figura 34-a. 
A Figura 38 mostra a mesma figura quando é utilizada a função de traço do sinal, estas transições incluem um quinto ponto além do desejado por que a placa MD1213DB1 não possui retorno à zero.

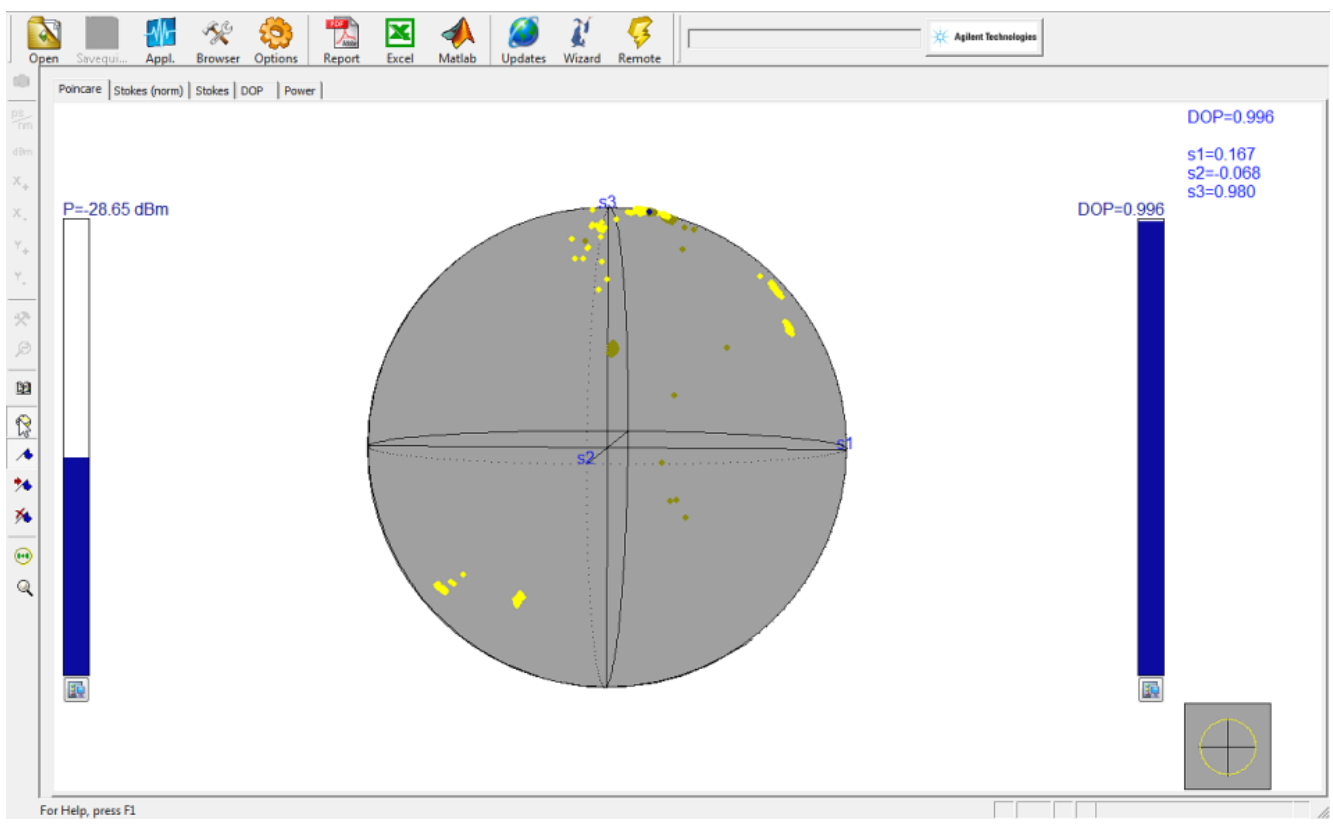

Figura 37 - Padrão obtido na reprodução do tetraedro, com tensões fixas, 04 pontos foram observados.

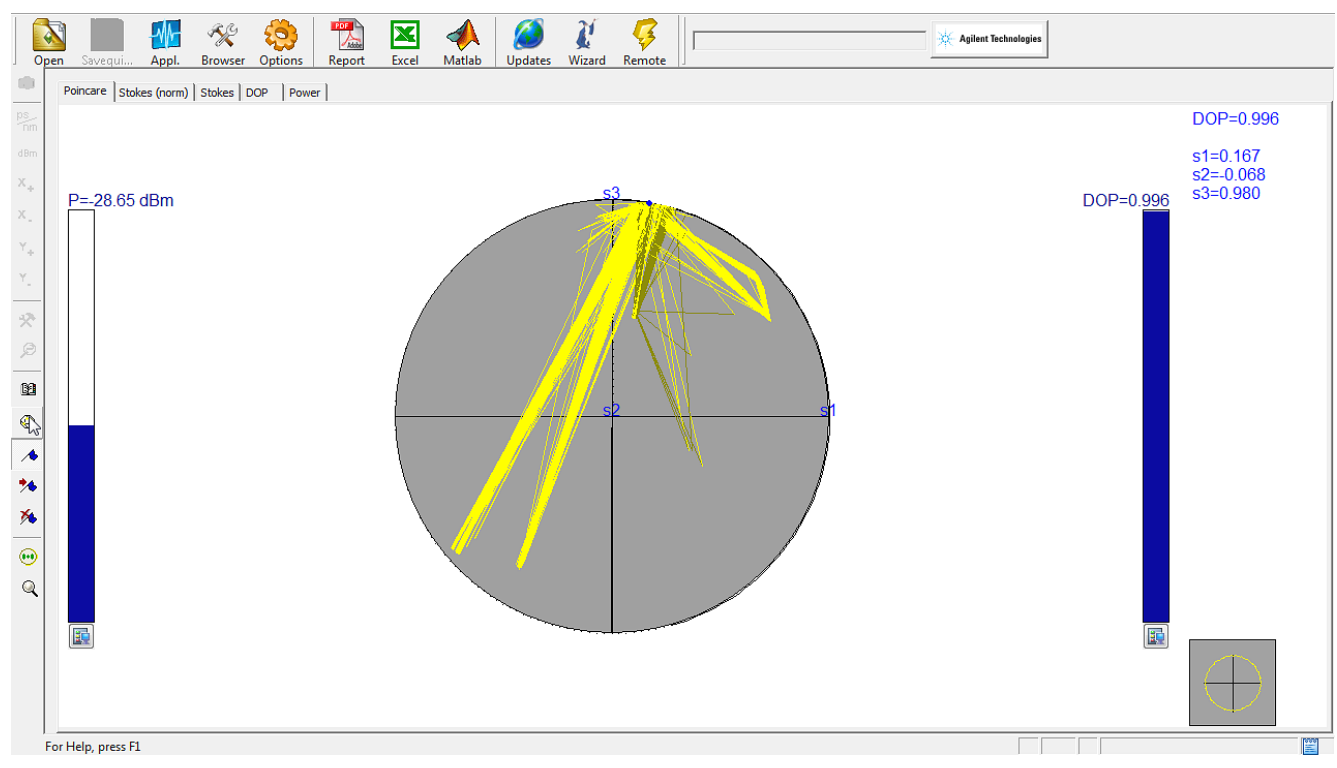

Figura 38 - Transição entre os estados de polarização do tetraedro. 


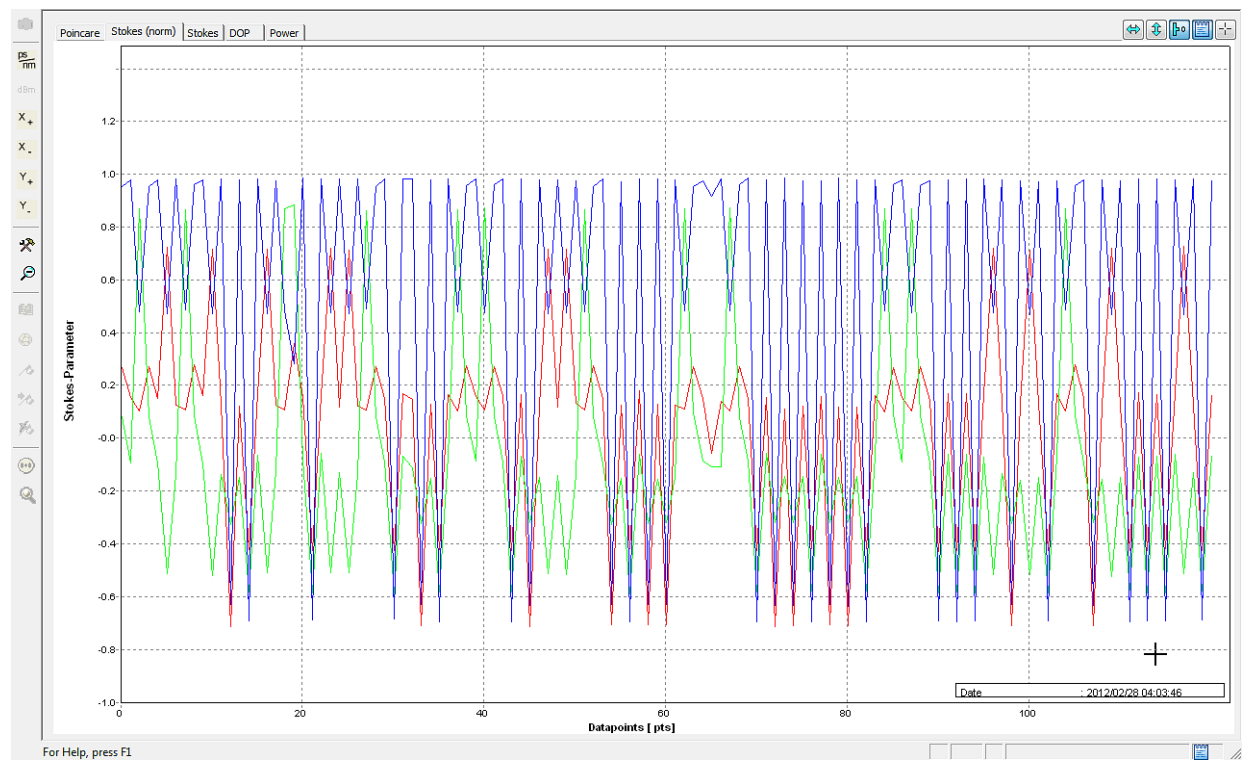

Figura 39 - Visualização da variação dos parâmetros de Stokes.

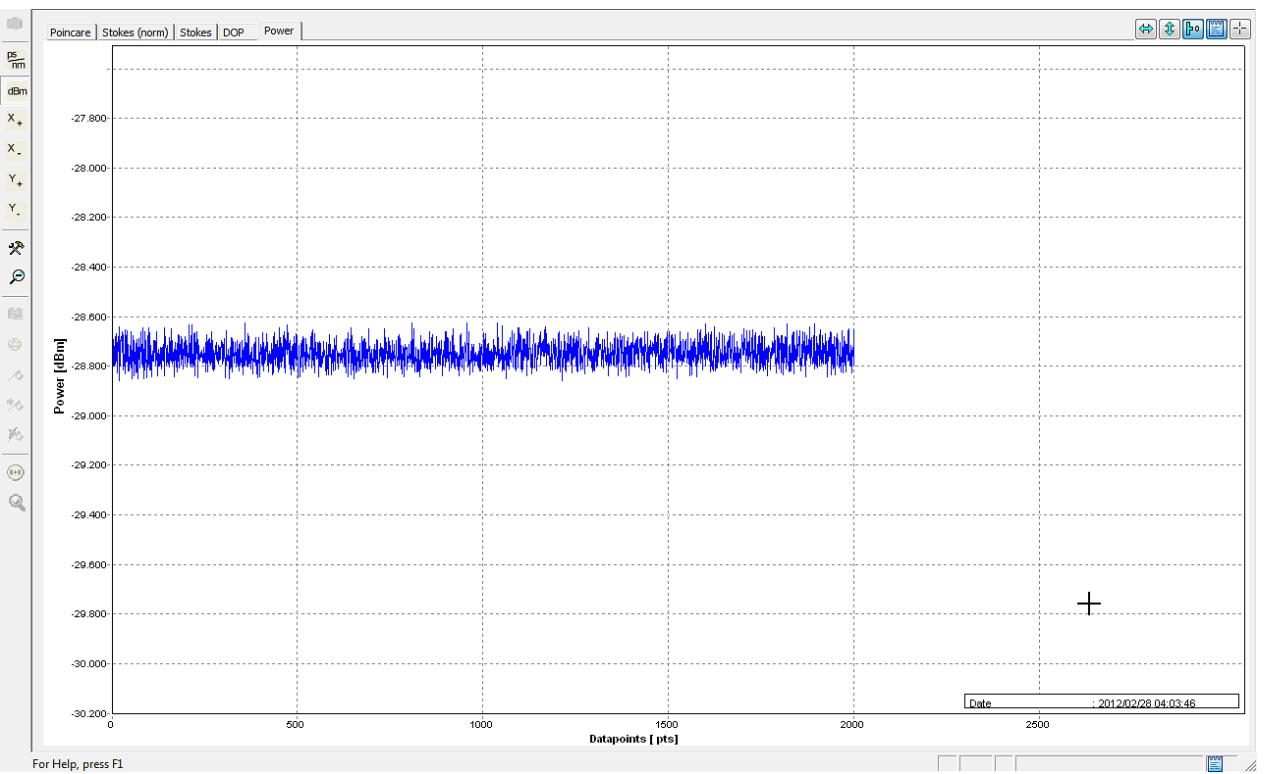

Figura 40 - Variação de potência do sinal modulado em polarização em $d B m$.

Os dados gráficos das Figura 39, e Figura 40 mostram respectivamente o padrão de variação dos vetores de Stokes e a variação da potência do sinal óptico modulado em polarização. As componentes normalizadas de Stokes mostraram boa repetibilidade e com razoáveis excursões, o grau de polarização medido mostra que o sinal exibe despolarização brusca em determinadas transições de estados. O gráfico de potência recebida mostra que num intervalo de 2.000 pontos de amostragem, onde todas as combinações foram repetidas várias vezes, a potência do sinal recebido varia de apenas $0,23 d B$. 


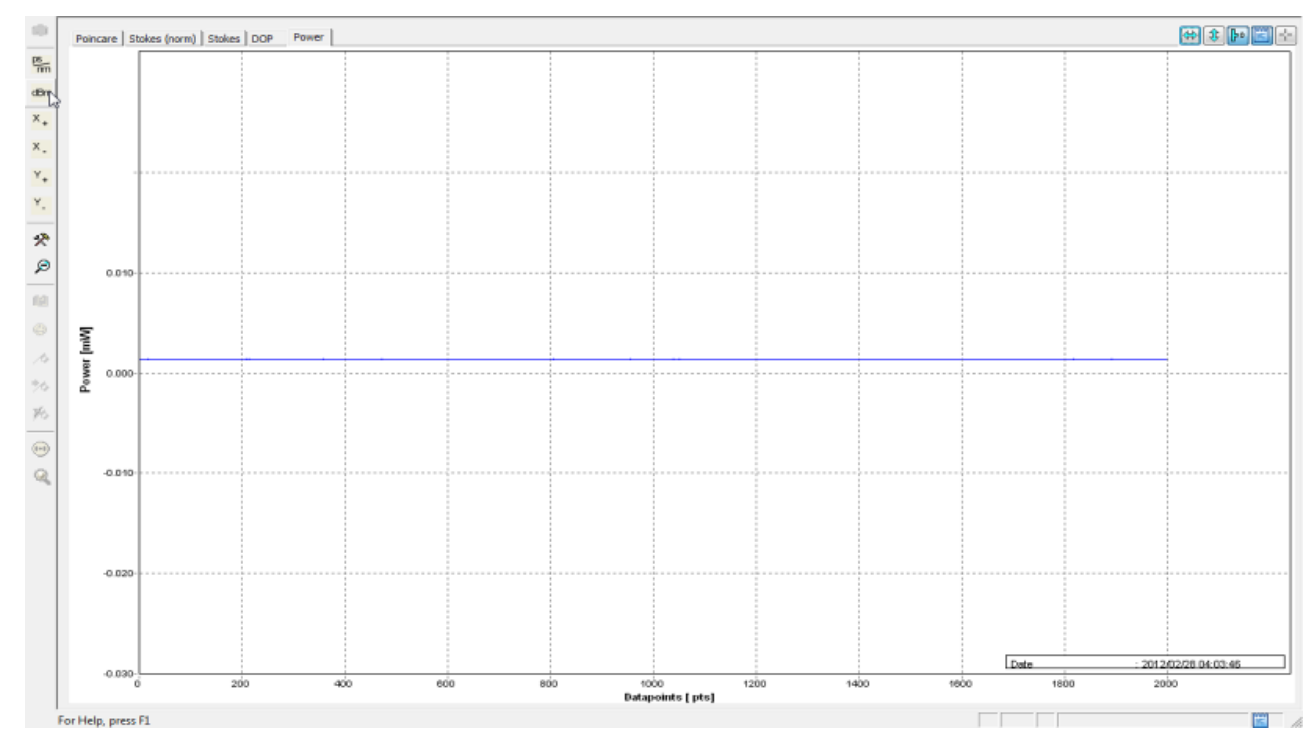

Figura 41 - Variação de potência do sinal modulado em polarização em $m W$

A observação do sinal modulado da Figura 39, mostra que é interessante encontrar uma correspondência de simetria nos domínios elétrico e óptico, desta forma podemos evitar que o tempo de subida dos pulsos varie ao chavear diferentes tensões. Para uma mesma frequência de transmissão teremos pulsos com larguras diferentes e consequentemente diferentes tempos de símbolo (tempo de bit). Isto ocorre por que no lado eletrônico do transmissor o que temos é um sinal modulado em amplitude, a interface eletro-óptica faz a conversão amplitude/polarização. Um sistema de transmissão com interface eletro-óptica, baseado em PolSK e operando em taxa de bit elevada pode necessitar de recursos de controle para mitigar os efeitos da conversão amplitude/fase do sinal elétrico.

As probabilidades de erro para as constelações 2-PolSK, 4-PolSK e 8-PolSK são descritas de forma detalhada em [12], de maneira geral a teoria estatística envolvida, estabelece a uma relação de compromisso entre o cone de decisão e a taxa de erro. Assim para constelações com poucos símbolos como é o caso do tetraedro regular, o ângulo de aceitação pode ser muito maior que o valor 0,2 radianos que utilizamos. 


\section{9 \\ Conclusões}

A modulação por chaveamento de polarização da luz (PolSK) foi analisada sob o ponto de vista teórico e experimental. A revisão bibliográfica buscou identificar o estado da arte e tendências nas comunicações ópticas. Requisitos de desempenho foram discutidos, principalmente aqueles relacionados com o tipo de modulação utilizado nos sistemas de transmissão. Eficiência espectral, roteamento totalmente óptico, redução do consumo de energia, flexibilidade para uso em topologias mistas e granularidade da banda de transmissão foram os requisitos para os quais, após análise teórica, a PolSK apresentou vantagens imediatas. O conceito de polarização dos materiais foi explicitamente relacionado com a polarização da luz e o efeito eletro-óptico. Desenvolvemos estes conceitos com mais profundidade em relação aos dispositivos do tipo Soleil-Babinet, fabricados sobre substratos de Niobato de Lítio $\left(\mathrm{LiNbO}_{3}\right)$, com ênfase nos tópicos relacionados com o componente eletro-óptico comercial que utilizamos (denominado EOSPACE) e cuja característica de tensão de compensação (offset) necessitava de esclarecimento.

A especificação dos componentes e a caracterização do controlador de polarização representaram desafios consideráveis, principalmente para análises qualitativas, uma vez que o parâmetro polarização não é facilmente observável em velocidades de dezenas de milhões de hertz. $\mathrm{O}$ uso de interfaces de software foi importante para realização do trabalho, igualmente importante foi a síntese de parte do hardware utilizando tecnologia FPGA, cuja flexibilidade nos poupou muito tempo. Apesar das nossas especificações iniciais, os módulos chaveadores MOSFET, realizados com placas de demonstração não atenderam a todas as expectativas. Na placa MD1711DB2, por exemplo, os canais A e B são alimentados com tensões iguais para ambos os chaveadores de saída, isto reduz pela metade os graus de liberdade em termos de níveis de tensão gerados. 
Outro ponto limitador foi a restrição dos MOSFETS utilizados em manter níveis DC acima de $12 \mathrm{~V}$, desta forma o chaveador não podia operar em baixa frequência quando alimentado por tensões superiores a $12 \mathrm{~V}$.

A montagem do transmissor PolSK permitiu o experimento de diversos conceitos. Os resultados obtidos face aos recursos empregados foram custoefetivo, geramos constelações de quatro (tetraedro regular), oito (hexaedro regular) e quatorze (poliedro irregular) estados de polarização. Algumas análises e métodos que utilizamos foram adaptados especificamente para trabalhar com a PolSK, principalmente em relação ao armazenamento, processamento e visualização dos dados, revelando novamente a boa experiência que obtivemos nesta abordagem. As rotações das constelações de Stokes foram caracterizadas na velocidade de $1 \mathrm{MHz}$, pois era esta a velocidade máxima de aquisição do polarímetro.

A repetibilidade foi satisfatória para ciclos de 1024 a 8092 repetições por símbolo nas constelações do tetraedro e do hexaedro. Na sequência gerada para a constelação do poliedro irregular observamos a quebra da rigidez da constelação após 14336 símbolos transmitidos. É interessante observar que a constelação de 14 símbolos foi gerada com diferencial de voltagem máximo de $32,5 \mathrm{~V}$ e tensão máxima, por pino do EOSPACE, igual a $18 \mathrm{~V}$.

As constelações geradas mostraram relativa rigidez, confirmando a expectativa para o modelo de propagação do sinal modulado em polarização. Observamos que a rigidez da constelação (manutenção da posição relativa entre os pontos) é alterada em função de mudanças no estado de polarização da fonte de luz laser, o controlador de polarização atua como modulador externo e neste caso observamos que quando o estado de polarização da fonte laser muda, os estados de polarização da constelação tendem a girar em eixos diferentes, isto gera uma distorção na geometria da constelação de símbolos, e consequentemente a rigidez da constelação é quebrada, podendo inclusive levar a interferência intersimbólica devido à proximidade de alguns pontos. Concluímos, portanto que a estabilidade em polarização da fonte laser é de grande importância para o desempenho do transmissor PolSK. Com a calibração da polarização do laser, os padrões de Stokes recebidos reproduziam proporcional estabilidade, a variação angular média dos estados de polarização nestas condições foi reduzida e ficou dentro do cone de decisão de 0,2 radianos (aproximadamente 11,4 graus). 
O tempo de observação foi de 16 horas para cada constelação gerada, sendo que cada cone de decisão foi tomado em relação a um símbolo (estado de polarização) específico. Apesar da quebra da rigidez, acreditamos que com um controle dinâmico para a polarização de entrada e com um laser mais estável, seria possível melhor resultado para a constelação de 14 símbolos.

Observamos que a velocidade de resposta do controlador de polarização pode levar a ausência de um estado constante entre as transições, desta forma o receptor deve trabalhar com limiares de sinal para discriminar os sinais de potência das componentes do vetor de Stokes. A potência de sinal recebido se manteve praticamente constante, apesar das variações observadas no grau de polarização, o que pode ser um indicativo de que as contribuições da PDL foram mínimas.

O trabalho que desenvolvemos forneceu o fluxo de trabalho necessário para realização de um transmissor PolSK genérico, diferentes velocidades de transmissão e constelações de símbolos podem ser utilizados em projetos específicos. Acreditamos que os resultados exibidos demonstram pontos fortes da PolSK frente aos requisitos dos sistemas de comunicações ópticas de nova geração. 
10

\section{Trabalhos futuros}

Os pontos fortes da PolSK devem ser avaliados com maior rigor contra pontos fracos relatados em outras publicações. Estas análises são objeto de trabalhos futuros.

1. Análise dos efeitos de conectores e componentes ópticos passivos sobre a rigidez de constelações PolSK.

2. Analise do impacto da modulação PolSK sobre modulações em amplitude, principalmente em sistemas WDM.

3. Realização de um receptor/demodulador, com base no produto interno dos vetores de Stokes.

4. Análise do impacto da conversão amplitude/fase do sinal elétrico sobre o sinal modulado em polarização, para transmissão PolSK com interface eletro-óptica.

5. Análise do efeito de conversão fase/frequência em sinais modulados em polarização, para receptores PolSK. 


\section{Referências Bibliográficas}

1. OHARA $\uparrow$, T.; ISHIDA, O. Standardization Activities for the Optical Transport Network. NTT Technical Review, v. 7, n. 3, Mar 2009.

2. KAHN, J. M.; HO, K.-P. Ultimate Spectral Efficiency Limits in DWDM Systems. OtpoElectronics and Communications Conference. Yokohama: [s.n.]. 2002.

3. LACH, E.; IDLER, W. Modulation formats for $100 \mathrm{G}$ and beyond. Optical Fiber Technology, p. 377-386, 2011.

4. SEIMETZ, M. Exploding Data Traffic and Banwidth Demands. In: SEIMETZ, M. High Order Modulation for Fiber Optic Transmission. [S.1.]: Springer-Verlag, 2009b. p. 1-12.

5. KIKUCHI, K. Coherent Optical Communications: Historical Perspectives and Future Directions. In: NAKAZAWA, M.; KIKUCHI, K.; MIYAZAKI, T. High Spectral Density Optical Communication Technologies. Berlin: Springer-Verlag, 2010. Cap. 2, p. 11-48.

6. SEIMETZ, M. Performance Trends. In: SEIMETZ, M. High-Order Modulation For Optical Fiber Transmission. Berlin: Springer, 2009a. p. 227-237.

7. MATSUURA, H. Key Devices for High Speed Optical Communications. In: NAKAZAWA, M.; KIKUCHI, K.; MIYAZAKI, T. High Spectral Density Optical Communication Technologies. [S.1.]: Springer-Verlag, 2010. Cap. 16, p. 287-301. ISBN 978-3-642-10418-3.

8. CHEN, H. et al. High Spectral Efficiency Orthogonal Modulation in All Optical Label Switching Network. Lasers and Electro-Optics, 2006 and 2006 Quantum Electronics and Laser Science Conference. CLEO/QELS 2006. Conference. [S.1.]: [s.n.]. 2006. p. 1-2.

9. BLAIKIE, R. J.; TAYLOR, D. P.; GOUGH, T. P. Multilevel Differential Polarization Shift Keying. IEEE TRANSACTIONS ON COMMUNICATIONS, 45, n. 1, January 1997. 
10. PIZURICA, A.; SENK, V.; PIZURICA, V. An Application of Spherical Codes to Polarization Shift Keying Modulation. Electronics and Energetics, 11, 1998. 207-221.

11. JAEGER, N. A. et al. 40-GHz electro-optic polarization modulator for fiber optic communications systems. Photonics North 2004. Ottawa Canada: [s.n.]. 2004. p. 133-143.

12. BENEDETTO, S.; POGGIOLINI, P. Theory of polarization shift keying modulation. IEEE Transactions on Communications, 40, 1992. 708-721.

13. BENEDETTO, S.; POGGIOLINI, P. Polarization Shift Keying: An efficient Coherent Optical Modulation.

14. BETTI, S. et al. Multilevel Coherent Optical System Based on Stokes Parameters Modulation. JOURNAL OF LIGHTWAVE TECHNOLOGY, 08, 1990 .

15. MATALGAH, M. M.; RADAYDEH, R. M. Hybrid Frequency-Polarization Shift-Keying Modulation for Optical Transmission. Journal of Lightwave Technology, 23, n. 3, March 2005. 1152-1163.

16. HIDAYAT, A. Fast Endless Polarization Control for Optical Commnunication Systems. Universitat Paderborn. Paderborn. 2008.

17. HOU, K.-S.; WU, J. The Performance Analysis of Polarization Shift Keying Optical Communication System With Differential 4-Quadrature Scheme. GLOBAL TELECOMMUNICATIONS CONFERENCE GLOBECOM'99. [S.1.]: [s.n.]. 1999.

18. H.C.JI; LEE, J. H.; CHUNG, Y. C. Effects of Polarization Dependent Loss on Polarization Transmission Systems. Proceedings of SPIE, v. 4906, 2002.

19. LEPLEY, J. J. E. J. G. E. S. G. S. A. S. W. S. D. Excess penalty impairments of polarisation shift keying transmission format in presence of polarisation mode dispersion. Electronics Letters, v. 36, p. 736-737, Apr 2000. ISSN 0013-5194.

20. JINNO, M. et al. Towards Ultra High-Speed High-capacity Networks. NTT Technical Review, v. 7, n. 5, p. 1-8, May 2009. 
21. GRAEDEL, T. UNEP. Disponivel em:

$<$ http://www.unep.org/resourcepanel/Portals/24102/PDFs/Metals_Recycling _ Rates_110412-1.pdf>. Acesso em: Jan 2012.

22. RUI FERNANDES P. JÚNIOR. DNPM, 2012. Disponivel em: $<$ https://sistemas.dnpm.gov.br/publicacao/mostra_imagem.asp?IDBancoArqu ivoArquivo=3976>. Acesso em: 10 Fevereiro 2012.

23. AGRAWAL, G. P. Nonlinear Fiber Optics. 3rd. ed. [S.1.]: Academic Press, 2001a.

24. ESSIAMBRE, R.-J. et al. Capacity Limits of Information Transport in FiberOptic Networks. PHYSICAL REVIEW LETTERS, October 2008. 163901.

25. NOÉ, R. Essentials of Modern Optical Fiber Communications. Berlin: Spinger-Verlag, 2010. ISBN 978-3642-04871-5.

26. TUCKER, R. S. Green Optical Communications-Part I: Energy Limitations in Transport. IEEE JOURNAL OF SELECTED TOPICS IN QUANTUM ELECTRONICS, 2010a.

27. KILPER, D. C.; ATKINSON, G.; KOROTKY, S. Optical Transparency and Network Energy Efficiency. Transparent Optical Networks (ICTON), 2010 12th International Conference. Munich: [s.n.]. 2010. p. 1-1.

28. BOnETTO, E. et al. Optical Technologies Can Improve the Energy Efficiency of Networks. ECOC 2009. Vienna: [s.n.]. September 2009. p. 2024.

29. TUCKER, R. S. Green Optical Communications - Part II: Energy Limitations in Networks. IEEE JOURNAL OF SELECTED TOPICS IN QUANTUM ELECTRONICS, 2010b.

30. XU, L. et al. A New Orthogonal Labeling Scheme Based on a 40-Gb/s DPSK Payload and a 2.5-Gb/s PolSK Label. IEEE PHOTONICS TECHNOLOGY LETTERS, 17, n. 12, Dez 2005. 2772-2774.

31. O'MAHONY, M. J. et al. Future Optical Networks. JOURNAL OF LIGHTWAVE TECHNOLOGY, 24, n. 12, December 2006. 4684-4696. 
32. ZERVAS, G. S. et al. Multi-Granular Optical Cross-Connect:Design, Analysis and Demonstration. IEEE JOURNAL ON SELECTED AREAS IN COMMUNICATIONS, 27, n. 3, April 2009. 1-13. SUPPLEMENT ON OPTICAL COMMUNICATIONS AND NETWORKING.

33. OIFORUM. Multisource Agreement for 100G Long-Haul DWDM Transmission Module - Electromechanical, June 2010. Disponivel em: $<$ http://www.oiforum.com/public/documents/OIF-MSA-100GLH-EM01.0.pdf $>$.

34. BERTRAN-PARDO et al. System benefits of temporal polarization interleaving with $100 \mathrm{~Gb} / \mathrm{s}$ coherent PDM-QPSK. Optical Communication, 2009. ECOC '09. 35th European. Vienna: [s.n.]. 2009. p. 1-2.

35. BRAUN, R.-P. 100Gbit/s IP-Router and DWDM Transmission Interoperability Field Tests. Photonic Networks; 12. ITG Symposium;Proceedings of. [S.1.]: [s.n.]. 2011. p. 1-3.

36. COLLET, E. Field Guide to Polarization. Bellingham: SPIE Press, 2009. ISBN 0-8194-5868-6. 2nd printing.

37. A.B.MILLER, D. Maxwell equations and electromagnetism. In: A.B.MILLER, D. Quantum Mechanics for Scientists and Engineers. [S.1.]: CAMBRIDGE, 2009. Cap. Appendix D, p. 509-518.

38. EOSPACE. Polarization Controllers. EOSPACE - Polarization Controllers, 2011. Disponivel em: $<$ http://www.eospace.com/polarization_controller.htm>. Acesso em: 11 mar. 2011.

39. CHEN, Z. et al. Multi-Envelope 3-Dimensional Constellations for Polarization Shift Keying Modulation. 2010 International Conference. [S.1.]: Information and Communication Technology Convergence (ICTC). 1719 Nov. p. 173-174.

40. WEISHENG HU, S. S. P. K. E. Effect of Polarization Dependent Loss on Polarization-Shift-Keying Transmission System. In: PROCEEDINGS OF SPIE. [S.1.]: [s.n.], v. 4906, 2002. 
41. DAMASK, J. N. Polarization Optics in telecommunications. New York: Springer, 2004.

42. GERRARD, A. (.; BURCH, J. M. Introduction to Matrix Methods in Optics. New York: Wiley, 1975.

43. BANDARI, R.; LOVE, G. D. Polarization EigenModes of a QHQ retarder some new features. Optics Communications, 110, September 1994. 479-484.

44. WANG, J.; FANG, Q.; WANG, Y. Two Novel Polarization Transformers using rotatable waveplates. Optik - International Journal for Light and Electron Optics, 116, n. 2, March 2005. 93-98.

45. AGRAWAL, G. P. Polarization Effects. In: AGRAWAL, G. P. Nonlinear Fiber Optics. 3 edition. ed. San Diego: Academic Press, 2001b. Cap. 6, p. 203-259.

46. BEAZLEY, D. M. Python Essential Reference. Fourth Edition. ed. [S.1.]: Pearson Education, 2011. ISBN 978-0-672-32978-4.

47. WALT, S. V. D.; COLBERT, S. C.; VAROQUAUX, G. The NumPy Array: A Structure for Efficient Numerical Computation. Computing in Science \& Engineering, v. 13, p. 22-30, Apr 2011.

48. NEUBAUER, A.; FREUDENBERGER, J.; KÜHN, V. Algebraic Coding Theory. In: NEUBAUER, A.; FREUDENBERGER, J.; KÜHN, V. Coding Theory: Algorithms, Architectures and Applications. [S.l.]: Wiley, 2007. Cap. 2, p. 13-96.

49. AGRAWAL, G. P. P. ). Fiber-optic communications systems. [S.1.]: WileyInterscience publication, 1997.

50. BETTI, S. et al. Homodyne Optical Coherent Systems Based on Polarization Modulation. JOURNAL OF LIGHTWAVE TECHNOLOGY, 09, n. 10, October 1991. 1314-1320.

51. BONONI, A. et al. Degree of Polarization Degradation Due to Cross-Phase Modulation and Its Impact on Polarization-Mode Dispersion Compensators. JOURNAL OF LIGHTWAVE TECHNOLOGY, 21, n. 09, September 2003. 1903-1913. 
52. C.W.CHOW et al. Signal Remodulation PON without power sacrifice using PolSK. ECOC 2008. Brussels: [s.n.]. 2008.

53. CARENA, A; CURRI, V ; GAUDINO, R ; GRECO, N ; POGGIOLINI, P ; BENEDETTO, S. Polarization modulation in ultralong haul transmission systems: A promising alternative to intensity modulation. 24th European Conference on Optical Communications. MADRID: [s.n.]. 1998.

54. CHU, P. P. FPGA Prototyping by VHDL Examples. New Jersey: John Wiley \& Sons, 2008. ISBN 978-0-470-18531-5.

55. GENÉ, J. M. et al. Modified Duobinary Polarization-Shift Keying Transmission Scheme. IEEE PHOTONICS TECHNOLOGY LETTERS, v. 16, n. 1, p. 311-313, January 2004.

56. GOLUB, G. H.; LOAN, C. F. V. Matrix Computations. 3rd. ed. Baltimore: The Johns Hopkins University Press, 1996. ISBN 0-8018-5413-X.

57. HAN, Y.; LI, G. Theoretical Sensitivity of Direct-Detection Multilevel Modulation Formats for High Spectral Efficiency Optical Communications. IEEE JOURNAL OF SELECTED TOPICS IN QUANTUM ELECTRONICS, 12, n. 4, July/August 2006. 571-580.

58. HUI, R.; O'SUllivan, M. Fiber Optic Measurement Tecniques. San Diego: Elsevier Academic Press, 2009. ISBN 978-0-12-373865-3.

59. QIU, C. et al. Carrier Reuse Using PolSK Data Rewriting Method in PONs. Optical Fiber communication/National Fiber Optic Engineers Conference, 2008. OFC/NFOEC 2008. San Diego: [s.n.]. 2008. p. 1-3.

60. SHILOV, G. E. Linear Algebra. [S.1.]: DOVER, 1977.

61. UEHARA, H. et al. Impact of Local Oscilator Intensity Noise in Coherent Optical POLSK Heterodyne/Homodyne Receivers. IEEE Pac Rim '93. [S.1.]: [s.n.]. 1993. p. 757-760.

62. WENNINGER, M. J. Spherical Models. New York: Dover, 1979.

63. WOLF, E. Unified Theory of Polarization and Coherence. In: WOLF, E. Theory of Coherence and Polarization of Light. New York: Cambridge, 2007. Cap. 9, p. 174-201. 


\section{IVI FOUNDATION.}

http://www.ivifoundation.org/specifications/default.aspx. IVI Specifications, setembro 2012. Acesso em: 2012. 